\title{
USER'S GUIDE FOR MODTOOLS: COMPUTER PROGRAMS FOR TRANSLATING DATA OF MODFLOW AND MODPATH INTO GEOGRAPHIC INFORMATION SYSTEM FILES
}

U.S. GEOLOGICAL SURVEY

Open-File Report 97-240

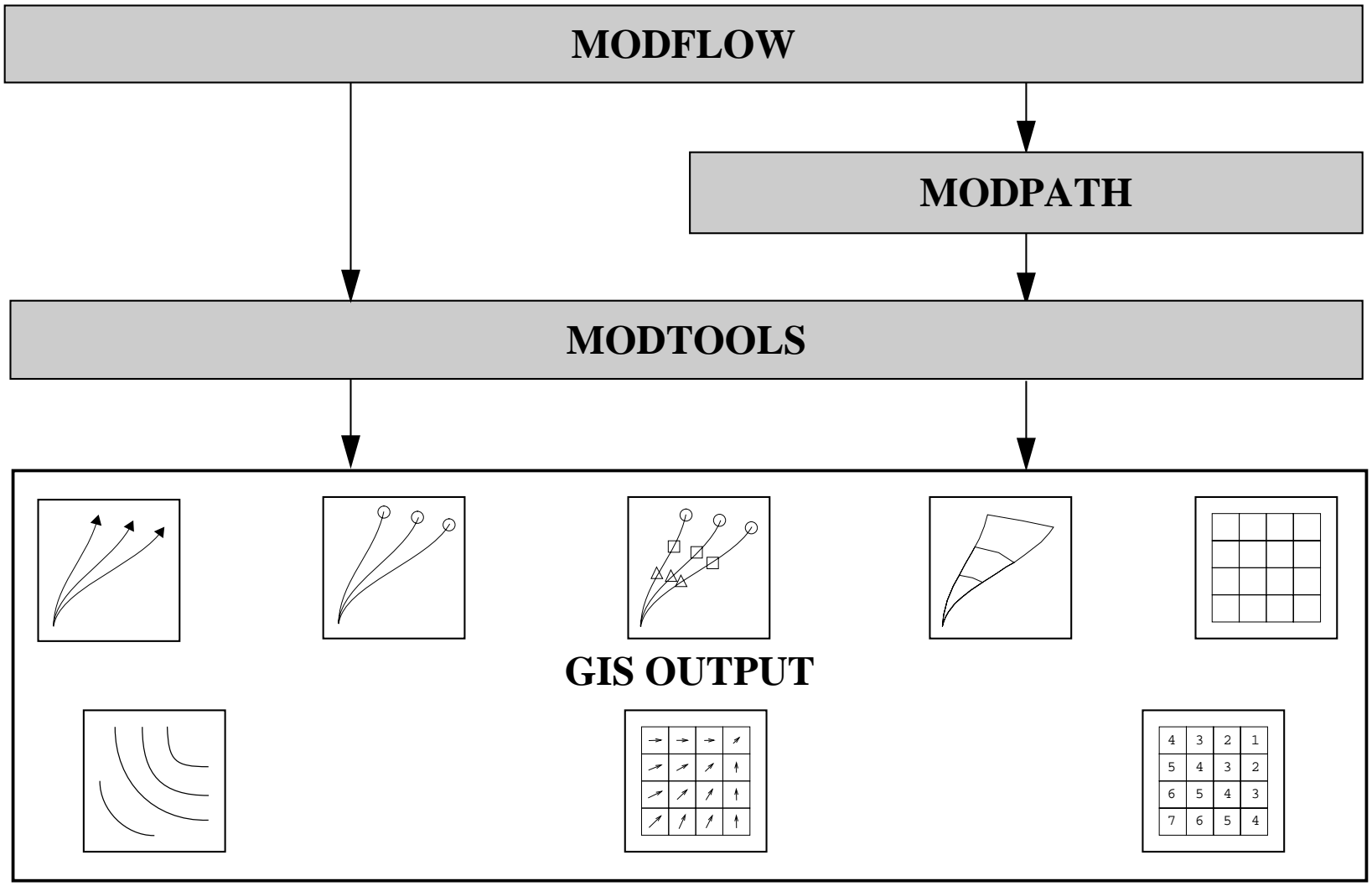




\section{USER'S GUIDE FOR MODTOOLS: \\ COMPUTER PROGRAMS FOR}

TRANSLATING DATA OF MODFLOW AND MODPATH INTO GEOGRAPHIC INFORMATION SYSTEM FILES

By Leonard L. Orzol

U.S. GEOLOGICAL SURVEY

Open-File Report 97-240

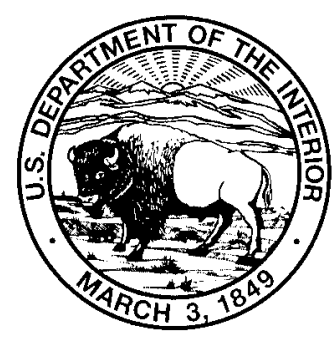

Portland, Oregon 


\title{
U.S. DEPARTMENT OF THE INTERIOR BRUCE BABBITT, Secretary
}

\author{
U.S. GEOLOGICAL SURVEY
}

Gordon P. Eaton, Director

The use of firm, trade, and brand names in this report is for identification purposes only and does not constitute endorsement by the U.S. Government.

For addtional information write to:

District Chief

U.S. Geological Survey, WRD

10615 S.E. Cherry Blossom Drive

Portland, OR 97216

E-mail:info-or@usgs.gov
Copies of this report can be purchased from:
U.S. Geological Survey
Branch of Information Services
Box 25286
Denver, CO 80225-0286
E-mail: infoservices@usgs.gov 


\section{PREFACE}

This report presents a version of the computer programs called MODTOOLS for translating data from the U.S. Geological Survey (USGS) modular finite-difference ground-water flow model (commonly known as MODFLOW) and particle-tracking programs (commonly known as MODPATH) into geographic information system (GIS) files. The programs have been tested by using them for a variety of model simulations, but it is possible that other applications could reveal errors. Users are requested to notify the USGS if errors are found in this report or the programs.

Although these programs have been used by the USGS, no warranty, expressed or implied, is made by the USGS or the United States Government as to the accuracy and functioning of the programs and related program material. Nor shall the fact of distribution constitute any such warranty, and no responsibility is assumed by the USGS in connection therewith.

The computer programs are available through the World Wide Web at the address: http://water.usgs.gov/software/ or by anonymous ftp file transfer from directory /pub/software/ground_water/modtools at the Internet address

water.usgs.gov

The computer programs are also available on diskette for the cost of processing from:

U.S. Geological Survey

NWIS Program Office

437 National Center

Reston, VA 20192

Telephone: (703) 648-5695 



\section{CONTENTS}

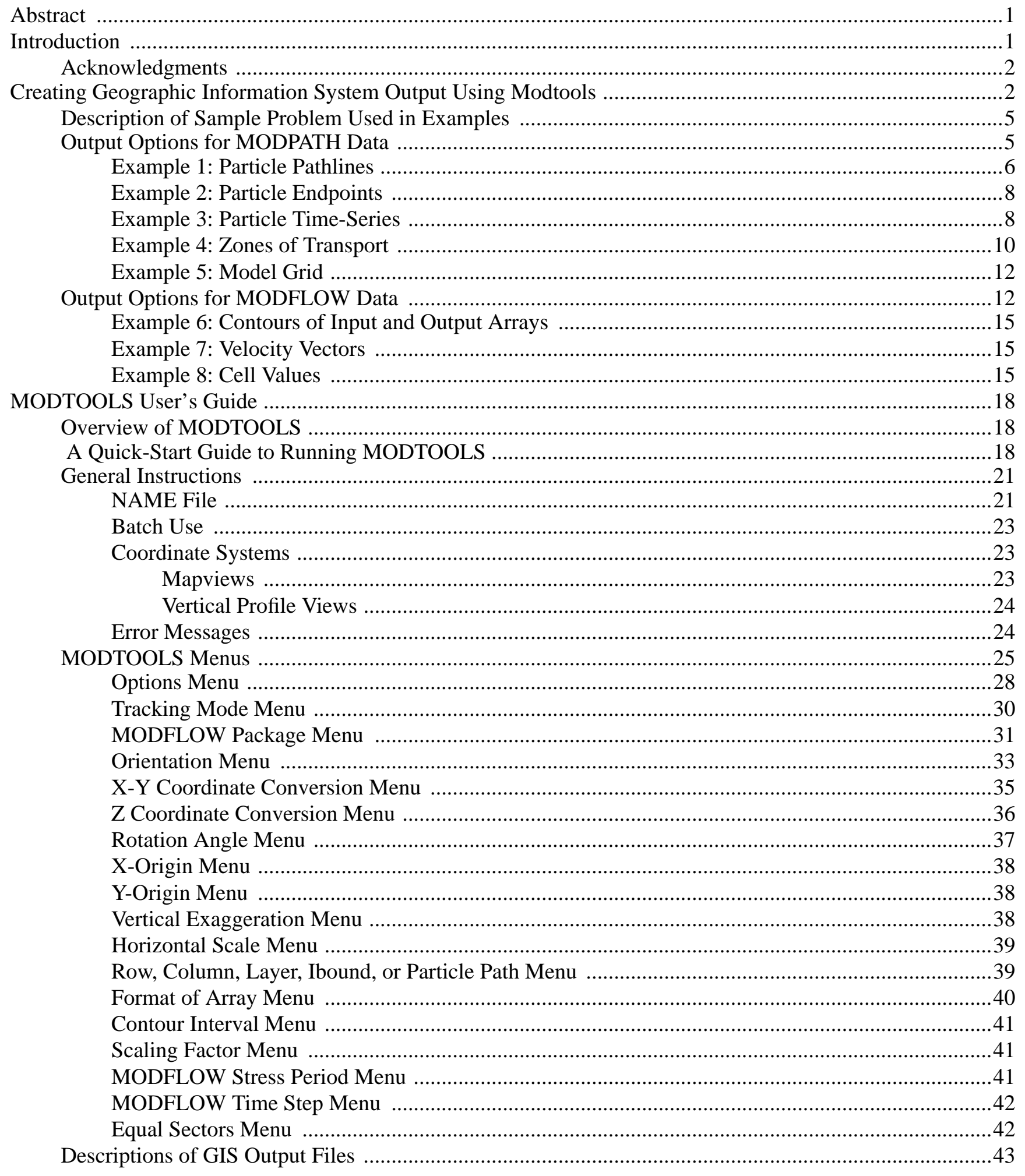




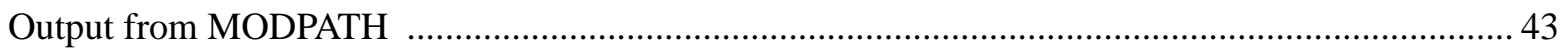

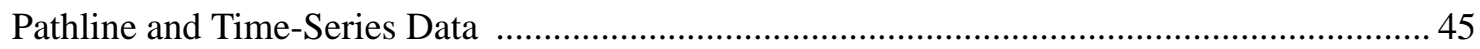

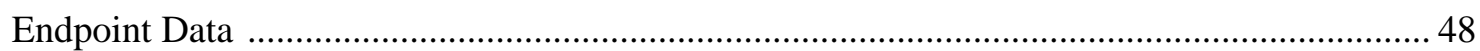

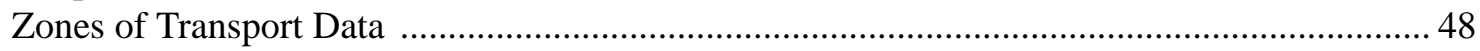

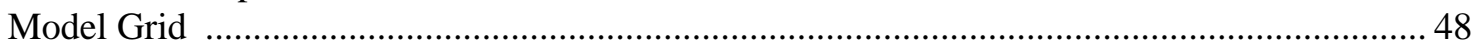

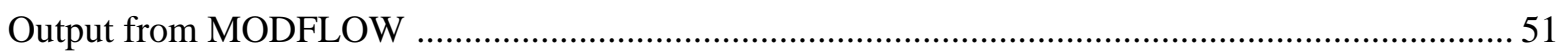

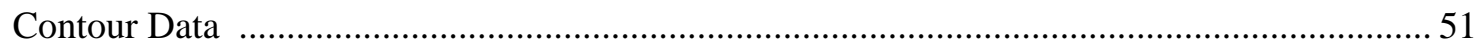

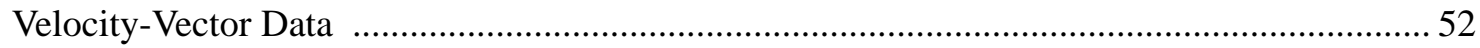

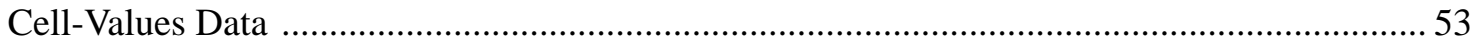

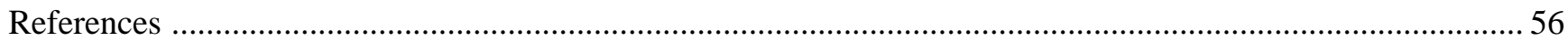

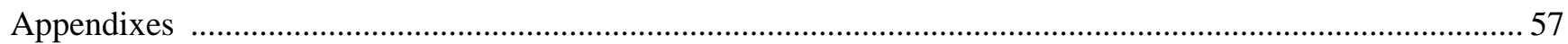

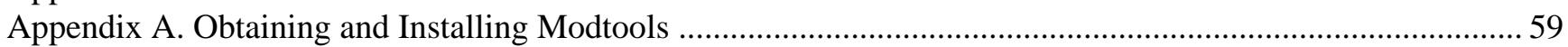

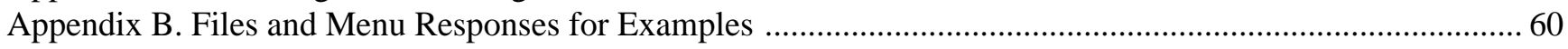

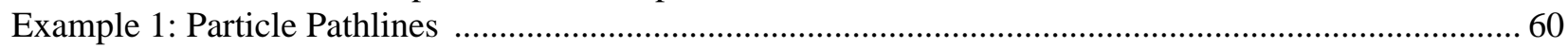

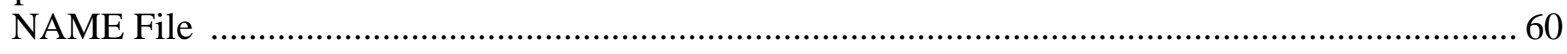

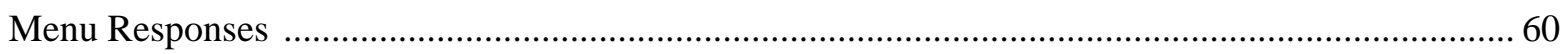

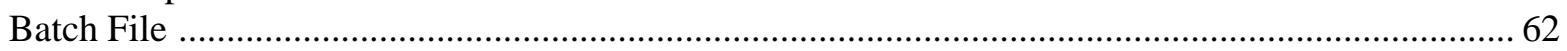

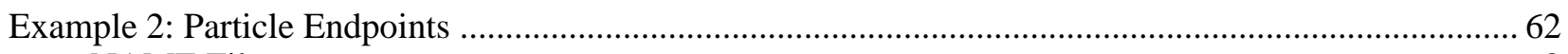

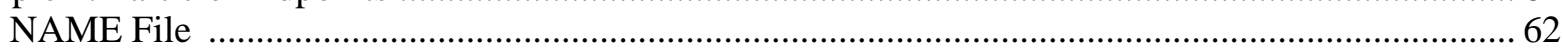

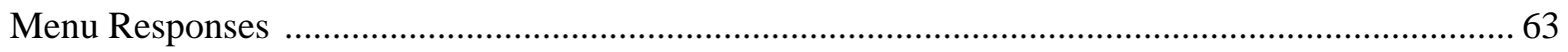

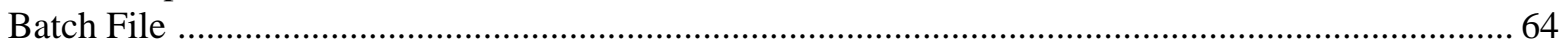

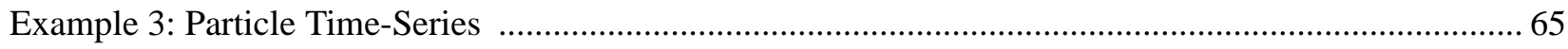

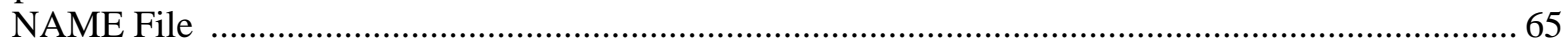

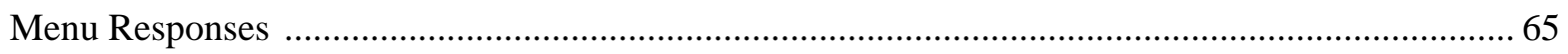

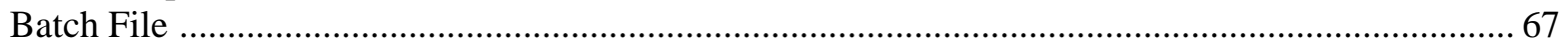

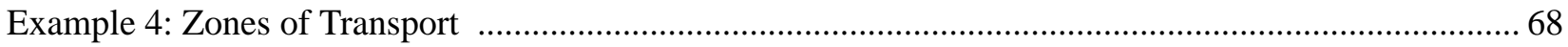

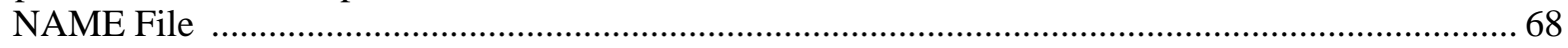

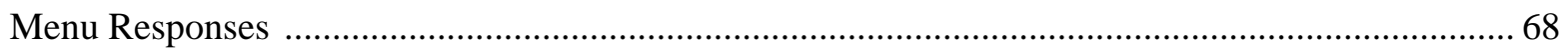

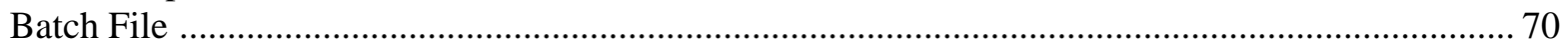

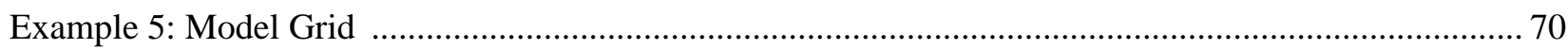

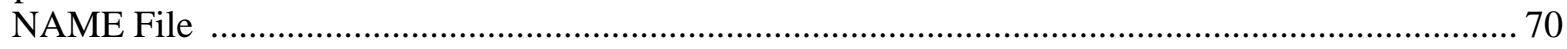

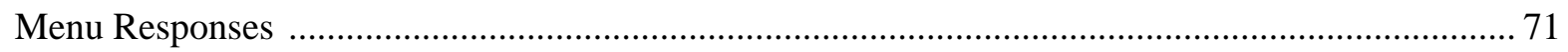

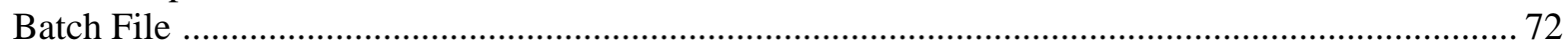

Example 6: Contours of Input and Output Arrays ........................................................................... 73

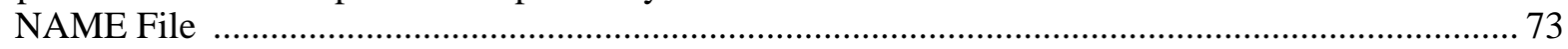

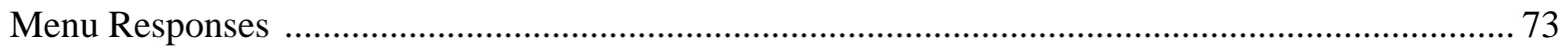

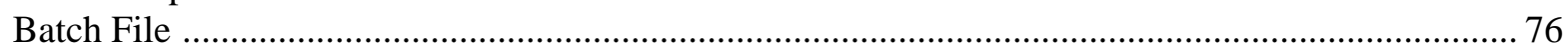

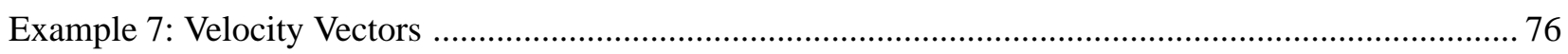

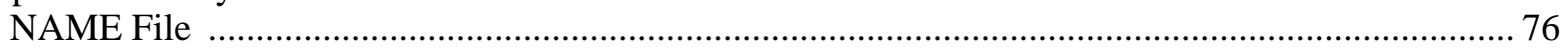

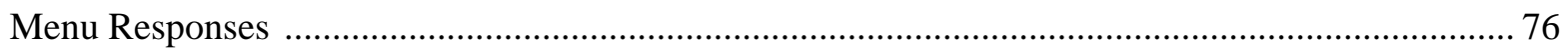

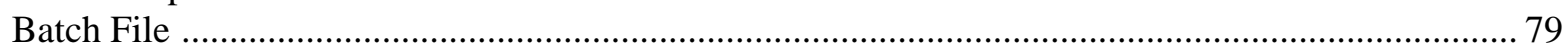

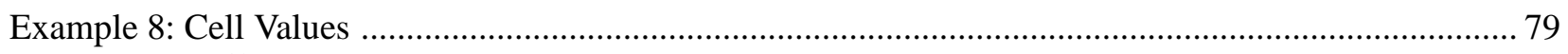

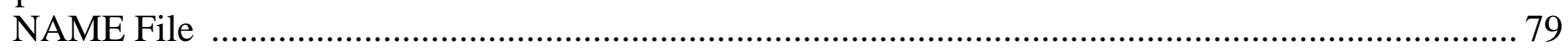

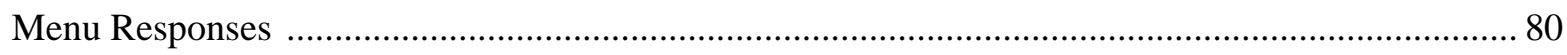

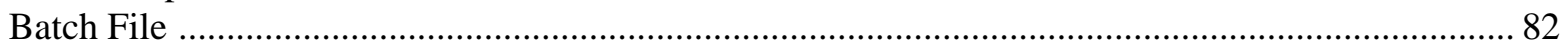

Appendix C. Documentation of the Method Used to Construct Zones of Transport ….................................... 83 
1. The functional relation between MODFLOW, MODPATH, and MODTOOLS, and GIS output that can be produced by MODTOOLS

2. Diagram of hypothetical flow system simulated in examples ........................................................ 6

3. Simulated pathlines resulting from backward tracking of two particles from well 2 under transient conditions

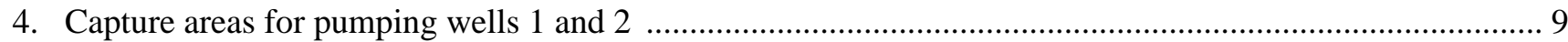

5. Vertical profile view along row 14 showing the movement of a particle plume formed by 10 years of continuous release of particles at the water table under steady-state flow conditions ............................... 6

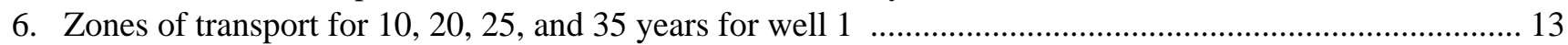

7. A vertical profile view of the model grid and pathline traveled by particle 1 ......................................... 14

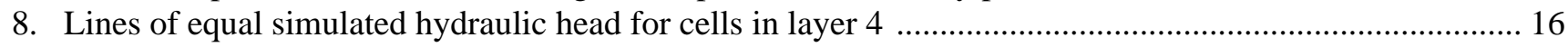

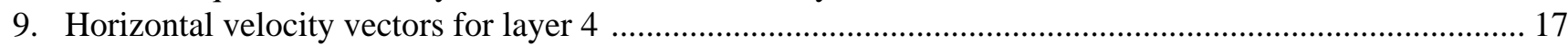

10. Vertical view along row 14 showing model grid and simulated heads ................................................. 19

11. Example showing the backward movement of a particle and attributes created for the particle

\section{TABLES}

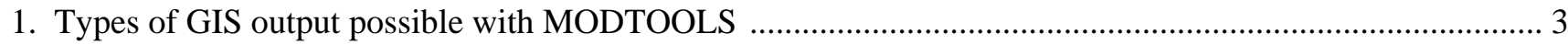

2. Summary of data file requirements for MODPATH, MODPATH-PLOT, and MODTOOLS ................... 22

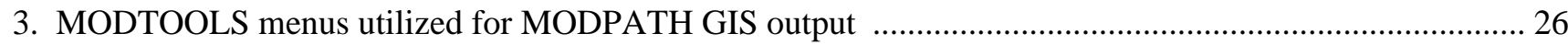

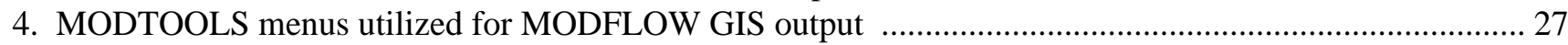

5. Attributes associated with pathline and time-series GIS output from MODTOOLS ................................ 46

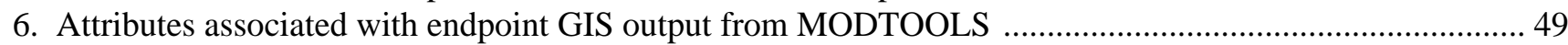

7. Attributes associated with zones of transport GIS output from MODTOOLS .........................................50

8. Attributes associated with model grid GIS output from MODTOOLS ................................................ 51

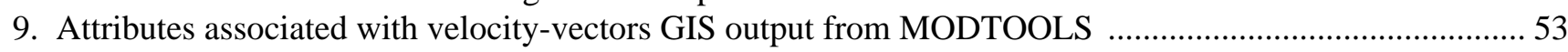

10. Attributes associated with cell values GIS output from MODTOOLS ....................................................5 



\title{
USER'S GUIDE FOR MODTOOLS: COMPUTER PROGRAMS FOR TRANSLATING DATA OF MODFLOW AND MODPATH INTO GEOGRAPHIC INFORMATION SYSTEM FILES
}

\author{
By Leonard L. Orzol
}

\begin{abstract}
MODTOOLS is a set of computer programs for translating data of the ground-water model, MODFLOW, and the particle-tracker, MODPATH, into a Geographic Information System (GIS). MODTOOLS translates data into a GIS software called ARC/INFO. MODFLOW is the recognized name for the U.S. Geological Survey Modular Three-Dimensional Finite-Difference Ground-Water Model. MODTOOLS uses the data arrays input to or output by MODFLOW during a ground-water flow simulation to construct several types of GIS output files. MODTOOLS can also be used to translate data from MODPATH into GIS files. MODPATH and its companion program, MODPATH-PLOT, are collectively called the U.S. Geological Survey Three-Dimensional Particle Tracking Post-Processing Programs. MODPATH is used to calculate ground-water flow paths using the results of MODFLOW and MODPATH-PLOT can be used to display the flow paths in various ways.

MODTOOLS uses the particle data calculated by MODPATH to construct several types of GIS output. MODTOOLS uses particle information recorded by MODPATH such as the row, column, or layer of the model grid, to generate a set of characteristics associated with each particle. The user can choose from the set of characteristics associated with each particle and use the capabilities of the GIS to selectively trace the movement of water discharging from specific cells in the model grid. MODTOOLS allows the hydrogeologist to utilize the capabilities of the GIS to graphically combine the results of the particle-tracking analysis, which facilitates the analysis and understanding of complex ground-water flow systems.
\end{abstract}

\section{INTRODUCTION}

MODTOOLS is a set of computer programs for translating data from the popular ground-water modeling programs, MODFLOW and MODPATH, into Geographic Information System (GIS) data files. MODTOOLS translates data into a GIS software called ARC/INFO. MODFLOW can simulate groundwater flow in a three-dimensional heterogeneous and anisotropic medium (McDonald and Harbaugh, 
1988). MODPATH is a particle tracking post-processing program designed to work with MODFLOW. MODPATH can compute the movement of hypothetical water particles through the simulated groundwater flow system (Pollock, 1994). Geographic Information Systems are effective tools for storing, managing, and displaying the types of spatial data often used in ground-water modeling analyses. The graphical, statistical, and database capabilities of the GIS provide powerful tools for the analysis of model data and results. Geographic Information Systems are useful tools to construct input data or to display output data from ground-water model simulations. An example of a ground-water modeling study that used a GIS is that of Morgan and McFarland (1994). MODTOOLS was used to help analyze the results of this same study to evaluate ground-water vulnerability (Snyder and others, 1996) and for comparison with chlorofluorocarbon age dating (Hinkle and Snyder, in press).

The use of a GIS enables the graphical combination of output from MODFLOW and MODPATH with other spatial data, which facilitates the analysis and understanding of complex ground-water flow systems and evaluation of the impact of human activities. MODPATH-PLOT (Pollock, 1994), the graphical companion program of MODPATH, has a variety of options for displaying results from MODPATH and MODFLOW, but does not have the power of a full-featured GIS for spatial analysis. Also, MODTOOLS has features that enables it to produce GIS data files compatible with those produced by MODFLOWARC, a modified version of MODFLOW that reads and writes to GIS files (Orzol and McGrath, 1992).

This report documents MODTOOLS and serves as a user's manual for operating MODTOOLS. Possible uses of MODTOOLS are demonstrated in eight examples. All instructions necessary to reproduce these examples are listed in Appendix B. The report also includes a "quick-start guide" listing the basic instructions for operating MODTOOLS, a detailed discussion of the program menus, descriptions of GIS files output by MODTOOLS, and instructions for installing MODTOOLS.

\section{Acknowledgments}

I would like to thank report team members Dave Morgan, Daryll Pope, John Williams, and Bill McFarland of the U.S. Geological Survey (USGS) for their helpful comments and especially acknowledge Dan Snyder (USGS) for his contribution to this project. I would also like to thank Arlen Harbaugh and Dave Pollock of the USGS Office of Ground Water for their suggestions.

\section{CREATING GEOGRAPHIC INFORMATION SYSTEM OUTPUT USING MODTOOLS}

MODTOOLS creates eight major types of GIS output from data of MODPATH and MODFLOW. The types of GIS output are listed in table 1 and their relations to MODFLOW, MODPATH, and MODTOOLS are shown in figure 1. The GIS output consists of particle and model-grid coverages (the spatial arrangement of points, lines, or polygons) and INFO files, which contain characteristics associated with the appropriate particle or cell. There are four types of GIS output created from the particle data output by MODPATH: pathline, endpoint, time-series, and zones of transport. A fifth type 
of GIS output is created from the input data to MODPATH defining the physical dimensions of the model grid and is called model-grid GIS output. Three types of GIS output are created from data of MODFLOW: contour, velocity vector, and cell values. In addition, MODTOOLS can utilize any data in array format to create GIS output.

Table 1. Types of GIS output possible with MODTOOLS

\begin{tabular}{|c|c|c|}
\hline Source & $\begin{array}{l}\text { Types of GIS } \\
\text { output }\end{array}$ & Description \\
\hline \multirow{5}{*}{$\begin{array}{l}\text { I } \\
\text { 号 } \\
\text { Oे }\end{array}$} & $\begin{array}{l}\text { PARTICLE } \\
\text { PATHLINES }\end{array}$ & $\begin{array}{l}\text { Pathline GIS output is constructed from particle data describing particle paths recorded by MODPATH } \\
\text { in the PATHLINE file. This output consists of a set of lines which represent each particle path. }\end{array}$ \\
\hline & $\begin{array}{l}\text { PARTICLE } \\
\text { ENDPOINTS }\end{array}$ & $\begin{array}{l}\text { Endpoint GIS output is constructed from particle data describing the starting or final positions of } \\
\text { particles recorded by MODPATH in the ENDPOINT file. This output consists of points which represent } \\
\text { the starting or final positions of each particle. }\end{array}$ \\
\hline & $\begin{array}{l}\text { PARTICLE } \\
\text { TIME-SERIES }\end{array}$ & $\begin{array}{l}\text { Time-series GIS output is constructed from particle data describing particle locations at specified model } \\
\text { time steps recorded by MODPATH in the TIMESERS file. This output consists of points that represent } \\
\text { the positions of each particle along the particle path at specified times of travel. }\end{array}$ \\
\hline & $\begin{array}{l}\text { ZONES } \\
\text { OF } \\
\text { TRANSPORT }\end{array}$ & $\begin{array}{l}\text { Zones-of-transport (ZOT) GIS output is constructed from particle data describing particle locations at } \\
\text { specified model time steps recorded by MODPATH in the TIMESERS and ENDPOINT files. This } \\
\text { output consists of polygons representing the projection of the zones of transport onto the user-specified } \\
\text { plane of the model grid. }\end{array}$ \\
\hline & MODEL GRID & $\begin{array}{l}\text { Model-grid GIS output is constructed from data arrays defining the model-cell geometry input to } \\
\text { MODPATH. This output consists of polygons that represent the cell faces of the user-specified plane of } \\
\text { the model grid. }\end{array}$ \\
\hline \multirow{3}{*}{$\begin{array}{l}3 \\
0 \\
\text { ப’ } \\
\text { 일 }\end{array}$} & $\begin{array}{l}\text { CONTOURS OF } \\
\text { INPUT AND } \\
\text { OUTPUT } \\
\text { ARRAYS }\end{array}$ & $\begin{array}{l}\text { Contour GIS output is constructed from data arrays of MODFLOW or arrays gridded to same scale as } \\
\text { the MODFLOW grid. This output consists of lines connecting points of equal value. }\end{array}$ \\
\hline & $\begin{array}{l}\text { VELOCITY } \\
\text { VECTORS }\end{array}$ & $\begin{array}{l}\text { Velocity-vector GIS output is constructed from the head values and cell-by-cell flow terms output by } \\
\text { the Basic and Block Centered Flow Packages of MODFLOW. Velocity-vector output consists of lines } \\
\text { indicating the direction and magnitude of simulated ground-water velocity. }\end{array}$ \\
\hline & CELL VALUES & $\begin{array}{l}\text { Cell-value GIS output is constructed from data arrays of MODFLOW or arrays gridded to same scale } \\
\text { as the MODFLOW grid. This GIS output consists of records in GIS files that contain the values of the } \\
\text { specified data arrays corresponding to model-grid cells. }\end{array}$ \\
\hline
\end{tabular}

MODTOOLS incorporates all the types of output options of MODPATH-PLOT, but has several capabilities not found in MODPATH-PLOT. Both MODTOOLS and MODPATH-PLOT can create output in both mapview and vertical profile orientations. MODPATH-PLOT vertical profiles, however, can be viewed only along rows or columns, whereas MODTOOLS can construct GIS output of a profile view along a specified particle pathline. Another capability of MODTOOLS that is not available in MODPATH-PLOT is creation of zones of transport GIS output from particle data output by MODPATH. Zones of transport are the volumes of an aquifer that recharge or contribute water to a well or well field for specific times of travel (U.S. Environmental Protection Agency, 1987).

MODTOOLS can produce mapview GIS output of contour lines like MODPATH-PLOT, but the user has the additional option of viewing the contours in a vertical profile orientation along a row or column of the model grid. Another type of GIS output created by MODTOOLS is velocity vectors that show the direction and magnitude of ground-water velocity within each model cell. MODTOOLS can 


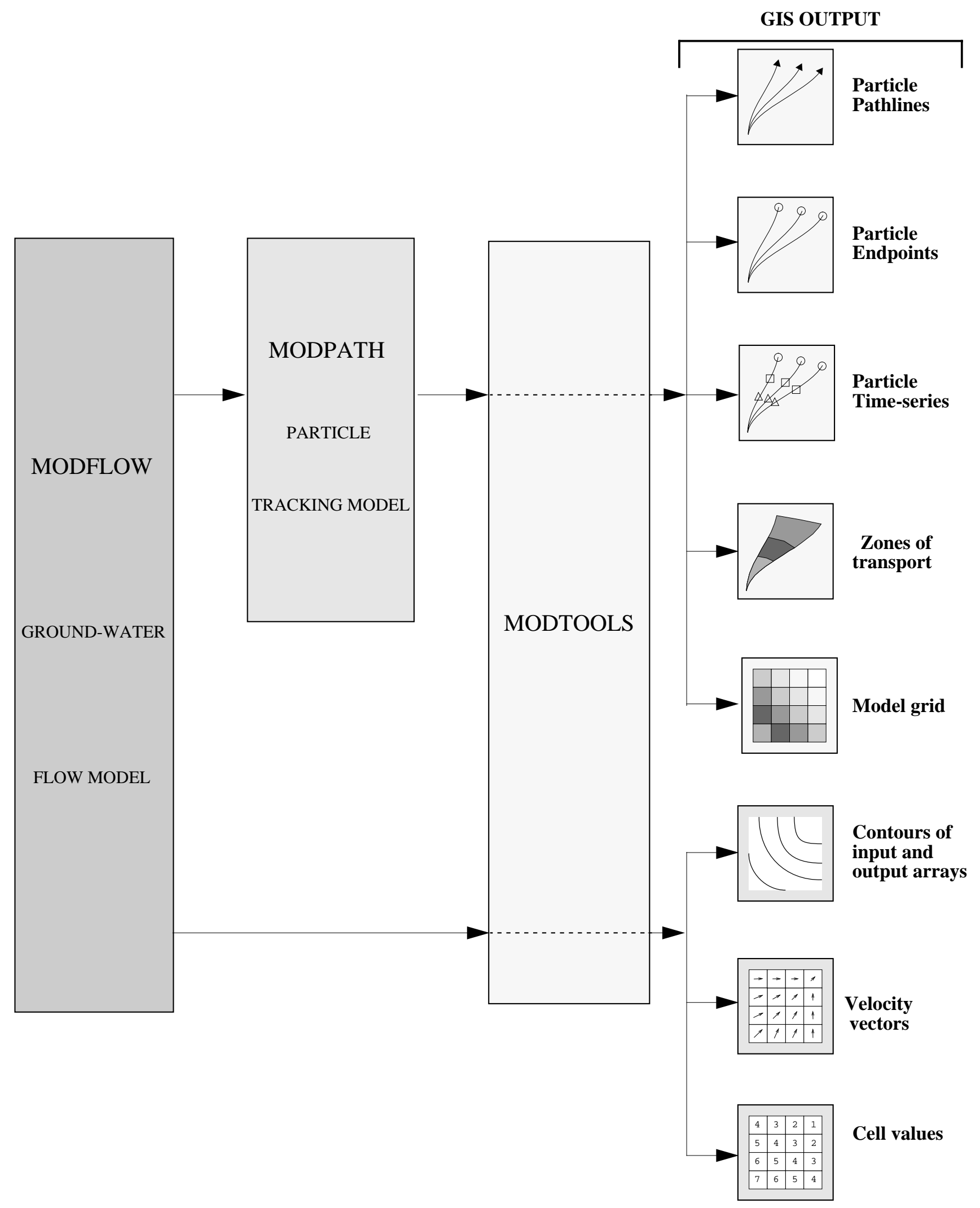

Figure 1. The functional relation between MODFLOW, MODPATH, and MODTOOLS, and GIS output that can be produced by MODTOOLS. 
also create GIS output from the output data arrays of MODFLOW corresponding to model-grid cells, such as the head and drawdown values output by the Basic Package or cell-by-cell flow terms from other stress packages in MODFLOW. Examples of the eight types of GIS output available from MODTOOLS are illustrated in the following sections. The examples were developed using the sample problem in Pollock (1994).

\section{Description of Sample Problem Used in Examples}

The hypothetical flow system used as a sample problem in these examples is from Pollock (1994) and is illustrated in figure 2. The flow system consists of two aquifers separated by a 20-foot-thick confining layer. Recharge to the system is uniformly distributed over the water table at a rate of 0.0045 feet per day. Discharge is to a partially penetrating river along the right side of the flow system in the upper aquifer and to wells.

Two simulations were used in the examples. In the first simulation (problem 1 of Pollock [1994, $p$ 6-4]), steady-state conditions were simulated with one pumping well, which is located in the lower aquifer and discharges at 80,000 cubic feet per day. In the second simulation (problem 2 of Pollock [1994, p. 6-15]), transient conditions were simulated after the addition of a second well discharging from the upper aquifer immediately above the well in the lower aquifer (fig. 2). The transient MODFLOW simulation was divided into three stress periods. Stress period 1 was 500 years long with one time step. During stress period 1, only one well was present in layer 4 and all stresses were identical to those of the steady-state simulation. Stress period 2 was 30 years long and consisted of eight time steps. During stress period 2, wells present in layers 1 and 4 each discharged at 80,000 cubic feet per day. Stress period 3 was 1,250 years long and consisted of one time step. Both wells continued to discharge at 80,000 cubic feet per day during stress period 3.

The system was simulated using a finite-difference grid containing 27 rows, 27 columns, and 5 layers. Horizontal grid spacing varied from 40 foot by 40 foot squares at the wells to 400 foot by 400 foot squares away from the wells. The upper unconfined aquifer was simulated by one layer. The confining unit was represented implicitly using a quasi-three-dimensional layer and a vertical leakance coefficient. The lower aquifer was represented by four 50-foot-thick layers. Both wells were located in row 14, column 14. The well in the lower aquifer was located in model layer 4.

\section{Output Options for MODPATH Data}

MODPATH computes particle locations for particle pathlines, starting or final positions, and timeseries positions at selected times of travel. MODTOOLS uses these particle locations to create GIS output. In addition to particle locations, MODPATH records characteristics such as the row, column, and layer of each model cell the particle has entered. MODTOOLS associates these characteristics with the appropriate particle in the GIS output. These characteristics can be used to identify specific particles in the analysis of particle-tracking results. 


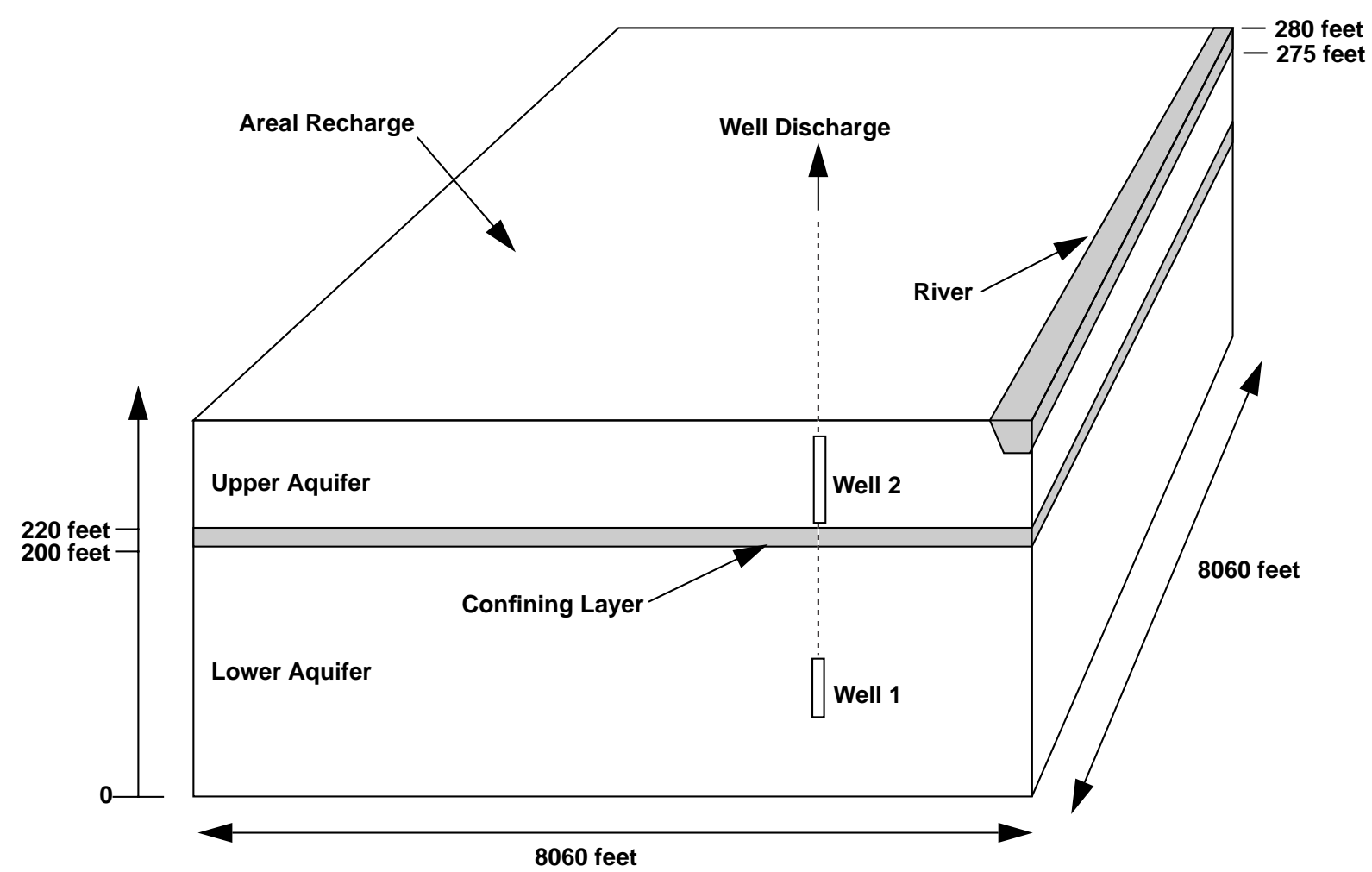

Figure 2. Diagram of hypothetical flow system simulated in examples (modified from Pollock, 1994, p. 6-2).

The files necessary to reproduce examples 1 through 5 are listed in Appendix B; a listing of the menu responses necessary to create the GIS output for these five examples is also included.

\section{Example 1: Particle Pathlines}

MODPATH provides the option to record the locations of particles along pathlines. This option is called a pathline analysis (Pollock, 1994). A pathline analysis is useful to illustrate the movement of water within a flow system. MODTOOLS uses the particle data recorded by MODPATH in the PATHLINE file (Pollock, 1994) to construct GIS output consisting of lines that represent the particle pathlines. Example 1 (fig. 3) combines the GIS output from the results of four particle-tracking analyses. This example was taken from the transient simulation and shows a pathline analysis for well 2 in mapview using the backward-tracking mode of MODPATH (see Pollock, 1994, problem 2, run 1, p. 6-5 to 6-18). Well 2 begins pumping at a simulation time of 500 years. A pair of particles was started from the cell that contains well 2 (row 14, column 14, layer 1) at four points in time and the particles were tracked backward in the reverse direction of ground-water flow. The user must run MODPATH four times to produce particle data at the four simulation times, 500, 501, 503, and 510 years. After each particle-tracking analysis using MODPATH, the user would then create pathline GIS output using MODTOOLS.

Using the capabilities of the GIS, the user is able to overlay the GIS output from MODTOOLS of the four pathline analyses and to distinguish the pathlines from each analysis with a different line symbol (fig. 3). For illustrative purposes arrows to indicate the direction of ground-water flow were added to 


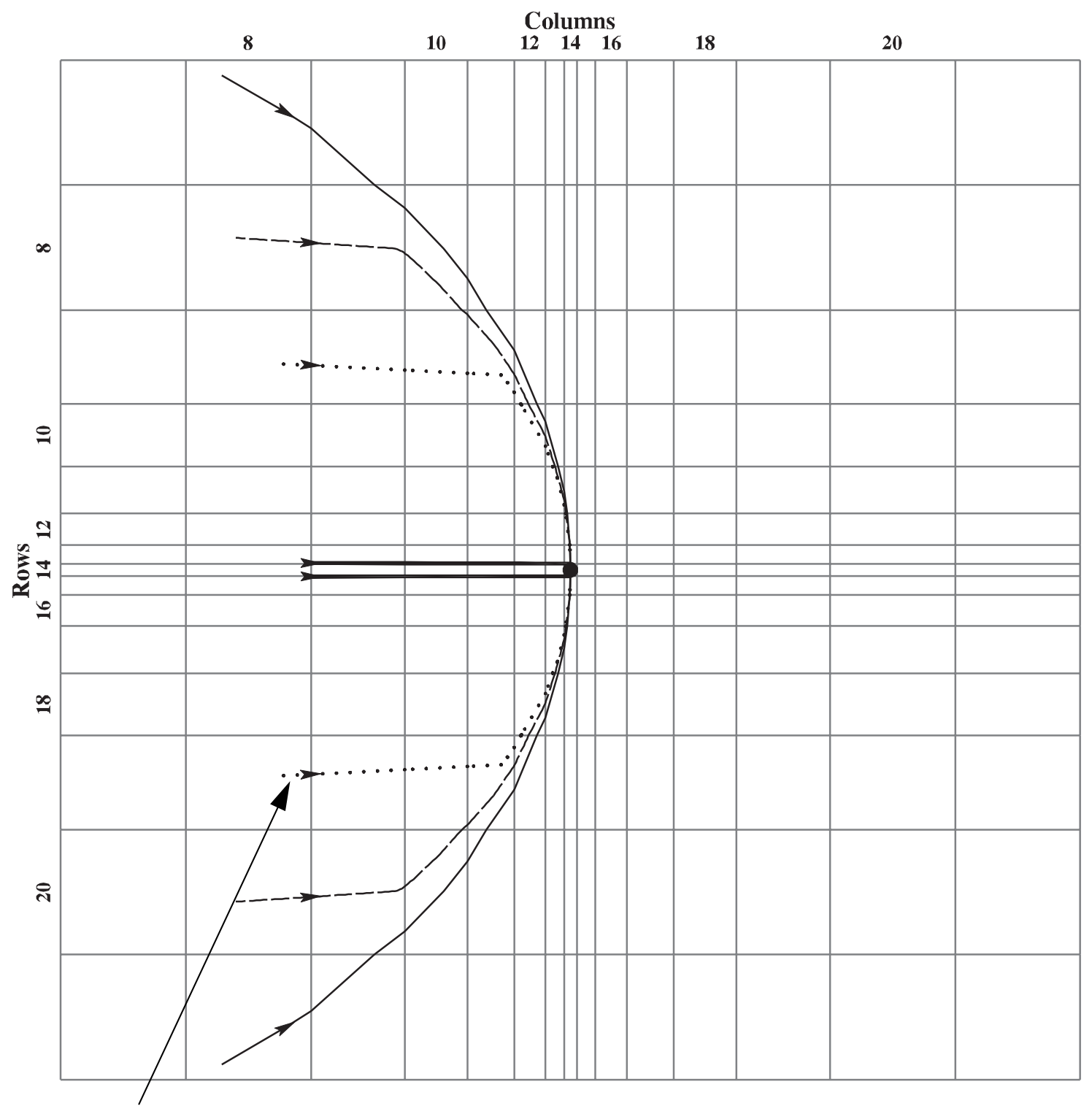

Pathline of particle 1 after 10 years of pumping

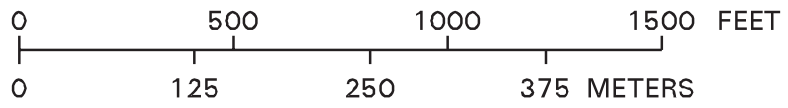

\section{EXPLANATION}

Model Grid

- Particle pathlines before the start of pumping of well 2 (at reference time $=500$ years)

-.. Particle pathlines after 1 year of pumping of well 2 (at reference time $=501$ years)

- - Particle pathlines after 3 years of pumping of well 2 (at reference time $=503$ years)

- Particle pathlines after 10 years of pumping of well 2 (at reference time $=510$ years)

Figure 3. Simulated pathlines resulting from backward tracking of two particles from well 2 under transient conditions (see Appendix B, example 1).
- Well 2 (in layer 1 )

- Direction of ground-water flow 
each particle pathline, and a dot was added to show the location of well 2 . These lines represent the paths taken by water discharging to well 2 at the start of pumping in layer 1, after 1 year of pumping, after 3 years of pumping, and after 10 years of pumping. The shape and direction of the pathlines indicates the progressive changes of the ground-water system through time caused by pumping of well 2 . The sharp bends in the pathlines correspond to the time at which pumping began in layer 1 .

\section{Example 2: Particle Endpoints}

MODPATH provides the option to record the starting or final locations of particles from a particletracking analysis. This option is called an endpoint analysis (Pollock, 1994). An endpoint analysis is useful in delineating sources of water to major discharge points such as rivers and wells or to any location within a flow system. MODTOOLS uses particle data recorded by MODPATH in the ENDPOINT file (Pollock, 1994) to produce a GIS output consisting of points which represent starting or final locations of particles and up to 30 characteristics associated with each particle.

Example 2 (fig. 4) uses the transient simulation and shows an endpoint analysis for wells 1 and 2 in mapview using the forward-tracking mode of MODPATH (see Pollock, 1994, problem 2, run 3, p. 6-20 to 6-21). The system has attained a new hydraulic steady state by the end of stress period two. Four particles were placed at the water table in each cell in layer 1 at the beginning of stress period 3 (simulation time equals 530 years), and the particles were tracked forward in the direction of the groundwater flow. The GIS output produced by MODTOOLS consists of 2,808 points, which represent the starting locations of the particles that discharged to either of the two wells.

In this endpoint analysis (fig. 4), characteristics associated with each particle were used to identify only those particles discharging to wells 1 and 2. Creation of the endpoint plot for this example using MODPATH-PLOT (Pollock, 1994, page 6-21) required the creation of a zone code array (Pollock, 1994) in order to distinguish and shade locations of the starting points for the particles discharging to the two wells, which is unnecessary for MODTOOLS.

\section{Example 3: Particle Time Series}

MODPATH provides the option to record the locations of particles at specific points in time. This option is called a time-series analysis (Pollock, 1994). A time-series analysis is useful to track the migration of particles at specific points in time. MODPATH also has the capability to release a stream of particles over a specified period of time. Combining a multiple particle release with time-series analysis allows the user to track a plume of particles which is helpful for both steady-state and transient simulations. MODTOOLS uses particle data recorded by MODPATH in the TIMESERS file (Pollock, 1994) to produce GIS output consisting of points that represent the locations of particles at specified times of travel; each point has 62 characteristics, such as present time, cumulative travel time, and velocity. 


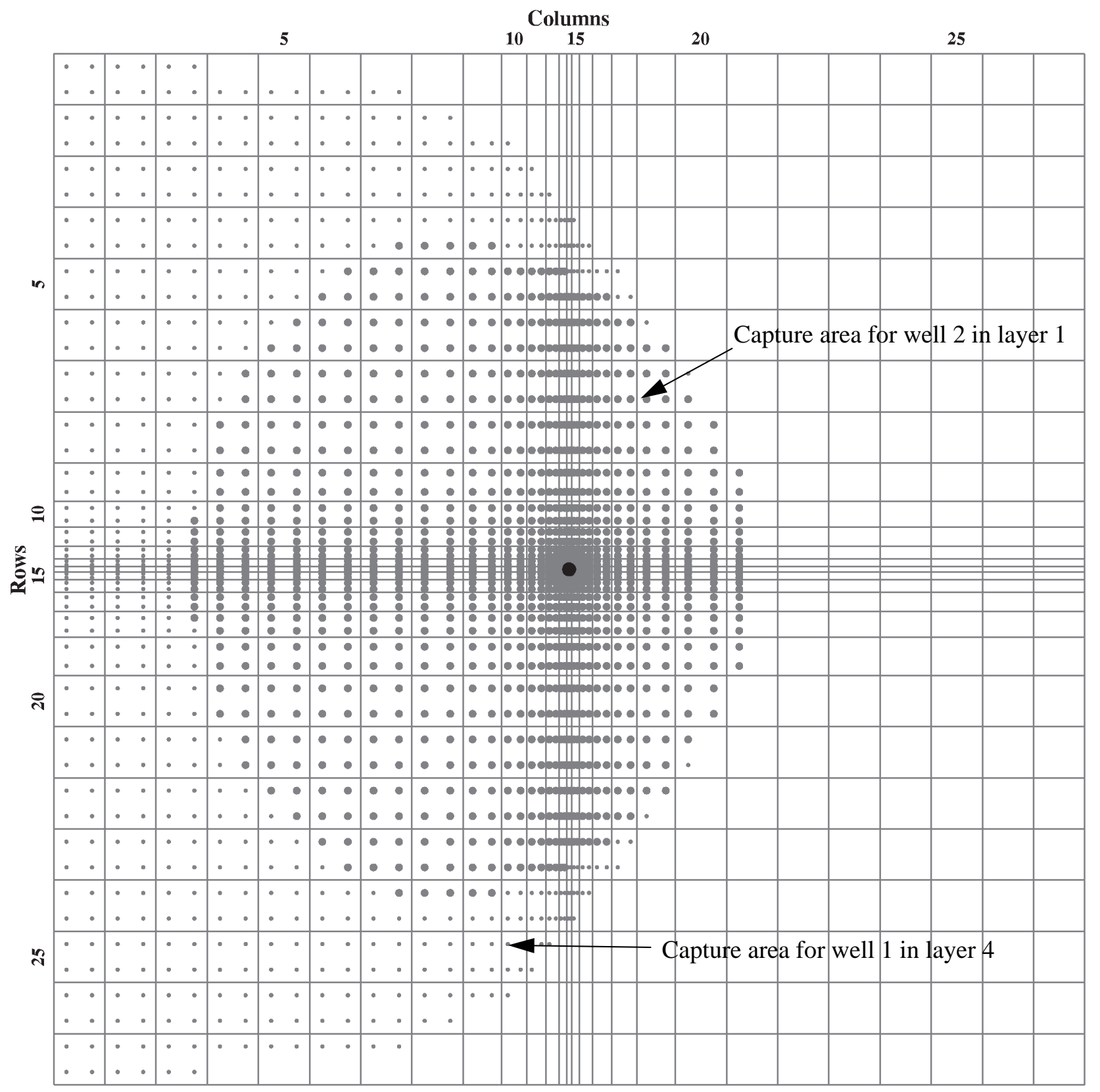

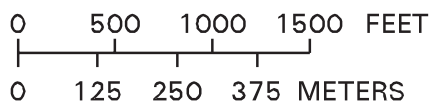

\section{EXPLANATION}

- Model Grid

- Particles that discharged to well 1

- Particles that discharged to well 2

Figure 4. Capture areas for pumping wells 1 and 2 (see Appendix B, example 2). 
Example 3 (fig. 5) uses the steady-state simulation and shows a time-series analysis with multiple particle release using the forward-tracking mode of MODPATH (see Pollock, 1994, problem 1, run 4, p. 6-13 to 6-14). Particles were released every 0.5 years for 10 years at the water table in columns 8 and 9 of row 14. Viewed in profile along row 14, the movement of the particle plume towards the well and the river over time can be easily visualized. The locations of particles at specified times of travel are identified by using the GIS to select particles having corresponding cumulative times of travel. In this example, particles were selected for times of travel of 10,20,25, and 35 years. These plots give a visual representation of the plume as it moves vertically and laterally through the system. Note how the plume eventually splits into two parts, with one part discharging toward the well and the other to the stream.

\section{Example 4: Zones of Transport}

MODTOOLS provides an option for projecting the delineations of zones of transport for discharge features such as wells, streams, or springs onto a two-dimensional surface, such as the water-table layer. (A zone of transport is a volume within a ground-water system that contributes water to a discharge feature for a specific time of travel.) This option is called a zone of transport analysis. The delineation of zones of transport is one of several methods used to assist with delineating wellhead protection areas for wells (U.S. Environmental Protection Agency, 1987). The approach used in MODTOOLS to delineate the zones of transport is documented in Appendix C. MODTOOLS constructs two GIS outputs for this option using particle data recorded by MODPATH in the TIMESERS and ENDPOINT files (Pollock, 1994). The first GIS output is the polygons that result from projecting the zones of transport for specified times of travel onto a two-dimensional surface (user specified plane), such as the water table. The resulting polygons are not necessarily equivalent to recharge or source areas, because the particle positions used to delineate the zones of transport may be several tens or hundreds of feet beneath the water table. The second GIS output is the points that form the vertices of the polygons. This GIS output contains information about the particles used to delineate the zones, such as elevation or position within the model grid. A zone of transport analysis can be done for a particle-tracking analysis only by using the time-series option for particle output and the backward-tracking mode of MODPATH.

Example 4 (fig. 6), a zone of transport analysis, used the steady-state simulation (see Pollock, 1994, problem 1, run 2, p. 6-10); however, particles were tracked using the time-series option instead of the endpoint option used by Pollock (1994). Particles were arranged as described in Appendix C for the cell containing well 1 (row 14, column 14, layer 4) and were tracked backward toward the cells where the water recharged the ground-water system. Particle data output by MODPATH was recorded every 5 years for times of travel up to 50 years (10 model time steps). The mapview of the 10,20, 25, and 35 year zones of transport is shown in figure 6. The approach used by MODTOOLS to delineate the zones of transport approximates these zones from particle positions. This approach can sometimes produce noticeable inflections in the boundaries of the zones of transport that are caused by limitations of the 


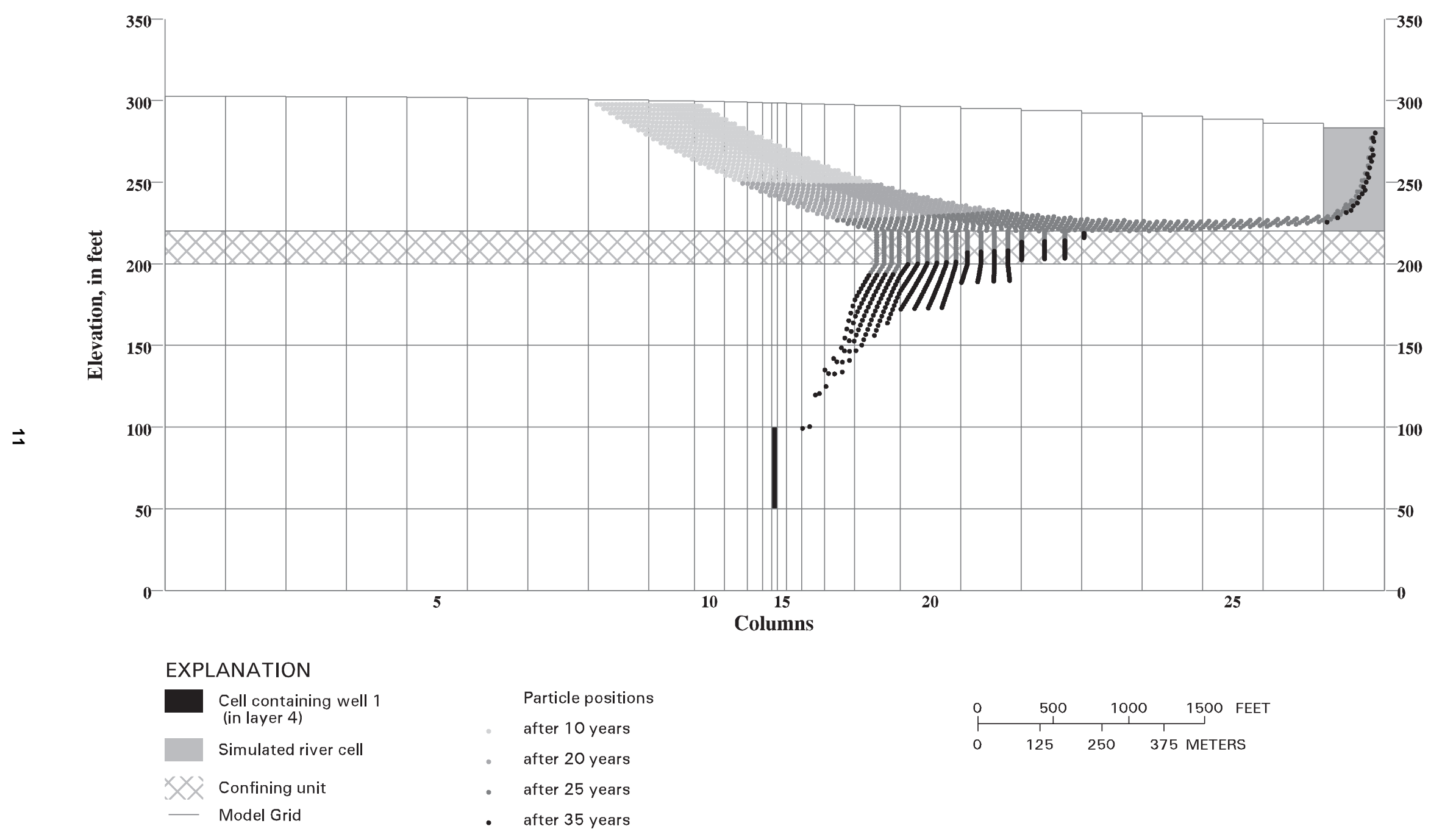

Figure 5. Vertical profile view along row 14 showing the movement of a particle plume formed by a simulated 10 years of continuous release of particles at the water table under steady-state flow conditions (see Appendix B, example 3). 
method used to delineate zones of transport (see Appendix C). In figure 6, the triangular inflections in the boundaries of the zones of transport delineated in the downgradient direction are due to one or more of these limitations.

\section{Example 5: Model Grid}

MODTOOLS provides an option to construct GIS output of the model grid in mapview or in vertical profile view along a specified row, column, or particle pathline. This option is most useful for creating a model grid for use in displaying other GIS output in mapview or profile view on row, column, or pathline plots. MODTOOLS uses the data arrays defining grid dimensions from the MAIN file for MODPATH (Pollock, 1994). To create GIS output of a vertical profile view along a particle pathline, the user must first make a particle pathline analysis for which MODTOOLS constructs a pathline GIS output for the specified particle. For a mapview or a vertical profile view along a model row or column, the user need only construct the MODPATH MAIN file. For vertical profile views, MODTOOLS uses the values of the simulated head for the tops of the cells in layer 1 if layer 1 is a water-table layer.

Example 5 (fig. 7) illustrates the use of MODTOOLS to create vertical profile model-grid GIS output. A pathline analysis for well 2 in stress period 2 of the transient simulation was made using the backward-tracking mode of MODPATH (see Pollock, 1994, problem 2, run 1, p. 6-15 to 6-18).

MODTOOLS was used to construct a model-grid GIS output in vertical profile view along the pathline of particle 1 and a pathline GIS output of the pathline of particle 1 both of which are shown in figure 7 . Particle 1 was started after 10 years of simulated pumping from well 2 in row 14, column 14, layer 1. MODPATH records the particle positions when the particle enters a new cell and at intermediate points whenever the cumulative time of travel corresponds to (1) a user-specified point in time, or (2) the end of a MODFLOW time step in a transient simulation (Pollock, 1994). MODTOOLS used the head values from the beginning of stress period 2 as the tops of the cells in layer 1.

\section{Output Options for MODFLOW Data}

MODTOOLS provides three options to construct GIS output from the data arrays of MODFLOW. These options are useful for displaying MODFLOW input and output data with other spatial data in the user's GIS, such as streams or geology. The first option allows the user to construct GIS output of contour lines using data arrays, such as head, drawdown, or cell-by-cell flow terms. The second option allows the user to construct velocity vectors representing the magnitude and direction of ground-water velocity in each active cell of the model grid. The third option allows the user to construct GIS files from the data arrays of MODFLOW; data in the files can be displayed or plotted with other GIS data, such as the model grid.

The files necessary to reproduce examples 6 through 8 are listed in Appendix B; a listing of the menu responses necessary to create the GIS output for these three examples is also included. 


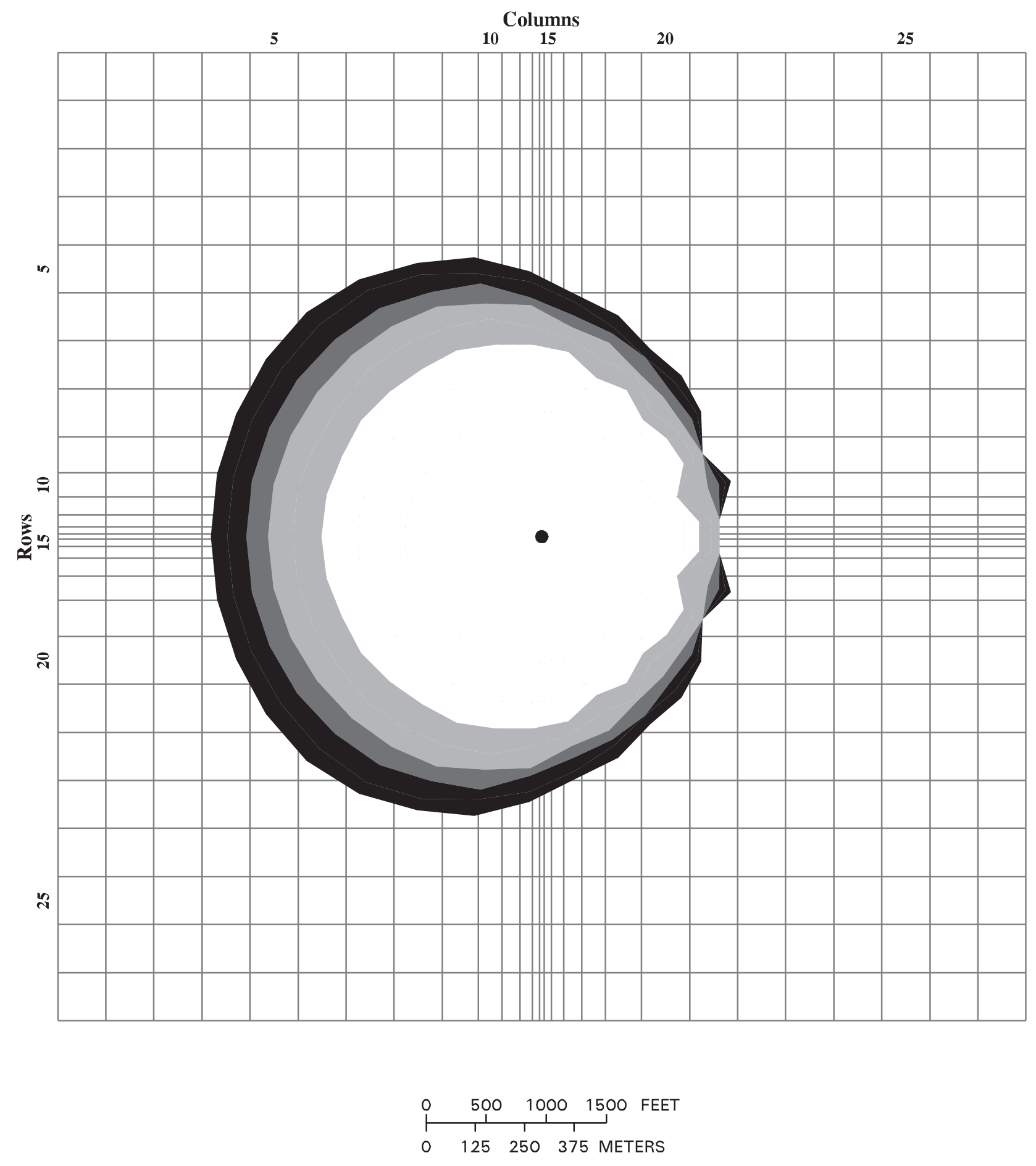

EXPLANATION

Zones of transport, in years

$\square 0-10$

$\square 10-20$

— Model Grid

$20-25$

$25-30$

Figure 6. Zones of transport for 10, 20, 25, and 35 years for well 1 (see Appendix B, example 4). 


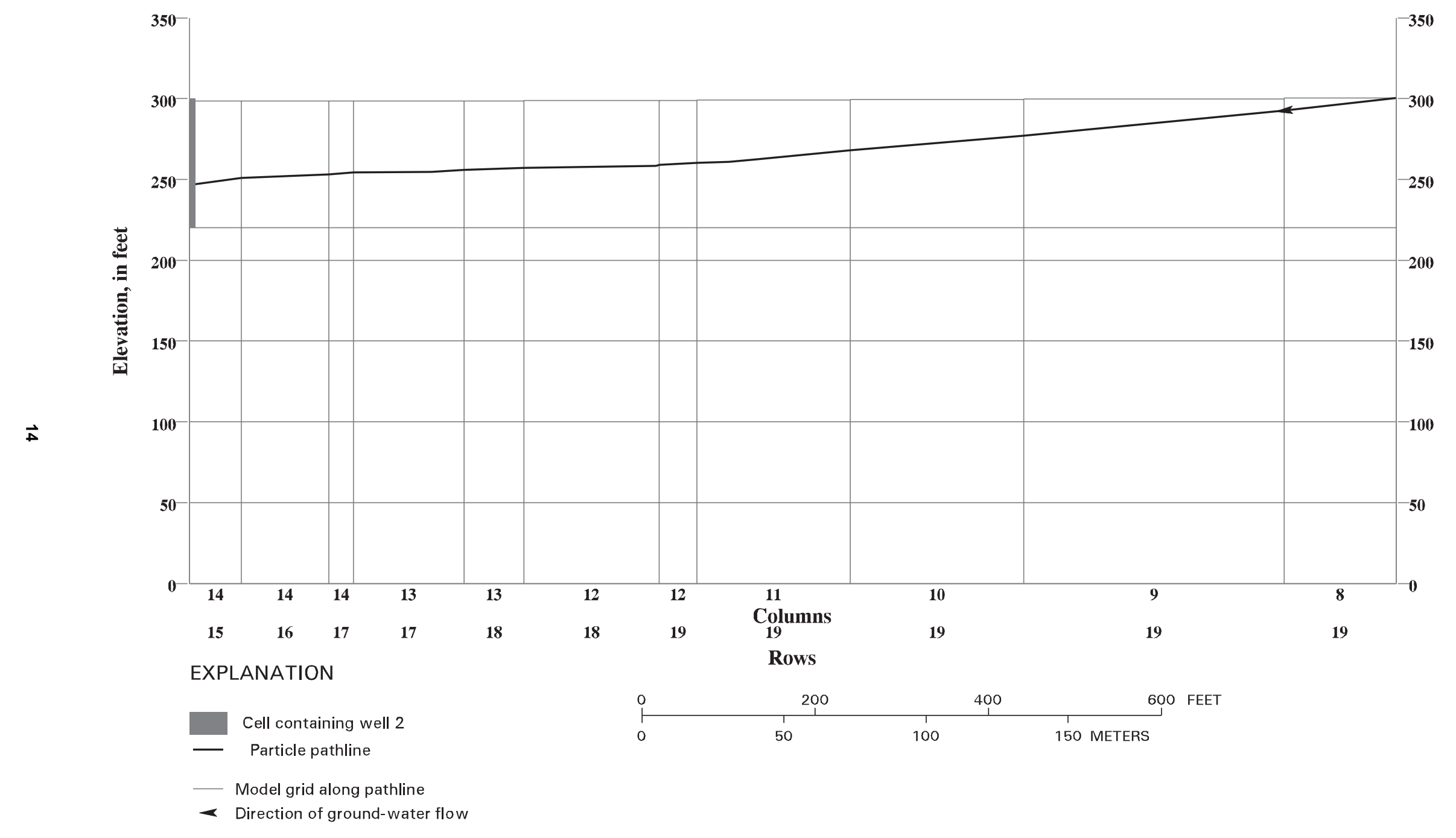

Figure 7. A vertical profile view of the model grid and pathline traveled by particle 1 (see Appendix B, example 5) (see figure 3 for pathline of particle 1 in mapview). 


\section{Example 6: Contour lines of values in Input and Output Arrays}

MODTOOLS provides an option to construct GIS output consisting of lines connecting points of equal value (contour lines) from the cell-by-cell terms of MODFLOW. This option is useful in producing contours of MODFLOW data, such as the simulated head values, in a GIS format that can be displayed or plotted with other GIS data. One option would be to graphically overlay lines of equal observed head with the lines of equal simulated head to facilitate model calibration.

Figure 8 illustrates contour GIS output showing lines of the equal simulated head for cells in layer 4. Two types of GIS output were used to create this figure: (1) lines of equal hydraulic head constructed by MODTOOLS using the simulated steady-state head values output by MODFLOW, and (2) model grid in mapview.

\section{Example 7: Velocity Vectors}

MODTOOLS provides an option to construct GIS output consisting of velocity vectors showing the magnitude and direction of simulated ground-water movement in the active cells of the model grid. This option is useful in displaying the results of a ground-water flow simulation, for checking hypotheses regarding the magnitude and direction of water movement, and for identifying potential ground-water flow paths. To produce this type of GIS output, the user must make a MODFLOW simulation and assemble the MODPATH MAIN file (MODPATH does not need to be run). Data required to construct a velocity-vector GIS output include grid dimensions and porosity arrays used by MODPATH, and the simulated head and cell-by-cell flow terms output by the Basic and the Block Centered Flow Packages of MODFLOW.

Figure 9 illustrates velocity-vector GIS output. The velocity vectors, representing the magnitude and direction of ground-water velocity in layer 4 , were generated for the steady-state simulation. The direction of ground-water flow is computed from the $\mathrm{x}$ and $\mathrm{y}$ components of the cell-by-cell flow terms. The length of the vector indicates the relative magnitude of ground-water velocity, which is based on the rates of flow through the cell faces, the wetted cross-sectional area of the faces, the porosity of the material in the cell, and a user-specified scaling value. This part of MODTOOLS was adapted from the work of Scott (1990).

\section{Example 8: Cell Values}

MODTOOLS provides an option to construct GIS output from the data arrays of MODFLOW. This option is useful in translating MODFLOW data into a GIS format that can be displayed or plotted with other GIS data, such as the locations of pumping wells, streams, or cultural features.

For example 8 (fig. 10), the simulated head values and the data defining the cell dimensions in the MODPATH MAIN file were used to construct GIS output for a vertical profile of the heads and model grid along row 14. Values of simulated head in layer 1 for stress period 3 at time step 1 from the transient simulation were used for this example. MODTOOLS used the simulated head values for stress period 1, time step 1 for the tops of the cells in layer 1 . The values of simulated head for layer 1 were selected 

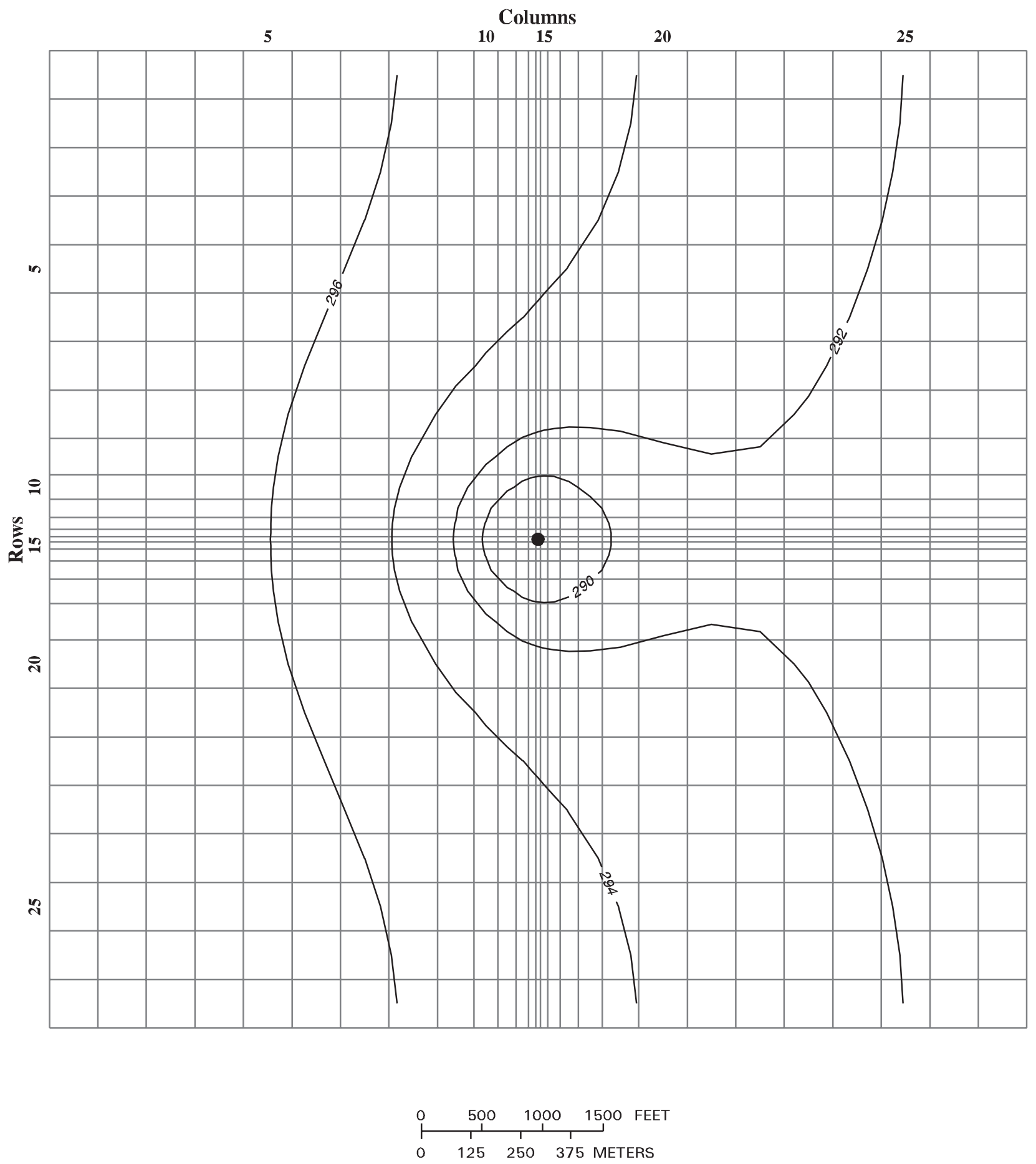

EXPLANATION

- 296- Lines of equal hydraulic head in layer 4 , in feet

(Contour interval variable)

- Model grid

- Well 1 (in layer 4)

Figure 8. Lines of equal simulated hydraulic head for cells in layer 4 (see Appendix B, example 6). 


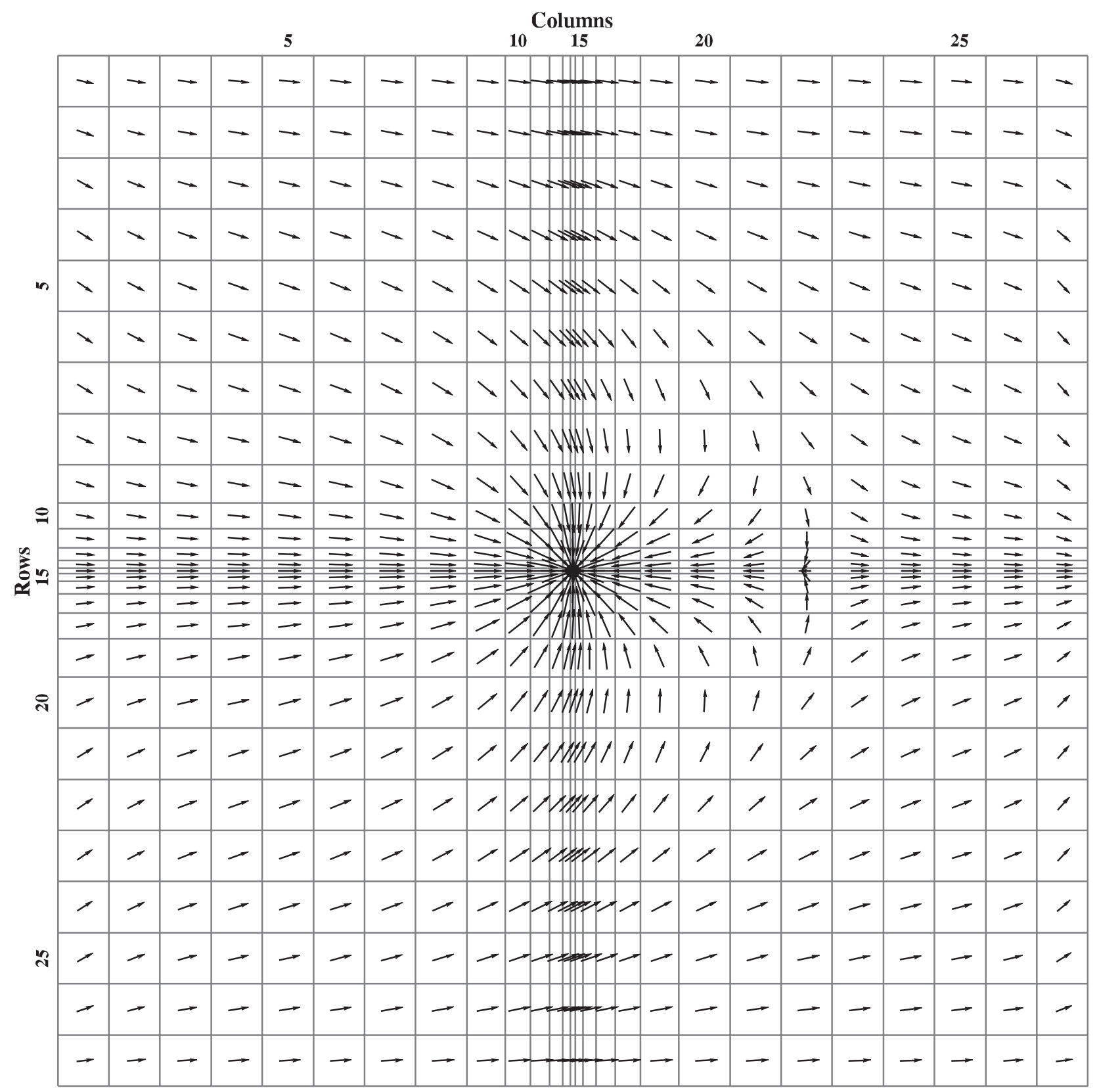

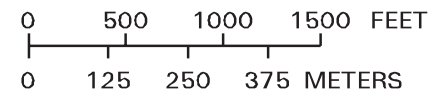

\section{EXPLANATION}

- Flow vector (length scaled logarithmically)

- Model grid

- Well 1 (in layer 4)

Figure 9. Horizontal velocity vectors for layer 4 (see Appendix B, example 7). 
using the GIS and are shown in figure 10 as a solid line. The differences in elevation between the tops of the cells in layer 1 and the solid line drawn in each cell are the simulated drawdown between the end of stress period 1, time step 1 and the end of stress period 3, time step 1 .

\section{MODTOOLS USER'S GUIDE}

\section{Overview of MODTOOLS}

The set of MODTOOLS computer programs consists of a main AML (Arc Macro Language) program called MODTOOLS.AML, a main FORTRAN program called MODTOOLS.F, a large number of FORTRAN subroutines, and two secondary AML programs. The primary purpose of the MODTOOLS.AML program is to manage the process of constructing GIS output from the particle and array data of MODPATH and MODFLOW. Subsequently, MODTOOLS.AML passes control to MODTOOLS.F and other FORTRAN programs. The primary purpose of the FORTRAN programs is the creation of features such as particle pathlines or the model grid in a GIS format. The particle and array data are stored in a single, one-dimensional master array that can be adjusted to accommodate large simulations simply by changing its dimension in the MODTOOLS.F program. The primary purpose of secondary AML programs is the creation of GIS features.

MODTOOLS obtains data from a combination of file and interactive keyboard input. Files containing the basic information describing the flow system, such as geometry, boundary conditions, and the cell-by-cell flow terms, are referred to as "flow system files." Interactive keyboard input is used primarily to supply information about GIS output options that change frequently. Keyboard input is recorded in a special batch file called MODTOOLS.OUT. A batch file generated from a previous MODTOOLS session can be used in place of keyboard input.

The user's guide part of this report is organized into several sections:

(1) a "quick-start guide" that briefly describes the overall process of using MODTOOLS with MODFLOW and MODPATH to produce GIS output,

(2) instructions for constructing the NAME file required by MODTOOLS to open and close files,

(3) instructions for using MODTOOLS in batch mode,

(4) a discussion of coordinate systems used in MODTOOLS,

(5) a description of MODTOOLS error messages and common errors,

(6) a description of the menu and response system for interactive input, and

(7) a description of GIS output file structure and content.

\section{A Quick-Start Guide to Running MODTOOLS}

Five basic steps are necessary to generate GIS output using MODTOOLS. To generate GIS output from MODPATH results, all five steps must be followed. If the user is generating only GIS output of MODFLOW output (contour lines, velocity vectors, or cell values), then step 3 (running MODPATH) 


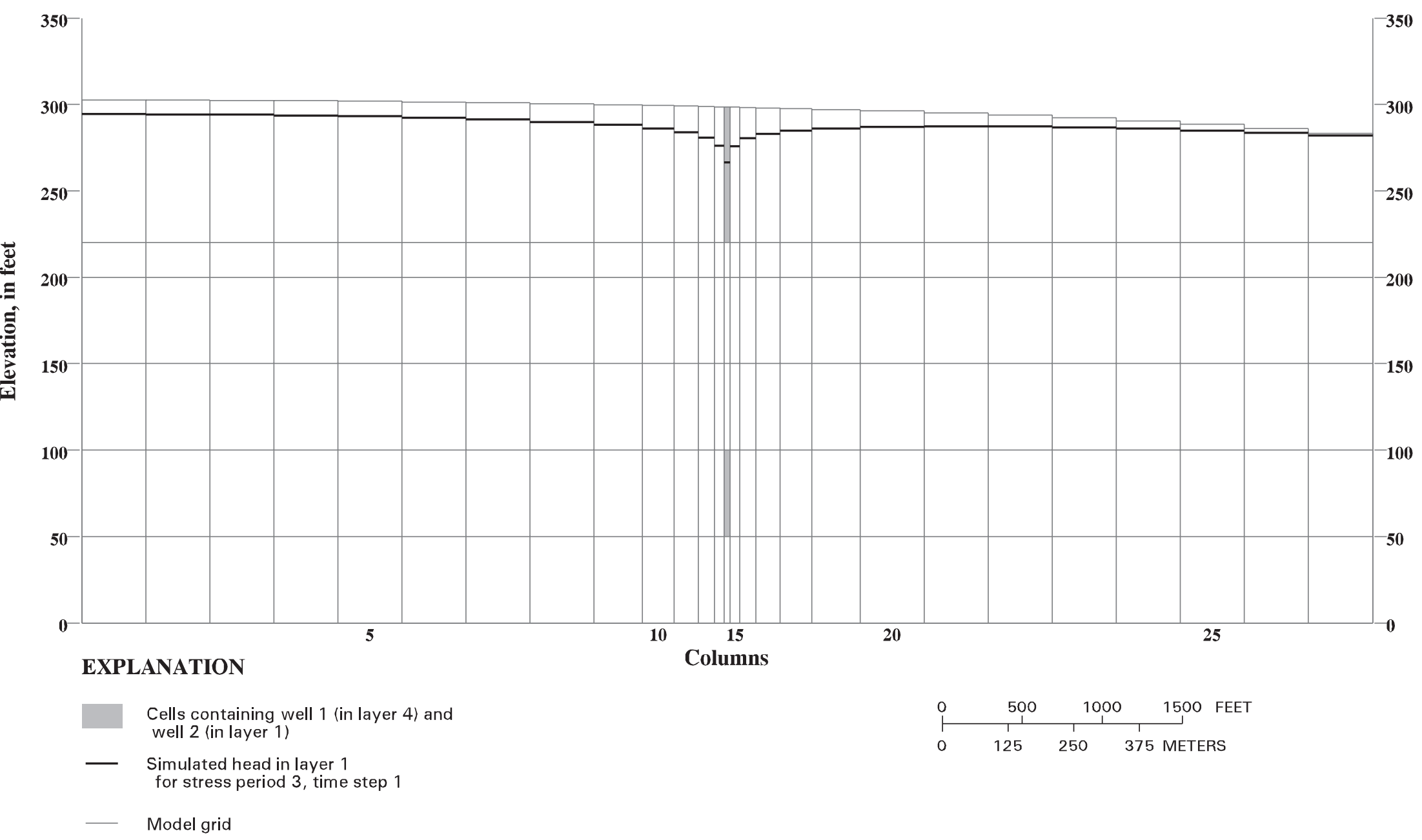

Figure 10. Vertical view along row 14 showing model grid and simulated heads (see Appendix B, example 8). 
can be omitted. If the user is generating only GIS output of MODFLOW input (contours or cell values), then steps 1 and 3 can be omitted. For more detailed instructions on using MODFLOW and MODPATH, the user may refer to McDonald and Harbaugh (1988) and Pollock (1994), respectively. Instructions for obtaining and installing MODTOOLS are given in Appendix A.

Step 1. Run MODFLOW (see Pollock, 1994, p. 3-4)

MODPATH computes velocity components using the cell-by-cell flow information generated by MODFLOW. Before MODPATH can be run, MODFLOW must be run and cell-by-cell output written to a file. MODPATH also requires MODFLOW head output for any layer that can have a water table within it.

Step 2. Assemble MODPATH Data Files (see Pollock, 1994, p. 3-4)

MODPATH always requires the following data files:

(1) Flow System Files -- MODFLOW and MODPATH data files that contain information about the physical dimensions of the ground-water system, boundary conditions, hydrologic properties, and output heads and cell-by-cell flows.

(2) NAME File -- A data file containing a list of input and output files required by MODPATH, FORTRAN unit numbers, and file-type descriptions. This information is used by MODPATH and MODTOOLS to open the files.

Step 3. Run MODPATH (see Pollock, 1994, p. 3-4)

Once the necessary data files have been prepared, MODPATH can be executed using the methods summarized by Pollock (1994, p. 3-4 to 3-5).

\section{Step 4. Run MODTOOLS}

The user must first initiate the ARC/INFO GIS software by issuing the appropriate command at the UNIX prompt. On many computer systems the command is simply,

arc

The user then issues the ARC/INFO system command that specifies the path to the directory where the MODTOOLS.AML program is stored. This command informs the ARC/INFO software to search the directory [path] first when a command is issued to execute an ARC/INFO AML program.

\section{\&amlpath [path]}

The user is now ready to run the MODTOOLS program by issuing the \&run command followed by the name of the AML program to run, modtools, and a list of arguments expected by the MODTOOLS programs:

\section{\&run modtools $<$ GIS output $><N A M E$ file $>$ \{batch file $\}$}

Two arguments, the name for the GIS output and the name of the NAME file, are mandatory. The NAME file contains a list of the files that will be read by MODTOOLS. These files contain data describing particle locations and characteristics associated with each particle, model-cell geometry, and other pertinent information. The third argument, the name of a batch file containing a list of menu responses for MODTOOLS to create GIS output, is optional. Use of a batch file eliminates the need to interactively answer the menu responses over and over again for similar runs. Use of the batch file is described in a later section. 


\section{Step 5. Review GIS Output from MODTOOLS}

MODTOOLS creates a file called MODTOOLS.LIST, which contains a listing of all operations preformed by MODTOOLS. This file is important, because MODTOOLS records any errors to this file. The user should review this file first if MODTOOLS does not properly produce the specified GIS output.

\section{General Instructions}

\section{NAME File}

The NAME file contains one line for each input data file. This file provides the information needed to manage the input data files. Each line of the NAME file consists of 3 items: (1) a character string signifying the type of data file (table 2), (2) an integer file unit number, and (3) the file name. The NAME file input is read using a free format. Any valid file unit number for a given operating system may be specified. However, MODTOOLS reserves unit numbers in the range of 80 to 99 for internal use. Files can be specified in any order. A typical NAME file for MODTOOLS is shown below:

$\begin{array}{ll}\text { MAIN } & 11 \text { main.dat } \\ \text { DATA } & 31 \text { ibound.1 } \\ \text { BUDGET } & 50 \text { budget.out } \\ \text { HEAD(BINARY) } & 60 \text { head.out }\end{array}$

The first item on each line is a keyword that identifies the type of data file. The character string identifier can be in upper or lower case. MODTOOLS uses the same naming convention as used by MODPATH and MODPATH-PLOT to indicate specific data files (table 2) (Pollock, 1994, p. A-6 to A-7). Ancillary data files usually contain large arrays that are referenced by array control records in other data files. Ancillary data files always must be declared as type DATA. For example, the IBOUND array for each layer of a model might be stored in separate files and only the array control records referenced in the MAIN file. Each file would be assigned a unit number and identified using the keyword DATA in the NAME file.

The naming conventions for the NAME file used by MODTOOLS are summarized in table 2 along with the data file requirements. Because MODTOOLS does not compute particle pathlines, many of the data arrays are not needed by MODTOOLS to create GIS output. MODTOOLS uses two files identified by the keywords CONTOUR-DATA and CONTOUR-CONTROL to create GIS output of contour lines. MODTOOLS allows the user to construct contour lines of miscellaneous gridded model data, such as hydraulic conductivity. The data can be provided in a standard ASCII text file (like the MODPATHPLOT option of Pollock [1994, p. 4-16]) or in a binary (unformatted) file. MODTOOLS identifies the data using the keyword CONTOUR-DATA. MODTOOLS requires a file identified by the keyword CONTOUR-CONTROL to determine the location and format of the data to be contoured (see "Format of Array Menu" [p. 48] or Pollock, 1994, p. A-2 to A-5). MODTOOLS provides an option for reading head and drawdown values from standard ASCII text files. These values may have been produced by MODFLOW-96 (Harbaugh and McDonald, 1996) or other means, such as by GIS techniques. MODTOOLS requires a file identified by the keyword HEAD-CONTROL to determine the location 
Table 2. Summary of data file requirements for MODPATH, MODPATH-PLOT, and MODTOOLS (adapted from Pollock, 1994, p. A-7)

\begin{tabular}{|c|c|c|c|c|c|}
\hline Description & $\begin{array}{l}\text { Type of data file } \\
\text { Keyword }\end{array}$ & $\begin{array}{l}\text { Needed for } \\
\text { MODPATH? }\end{array}$ & $\begin{array}{c}\text { Needed for } \\
\text { MODPATH-PLOT? }\end{array}$ & $\begin{array}{l}\text { Include in } \\
\text { NAME file? }\end{array}$ & $\begin{array}{l}\text { Needed for } \\
\text { MODTOOLS }\end{array}$ \\
\hline Main data file & MAIN & Yes & Yes & Yes & Yes \\
\hline Recharge Package & $\mathrm{RCH}$ & Yes $^{1}$ & No & Yes & No \\
\hline Well Package & WEL & Yes $^{1}$ & Yes & Yes & No \\
\hline River Package & RIV & Yes $^{1}$ & Yes & Yes & No \\
\hline Stream Package & STR & Yes $^{1}$ & Yes & Yes & No \\
\hline Drain Package & DRN & Yes $^{1}$ & Yes & Yes & No \\
\hline GHB Package & GHB & Yes $^{1}$ & Yes & Yes & No \\
\hline ET Package & EVT & Yes $^{1}$ & No & Yes & No \\
\hline Composite budget file & $\mathrm{CBF}$ & Transient only & Transient cross sections only & Optional $^{3}$ & No \\
\hline Drawing commands file & DCF & No & User's option for mapview plots & Optional $^{3}$ & No \\
\hline Endpoint file & ENDPOINT & Yes & Yes & Optional $^{3}$ & Endpoint mode \\
\hline Pathline file & PATHLINE & Pathline mode & Pathline mode & Optional $^{3}$ & Pathline mode \\
\hline Time series file & TIME-SERIES & Time-series mode & Time-series mode & Optional $^{3}$ & Time-series mode \\
\hline Time data file & TIME & User's option & No & Optional $^{3}$ & No \\
\hline Starting locations file & LOCATIONS & User's option & No & Optional $^{3}$ & No \\
\hline Binary budget file & BUDGET & Yes $^{1}$ & No & Yes & Yes \\
\hline $\begin{array}{l}\text { Head file } \\
\text { (ASCII text or binary) }\end{array}$ & $\begin{array}{l}\text { HEAD } \\
\text { HEAD(BINARY) }\end{array}$ & Yes $^{1}$ & $\mathrm{Yes}^{2}$ & Yes & Yes $^{2}$ \\
\hline Head format control file & HEAD-CONTROL & No & No & Optional $^{3}$ & User's option \\
\hline $\begin{array}{l}\text { Drawdown file } \\
\text { (ASCII text or binary) }\end{array}$ & $\begin{array}{l}\text { DRAWDOWN } \\
\text { DRAWDOWN(BINARY) }\end{array}$ & No & User's option for mapview plots & Yes & User's option \\
\hline $\begin{array}{l}\text { Drawdown format control } \\
\text { file }\end{array}$ & $\begin{array}{l}\text { DRAWDOWN- } \\
\text { CONTROL }\end{array}$ & No & No & Optional $^{3}$ & User's option \\
\hline Contour data file & CONTOUR-DATA & No & User's option for mapview plots & Optional $^{3}$ & User's option \\
\hline Contour format control file & CONTOUR-CONTROL & No & No & Optional $^{3}$ & User's option \\
\hline Contour level file & CONTOUR-LEVEL & No & User's option for mapview plots & Optional $^{3}$ & No \\
\hline Ancillary text data file & DATA & User's option & User's option & Yes & User's option \\
\hline Summary output file & LIST & Yes & Yes & Optional $^{3}$ & No \\
\hline Grid unit array file & GUA & No & User's option & Yes & No \\
\hline $\begin{array}{l}\text { Array data file } \\
\text { (ASCII text or binary) }\end{array}$ & $\begin{array}{l}\text { ARRAY } \\
\text { ARRAY(BINARY) }\end{array}$ & No & No & Optional $^{3}$ & User's option \\
\hline Array format control file & ARRAY-CONTROL & No & No & Optional $^{3}$ & User's option \\
\hline
\end{tabular}

Notes: 1. MODFLOW stress package, budget, and head files are not used by MODPATH in transient simulations that read data directly from a composite budget file.

2. The MODFLOW head file is not required by MODTOOLS or MODPATH-PLOT for some plot types.

3. Users have the option of specifying these files in the NAME file or allowing MODPATH to prompt for file names or, in some cases, assign default file names. 
and format of the head data to be input and a file identified by the keyword DRAWDOWN-CONTROL for the drawdown values. MODTOOLS can use the files identified by the keywords ARRAY, ARRAY(BINARY), and ARRAY-CONTROL to create GIS output of cell values for miscellaneous gridded model data, such as hydraulic conductivity. MODTOOLS requires a file identified by the keyword ARRAY-CONTROL to determine the location and format of the miscellaneous gridded model data if these data are stored in a standard ASCII text file. The user should follow the instructions outlined in the MODFLOW manual for U2DREL (McDonald and Harbaugh, 1988, p. 14-4 to 14-5) for the format-control lines to create the files, CONTOUR-CONTROL, HEAD-CONTROL, DRAWDOWN-CONTROL, and ARRAY-CONTROL. Additional instructions are given in the "Format of Array Menu" section on p. 48.

\section{Batch Use}

When making a series of MODTOOLS runs using similar input and output options, the user can avoid having to answer the interactive menus every time by using the batch mode of MODTOOLS. MODTOOLS records the menu responses by the user to a file called modtools.out each time the MODTOOLS menu system is active. This file can be used as batch input in subsequent runs by renaming the file and specifying it on the command line. MODTOOLS operates in batch mode when the user specifies a batch file in the argument list input to the MODTOOLS AML program. The batch file consists of a fixed set of lines, which represents the user responses to the MODTOOLS menus. Each line is a response to one menu. The user can edit a line to change the operation of MODTOOLS and, thus, the resulting GIS output. For example, the user may wish to reduce the contour interval of a GIS output showing the lines of equal hydraulic head output by MODFLOW. Generally, simple changes are easily performed by most users while more caution is required for major changes. Batch files for each of the eight examples are listed in Appendix B.

\section{Coordinate Systems}

\section{Mapviews}

GIS output created by MODTOOLS must be referenced to real-world coordinates. MODTOOLS requires the user to specify coordinate information in order to translate particle coordinates from MODPATH into the coordinate system used in the user's GIS system. MODTOOLS prompts the user for unit-conversion multipliers, the origin of the MODFLOW grid, and a grid rotation angle to properly translate the particle coordinates for GIS output in mapview.

The unit-conversion multipliers are used to convert the units of length used in MODFLOW/ MODPATH to the proper units of length in the GIS coordinate system. MODTOOLS has two unitconversion multipliers the $\mathrm{x}-\mathrm{y}$ multiplier and $\mathrm{z}$ multiplier. The $\mathrm{x}-\mathrm{y}$ multiplier is used to convert the units of length of $x-y$ dimension. For example, if the model-grid dimensions are specified in MODFLOW or MODPATH using units of feet and the GIS output was required to have units of meters (to be compatible with other GIS data), the user would specify a multiplier of 0.3048 to convert feet to meters. The $\mathrm{z}$ 
multiplier is used to convert the units of length of $\mathrm{z}$ dimension. For example, if the gridded model data output by MODFLOW were in units of feet and the GIS output was required to have units of meters (to be compatible with other GIS data), the user would specify a multiplier of 0.3048 to convert feet to meters.

The values for the $\mathrm{x}$ and $\mathrm{y}$ coordinates of the origin are used to properly translate the origin of the MODFLOW/MODPATH grid to the real-world coordinates in the desired coordinate system. These values represent the origin of the MODFLOW grid, which is the intersection of outer boundaries of the cell in row 1 and column 1 (upper left corner). The grid rotation angle is the angle in degrees that the model grid is rotated from north. The angle is specified in the counterclockwise degrees of rotation around the origin of the grid.

\section{Vertical Profile Views}

MODTOOLS can create vertical profile views along a row or column or along a particle pathline computed by MODPATH. To properly scale the GIS output from MODTOOLS, the user must specify a vertical exaggeration and a horizontal scale in addition to specifying the $\mathrm{x}-\mathrm{y}$ and $\mathrm{z}$ unit-conversion multipliers. For example, if MODFLOW or MODPATH was operated using meters as the unit of length, MODTOOLS must convert the particle coordinates output by MODPATH as well as the cell geometry to units in feet to properly scale GIS output. The user would specify a multiplier of 0.3048 for the $x-y$ and $\mathrm{z}$ unit-conversion multipliers to convert meters to feet.

For vertical profile views of contour GIS output, MODTOOLS constructs the GIS outputs and the accompanying model-grid GIS outputs using a "normalized" approach (Pollock, 1994, p. 4-12). MODTOOLS constructs a rectangular cross section using the average thickness of each layer. This approach is used for contour GIS output, because MODTOOLS uses the computer program CONTOUR (Harbaugh, 1990), which was designed to work with gridded data in mapview. CONTOUR has been adapted to work for vertical profile views, but the "normalized" approach must be used because of the numerical problems caused by vertical discretization schemes.

For vertical profile views of the other seven types of GIS output, MODTOOLS constructs a rectangular cross section of the cells using the input model-grid dimensions. This type of plot gives a better representation of grids with variable thickness layers.

\section{Error Messages}

Some error checking and prevention is done by the MODTOOLS program. MODTOOLS checks the list of arguments for several conditions; errors are reported to the user. MODTOOLS creates a file called MODTOOLS.LIST and several temporary data files that can be referred to if MODTOOLS fails to construct GIS output properly. 
MODTOOLS records a listing of operations used to construct GIS output in the

MODTOOLS.LIST file. MODTOOLS records these operations together with error messages, which are helpful to the user in resolving errors in the event MODTOOLS fails. MODTOOLS records operations starting with the process of reading the NAME file and ending with the construction of GIS output. Typically, errors encountered in reading the NAME file are caused by using FORTRAN unit numbers reserved for use by MODTOOLS (units 80-99) or improper keywords in the NAME file. A common error when constructing contour GIS output is not including the file containing the cell-by-cell terms in the MODTOOLS NAME file. This file is identified by the keyword CONTOUR-DATA in the NAME file. Another common error is not including the file containing the simulated head terms in the NAME file. MODTOOLS uses the head terms in vertical profile views for the tops of cells in layer 1 if layer 1 was simulated as a water-table layer. This file is identified by the keywords HEAD or HEAD(BINARY) in the MODTOOLS NAME file.

MODTOOLS records other useful information in the MODTOOLS.LIST file, such as the number of particles used to construct particle pathline GIS output and the number of cells omitted from a modelgrid GIS output. Sometimes MODTOOLS must omit cells or particle pathlines because the polygons or lines cannot be represented properly in the GIS output when these features are projected onto the plane of view specified by the user. MODTOOLS records the number of dry cells omitted from the cell geometry and the number particles found in a user-specified time of travel in the MODTOOLS.LIST file. The user can review this file and check to see if any cells or particle pathlines were rejected.

\section{MODTOOLS Menus}

MODTOOLS uses an interactive menu and response system to obtain data from the user that controls the operations of MODTOOLS and the creation of the resulting GIS output. MODTOOLS menus are summarized in tables 3 and 4, which relate the GIS output to the specific menus. Only the appropriate menus for the selected GIS output are used in a MODTOOLS session. The choices available in each menu are discussed in the following sections. Most menus have a help option, which when selected, activates a help menu and message system. Most menus also have a "back" option, which enables the user to return to the previously seen menu and to reenter a response. Menu responses may be in either upper or lower case. 
Table 3. MODTOOLS menus used to produce MODPATH GIS output

[X, menu is activated]

\begin{tabular}{|c|c|c|c|c|c|c|c|c|c|c|c|c|}
\hline \multirow[b]{3}{*}{ Menus } & \multicolumn{3}{|c|}{ Particle pathlines } & $\begin{array}{l}\text { Particle } \\
\text { endpoints }\end{array}$ & \multicolumn{3}{|c|}{ Particle time-series } & \multicolumn{2}{|c|}{$\begin{array}{l}\text { Zones of } \\
\text { transport }\end{array}$} & \multicolumn{3}{|c|}{ Model grid } \\
\hline & \multicolumn{3}{|c|}{ View orientation } & \multirow{2}{*}{$\begin{array}{c}\begin{array}{c}\text { View } \\
\text { orientation }\end{array} \\
\text { Map }\end{array}$} & \multicolumn{3}{|c|}{ View orientation } & \multicolumn{2}{|c|}{ View orientation } & \multicolumn{3}{|c|}{ View orientation } \\
\hline & Map & $\begin{array}{c}\text { Row } / \\
\text { column }\end{array}$ & $\begin{array}{l}\text { Particle } \\
\text { path }\end{array}$ & & Map & $\begin{array}{c}\text { Row/ } \\
\text { column }\end{array}$ & $\begin{array}{l}\text { Particle } \\
\text { path }\end{array}$ & Map & $\begin{array}{c}\text { Row/ } \\
\text { column }\end{array}$ & Map & $\begin{array}{c}\text { Row/ } \\
\text { column }\end{array}$ & $\begin{array}{l}\text { Particle } \\
\text { path }\end{array}$ \\
\hline $\begin{array}{l}\text { MODTOOLS } \\
\text { options }\end{array}$ & $\mathbf{x}$ & $\mathbf{x}$ & $\mathbf{x}$ & $\mathbf{x}$ & $\mathbf{x}$ & $\mathbf{X}$ & $\mathbf{x}$ & $\mathbf{x}$ & $\mathbf{x}$ & $\mathbf{x}$ & $x$ & $\mathbf{X}$ \\
\hline Tracking mode & & & & $\mathbf{x}$ & & & & & & & & \\
\hline Orientation & $\mathbf{x}$ & $\mathbf{x}$ & $\mathbf{x}$ & $\mathbf{x}$ & $\mathbf{x}$ & $\mathbf{X}$ & $\mathbf{X}$ & $\mathbf{x}$ & $\mathbf{X}$ & $\mathbf{X}$ & $\mathbf{X}$ & $\mathbf{x}$ \\
\hline $\begin{array}{l}\mathrm{X} \text {-Y coordinate } \\
\text { conversion }\end{array}$ & $\mathbf{x}$ & $\mathbf{x}$ & $\mathbf{x}$ & $\mathbf{x}$ & $\mathbf{x}$ & $\mathbf{x}$ & $\mathbf{x}$ & $\mathbf{x}$ & $\mathbf{x}$ & $\mathbf{X}$ & $\mathbf{x}$ & $x$ \\
\hline $\begin{array}{l}\mathrm{Z} \text { coordinate } \\
\text { conversion }\end{array}$ & $\mathbf{x}$ & $\mathbf{x}$ & $\mathbf{X}$ & $\mathbf{x}$ & $\mathbf{x}$ & $\mathbf{X}$ & $\mathbf{X}$ & $\mathbf{x}$ & $\mathbf{X}$ & $\mathbf{X}$ & $\mathbf{x}$ & $\mathbf{x}$ \\
\hline Rotation angle & $\mathbf{x}$ & & & $\mathbf{x}$ & $\mathbf{x}$ & & & $\mathbf{x}$ & & $\mathbf{X}$ & & \\
\hline $\mathrm{X}$ origin & $\mathbf{x}$ & & & $\mathbf{x}$ & $\mathbf{x}$ & & & $\mathbf{x}$ & & $\mathbf{X}$ & & \\
\hline$Y$ origin & $\mathbf{x}$ & & & $\mathbf{x}$ & $\mathbf{x}$ & & & $\mathbf{x}$ & & $\mathbf{x}$ & & \\
\hline $\begin{array}{l}\text { Vertical } \\
\text { exaggeration }\end{array}$ & & $\mathbf{x}$ & $\mathbf{X}$ & & & $\mathbf{x}$ & $\mathbf{x}$ & & $\mathbf{x}$ & & $\mathbf{x}$ & $\mathbf{x}$ \\
\hline $\begin{array}{l}\text { Horizontal } \\
\text { scale }\end{array}$ & & $\mathbf{x}$ & $\mathbf{X}$ & & & $\mathbf{x}$ & $\mathbf{x}$ & & $\mathbf{x}$ & & $\mathbf{x}$ & $\mathbf{x}$ \\
\hline $\begin{array}{l}\text { Row, column, } \\
\text { layer, ibound, } \\
\text { or particle path } \\
\text { selection }\end{array}$ & & $\mathbf{x}$ & $\mathbf{x}$ & & & $\mathbf{x}$ & $\mathbf{x}$ & & $\mathbf{x}$ & & $\mathbf{x}$ & $\mathbf{x}$ \\
\hline Equal sectors & & & & & & & & $\mathbf{x}$ & $\mathbf{x}$ & & & \\
\hline
\end{tabular}


Table 4. MODTOOLS menus used to produce MODFLOW GIS output

$[\mathrm{X}$, menu is activated]

\begin{tabular}{|c|c|c|c|c|c|c|c|c|c|c|c|c|c|c|}
\hline \multirow[b]{3}{*}{ Menus } & \multicolumn{4}{|c|}{ Contours of Input and Output Arrays } & \multicolumn{4}{|c|}{ Velocity vectors } & \multicolumn{6}{|c|}{ Cell Values } \\
\hline & \multicolumn{4}{|c|}{ View orientation } & \multicolumn{4}{|c|}{ View orientation } & \multicolumn{6}{|c|}{ View orientation } \\
\hline & $\begin{array}{c}\text { Mapview } \\
\text { layer }\end{array}$ & $\begin{array}{c}\text { Row } / \\
\text { column }\end{array}$ & $\begin{array}{c}\text { Mapview } \\
\text { ibound }\end{array}$ & $\begin{array}{c}\text { Mapview } \\
\text { upper }\end{array}$ & $\begin{array}{c}\text { Mapview } \\
\text { layer }\end{array}$ & $\begin{array}{l}\text { Row/ } \\
\text { column }\end{array}$ & $\begin{array}{c}\text { Mapview } \\
\text { ibound }\end{array}$ & $\begin{array}{c}\text { Mapview } \\
\text { upper }\end{array}$ & Map & $\begin{array}{c}\text { Mapview } \\
\text { layer }\end{array}$ & $\begin{array}{c}\text { Row/ } \\
\text { column }\end{array}$ & $\begin{array}{l}\text { Particle e } \\
\text { path }\end{array}$ & $\begin{array}{c}\text { Mapview } \\
\text { ibound }\end{array}$ & $\begin{array}{c}\text { Mapview } \\
\text { upper }\end{array}$ \\
\hline $\begin{array}{l}\text { MODTOOLS } \\
\text { options }\end{array}$ & $\mathbf{x}$ & $\mathrm{x}$ & $\mathbf{x}$ & $\mathbf{x}$ & $\mathrm{x}$ & $\mathbf{x}$ & $\mathbf{x}$ & $\mathrm{x}$ & $\mathrm{x}$ & $\mathbf{x}$ & $\mathbf{x}$ & $\mathbf{x}$ & $\mathbf{x}$ & $\mathbf{x}$ \\
\hline $\begin{array}{l}\text { MODFLOW } \\
\text { package }\end{array}$ & & & & & & & & & $\mathbf{x}$ & $\mathbf{x}$ & $\mathrm{x}$ & $\mathbf{x}$ & $\mathrm{x}$ & $\mathrm{x}$ \\
\hline Orientation & $\mathbf{x}$ & $\mathbf{x}$ & $\mathbf{x}$ & $\mathbf{x}$ & $\mathbf{x}$ & $\mathbf{x}$ & $\mathbf{x}$ & $\mathbf{x}$ & $\mathbf{x}$ & $\mathbf{x}$ & $\mathbf{x}$ & $\mathbf{x}$ & $\mathbf{x}$ & $\mathbf{x}$ \\
\hline $\begin{array}{l}\mathrm{X}-\mathrm{Y} \\
\text { coordinate } \\
\text { conversion }\end{array}$ & $\mathbf{x}$ & $x^{1}$ & $\mathbf{x}$ & $\mathbf{x}$ & $\mathbf{x}$ & $x^{1}$ & $\mathbf{x}$ & $\mathbf{x}$ & & & $X^{1}$ & $X^{1}$ & & \\
\hline $\begin{array}{l}Z \text { coordinate } \\
\text { conversion }\end{array}$ & $\mathbf{x}$ & $X^{1}$ & $\mathbf{x}$ & $\mathbf{x}$ & $\mathbf{x}$ & $x^{1}$ & $\mathbf{x}$ & $\mathbf{x}$ & & & $X^{1}$ & $X^{1}$ & & \\
\hline Rotation angle & $\mathbf{x}$ & & $\mathbf{x}$ & $\mathbf{x}$ & $\mathbf{x}$ & & $\mathbf{x}$ & $\mathbf{x}$ & & & & & & \\
\hline $\mathrm{X}$ origin & $\mathbf{x}$ & & $\mathbf{x}$ & $\mathbf{x}$ & $\mathbf{x}$ & & $\mathbf{x}$ & $\mathbf{x}$ & & & & & & \\
\hline $\mathrm{Y}$ origin & $\mathbf{x}$ & & $\mathbf{x}$ & $\mathbf{x}$ & $\mathbf{x}$ & & $\mathbf{x}$ & $\mathbf{x}$ & & & & & & \\
\hline $\begin{array}{l}\text { Vertical } \\
\text { exaggeration }\end{array}$ & & $x^{1}$ & & & & $x^{1}$ & & & & & $x^{1}$ & $\mathrm{X}^{1}$ & & \\
\hline $\begin{array}{l}\text { Horizontal } \\
\text { scale }\end{array}$ & & $X^{1}$ & & & & $X^{1}$ & & & & & $x^{1}$ & $x^{1}$ & & \\
\hline $\begin{array}{l}\text { Row, column, } \\
\text { layer, ibound, } \\
\text { or particle } \\
\text { path selection }\end{array}$ & $x$ & $\mathbf{x}$ & $\mathbf{x}$ & $\mathbf{x}$ & $\mathbf{x}$ & $\mathrm{x}$ & $\mathbf{x}$ & $\mathbf{x}$ & $x$ & $\mathrm{x}$ & $\mathbf{x}$ & & $\mathbf{x}$ & $\mathrm{x}$ \\
\hline $\begin{array}{l}\text { Format of } \\
\text { array }\end{array}$ & $x$ & $x$ & $\mathbf{x}$ & $\mathbf{x}$ & & & & & $\mathrm{x}$ & $\mathrm{x}$ & $\mathrm{x}$ & $\mathrm{x}$ & $\mathrm{x}$ & $\mathrm{x}$ \\
\hline $\begin{array}{l}\text { Contour } \\
\text { interval }\end{array}$ & $x$ & $x$ & $x$ & $x$ & & & & & & & & & & \\
\hline Scaling factor & & & & & $\mathbf{x}$ & $\mathrm{x}$ & $x$ & $\mathbf{x}$ & & & & & & \\
\hline $\begin{array}{l}\text { MODFLOW } \\
\text { stress period }\end{array}$ & $x$ & $x$ & $\mathbf{x}$ & $x$ & & & & & $x$ & $x$ & $x$ & $x$ & $x$ & $x$ \\
\hline $\begin{array}{l}\text { MODFLOW } \\
\text { time step }\end{array}$ & $x$ & $x$ & $x$ & $x$ & & & & & $x$ & $\mathrm{x}$ & $\mathrm{x}$ & $\mathrm{x}$ & $x$ & $x$ \\
\hline
\end{tabular}

Note: 1. Responses to these menus are applied to model-grid GIS output that accompanies this option. 


\section{Options Menu}

The MODTOOLS Options menu (shown below) is the first menu displayed. The user determines the type of GIS output by selecting from one of eight choices. The first four choices produce GIS output using particle data output by MODPATH. The fifth choice produces a view of the model grid using data input to MODPATH. The last three choices produce GIS output using data arrays of MODFLOW. Data from a previous particle-tracking analysis using MODPATH is needed only for the first four choices.

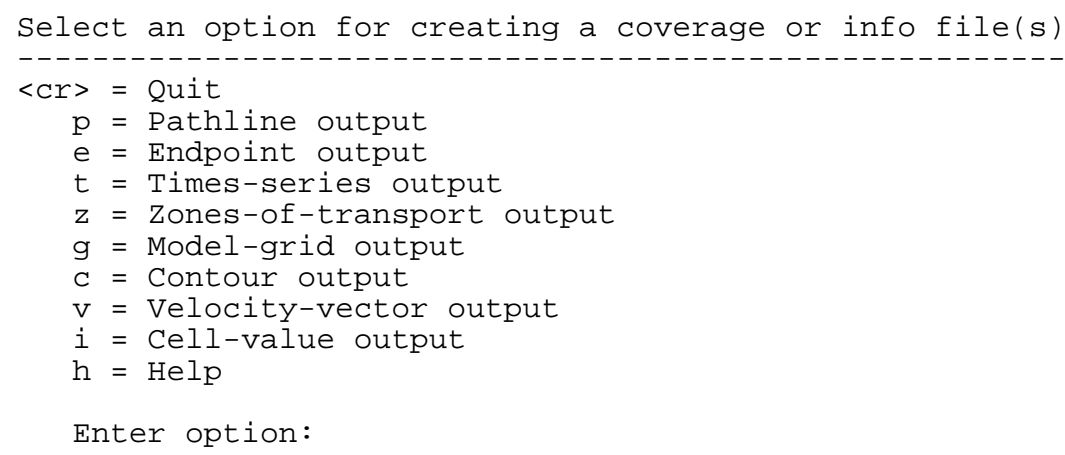

Each option is summarized below:

\section{----> p (Pathline output)}

MODTOOLS constructs a pathline GIS output using the particle data recorded in the PATHLINE file previously output by MODPATH. A particle pathline GIS output consists of a set of connected lines for each particle. MODTOOLS appends to each line up to 62 characteristics associated with each particle (see example 1 in Appendix B).

---> e (Endpoint output)

MODTOOLS constructs an endpoint GIS output using the particle data recorded in the ENDPOINT file previously output by MODPATH. An endpoint GIS output consists of the starting or final points, one for each particle. MODTOOLS appends to each point up to 32 characteristics associated with each particle (see example 2 in Appendix B).

\section{----> t (Time-series output)}

MODTOOLS constructs a time-series GIS output using the particle data recorded in the TIMESERS file previously output by MODPATH. A time-series GIS output consists of a set of points for each particle at specified times of travel. MODTOOLS appends to each point up to 62 characteristics 
associated with each particle (see example 3 in Appendix B).

---> z (Zones-of-transport output)

MODTOOLS constructs a zone-of-transport GIS output using the particle data recorded in the TIMESERS and ENDPOINT files previously output by MODPATH. MODPATH records particle data for each time of travel specified by the user in the TIMESERS file and the starting and final locations of the particles in the ENDPOINT file. MODTOOLS combines particle data recorded in both files and constructs two types of GIS output for this option. The first GIS output is the zones of transport, which consist of a set of polygons, one or more for each specified time of travel. MODTOOLS appends to each polygon the characteristic associated with the time of travel, which is represented by a model time step of MODPATH. The second GIS output consists of a set of points that form the vertices of each polygon; MODTOOLS appends to each vertex 33 characteristics associated with the particle that was used to determine each vertex (see example 4 in Appendix B).

\section{---> g (Model-grid output)}

MODTOOLS constructs model-grid GIS output using the data arrays defining grid dimensions from the MODPATH MAIN file. The model-grid GIS output consists of a set of polygons, one for each active cell. MODTOOLS appends to each polygon up to eight characteristics associated with each cell. The user need only assemble the MAIN file for mapview and for vertical profile views along a model row or column. The user will need to have previously completed a particle pathline analysis for GIS output of model-cell geometry along a particle pathline in the vertical profile view (see example 5 in Appendix B).

\section{--->> c (Contour output)}

MODTOOLS constructs a contour GIS output using the cell-by-cell terms output by or input to MODFLOW or miscellaneous gridded model data. A contour GIS output consists of a set of contour lines connecting points of equal value, and MODTOOLS appends the value to each line. For a GIS output in mapview, MODTOOLS constructs only one GIS output, which consists of a set of lines connecting 
points of equal value (see example 6 in Appendix B). For a GIS output in vertical profile view,

MODTOOLS also constructs a model-grid GIS output.

----> v (Velocity-vector output)

MODTOOLS constructs a velocity-vector GIS output using the cell-by-cell terms output by the Basic and Block Centered Flow Packages of MODFLOW. A velocity-vector GIS output consists of one line in each active cell that indicates the direction and magnitude of ground-water flow. MODTOOLS appends eight characteristics to each vector. For a GIS output in mapview, MODTOOLS constructs only one GIS output (see example 7 in Appendix B). For a GIS output in a vertical profile view, MODTOOLS also constructs a model-grid GIS output.

\section{---> i (Cell value output)}

MODTOOLS constructs a cell-value GIS output using the data arrays output by or input to MODFLOW. A cell-value GIS output consists of up to three GIS files, which contain one record for each cell. A record consists of a set of characteristics associated with each cell. The number of characteristics is dependent on the type of cell-by-cell terms selected, the number of layers in the model grid, and the type of orientation (see example 8 in Appendix B).

\section{Tracking Mode Menu}

The MODPATH tracking menu is displayed only when the user specifies an endpoint GIS output. The choice depends on the tracking mode (forward or backward) used in MODPATH during a particletracking analysis. Endpoint GIS output is only available for mapview. This menu is used to select which particle coordinates (starting locations or final locations) to use when constructing the endpoint GIS output.

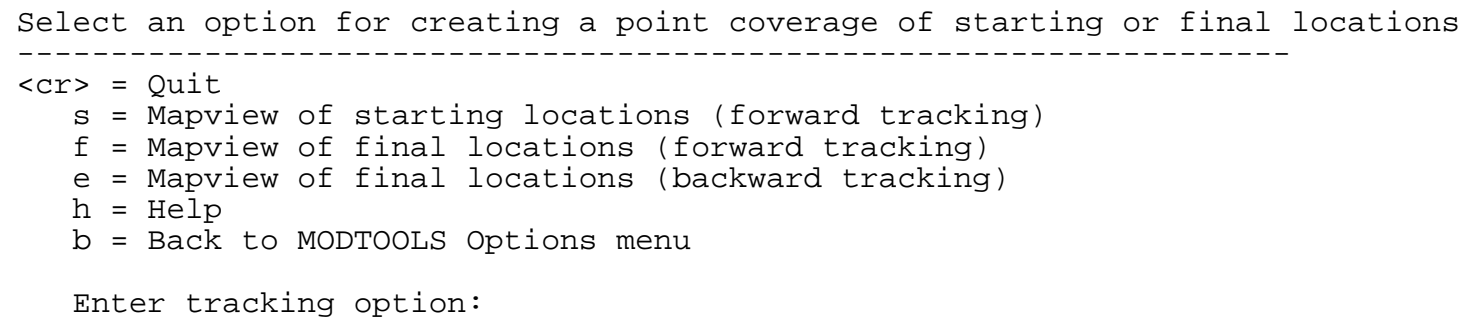


Each option is summarized below:

---> s (starting locations, forward tracking)

MODTOOLS constructs an endpoint GIS output in mapview using the starting locations of the particles from a forward-tracking MODPATH simulation.

---> f (final locations, forward tracking)

MODTOOLS constructs an endpoint GIS output in mapview using the final locations of the particles from a MODPATH forward-tracking simulation.

---> e (final locations, backward tracking)

MODTOOLS constructs the endpoint GIS output in mapview using the final locations of the particles from a MODPATH backward-tracking simulation.

\section{MODFLOW Package Menu}

The MODFLOW package menu is displayed when the user specifies a cell-value GIS output. The user determines which cell-by-cell terms output by MODFLOW will be used to construct GIS output. MODTOOLS constructs GIS files when the user specifies a mapview orientation. MODTOOLS constructs three GIS files for the Block Centered Flow Package, one for each of the three principal directions of flow. MODTOOLS constructs one GIS file for each of the other MODFLOW packages. Model-grid GIS output is constructed when the user specifies a vertical profile orientation. The value of the cell-by-cell terms are appended to the set of characteristics for each cell of the model-grid GIS output in profile orientation.

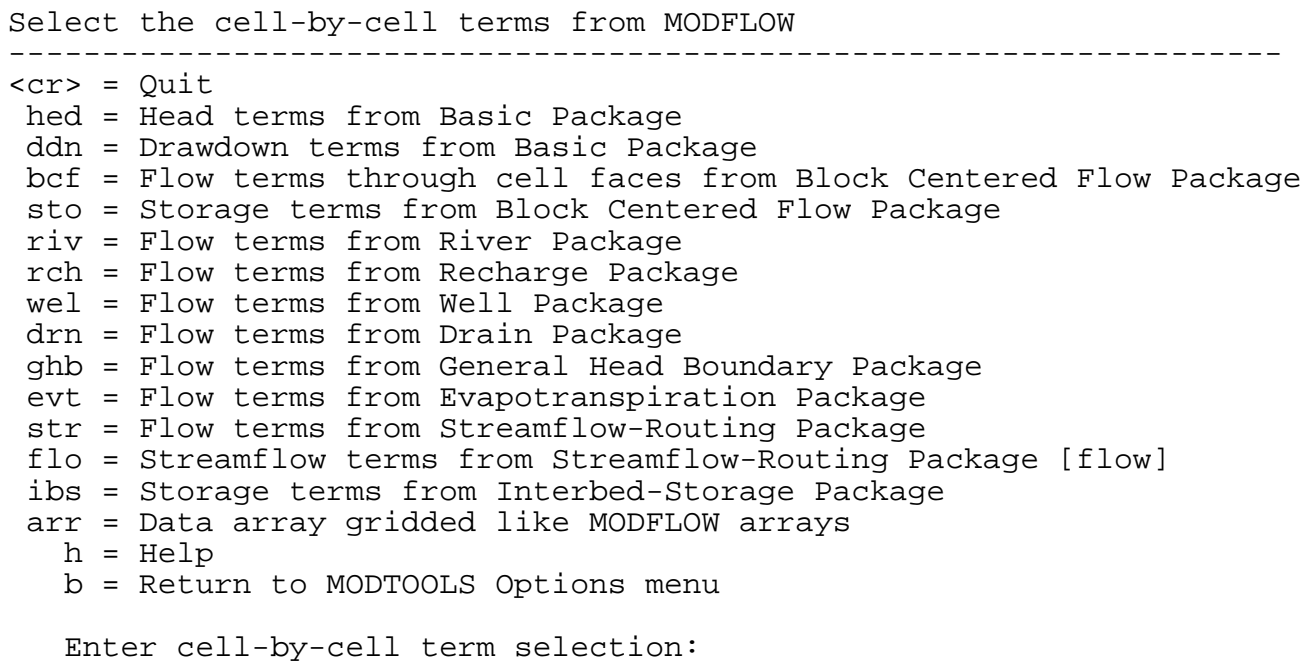


Each option is summarized below:

---> hed (head terms from Basic Package)

MODTOOLS constructs GIS output using the head values output by the Basic Package of MODFLOW. MODTOOLS will identify the file containing the terms using the keywords HEAD or HEAD(BINARY) in the NAME file. If the keyword HEAD is used in the NAME file, MODTOOLS needs another file identified by the keywords HEAD-CONTROL. The HEAD-CONTROL file contains format-control records used to read the head values. Instructions for creating the HEAD-CONTROL file are presented in the MODFLOW manual for U2DREL (McDonald and Harbaugh, 1988, p. 14-4 to $14-5)$.

---> ddn (drawdown terms from Basic Package)

MODTOOLS constructs GIS output using the drawdown values output by the Basic Package of MODFLOW. MODTOOLS will identify the file containing the terms using the keywords DRAWDOWN or DRAWDOWN(BINARY) in the NAME file. If the keyword DRAWDOWN is used in the NAME file, MODTOOLS needs another file identified by the keywords DRAWDOWN-

CONTROL. The DRAWDOWN-CONTROL file contains format-control records used to read the drawdown values. Instructions for creating the DRAWDOWN-CONTROL file are presented in the MODFLOW manual for U2DREL (McDonald and Harbaugh, 1988, p. 14-4 to 14-5).

---> bcf (flow terms through cell faces from Block Centered Flow Package)

MODTOOLS constructs GIS output using the cell-by-cell terms output by the Block Centered Flow Package of MODFLOW. MODTOOLS can construct up to three GIS files depending on the orientation selected. MODTOOLS uses the flow terms through the right, front, and lower faces of a cell. MODTOOLS will identify the file containing the terms using the keywords BUDGET in the NAME file.

---> sto (storage terms from Block Centered Flow Package)

MODTOOLS constructs GIS output using the cell-by-cell storage output by the Block Centered Flow Package of MODFLOW. MODTOOLS will identify the file containing the terms using the keywords BUDGET in the NAME file. 
---> riv, rch, wel, drn, ghb, evt, str, or ibs (select one only for other packages)

MODTOOLS constructs GIS output using the cell-by-cell flow terms output by the remaining packages of MODFLOW. MODTOOLS will identify the file containing the terms using the keywords BUDGET in the NAME file.

----> flo (streamflow terms from Streamflow-Routing Package)

MODTOOLS constructs GIS output using the streamflow terms output by the StreamflowRouting Package (STR) developed by Prudic (1989) for MODFLOW. These terms are the cumulative streamflow for all streams occurring in each cell. MODTOOLS will identify the file containing the terms using the keywords BUDGET in the NAME file.

\section{---> arr (data array gridded like MODFLOW arrays)}

MODTOOLS constructs GIS output using miscellaneous gridded model data that are in the binary (unformatted) or standard ASCII text formats like those of MODFLOW. For example, MODTOOLS could construct a contour GIS output from the porosity array that was input to MODPATH. MODTOOLS will identify the file containing these miscellaneous data using the keywords ARRAY or ARRAY(BINARY) in the NAME file. In addition, MODTOOLS requires a file identified by the keyword, ARRAY-CONTROL, to determine the location and format of these data to be input. The ARRAY-CONTROL file contains format-control records, which MODTOOLS uses to operate the MODFLOW utility module U2DREL (McDonald and Harbaugh, 1988, p. 14-4 to 14-5) or an adapted U3DREL utility module from the MMSP programs (Scott, 1990, p. 197).

MODTOOLS will invoke the proper utility module using the user's response to the format of array menu. For MODTOOLS to read a data array in a binary format like those of MODFLOW, the format of the file containing this data array must match the binary format used by the array writing utility modules of MODFLOW. For MODTOOLS to read a data array in a ASCII text format like those of MODFLOW, the format of the file containing this data array must be readable by either the utility reading modules U2DREL of MODFLOW or U3DREL of MODTOOLS.

\section{Orientation Menu}

The orientation menu determines the type of view for all types of GIS output, except for an endpoint GIS output, which is available only in mapview. The choice of view orientation controls many of the subsequent menus. All eight possible choices are shown below; however, only the applicable choices appropriate for the type of GIS output request will be displayed during execution of MODTOOLS. 


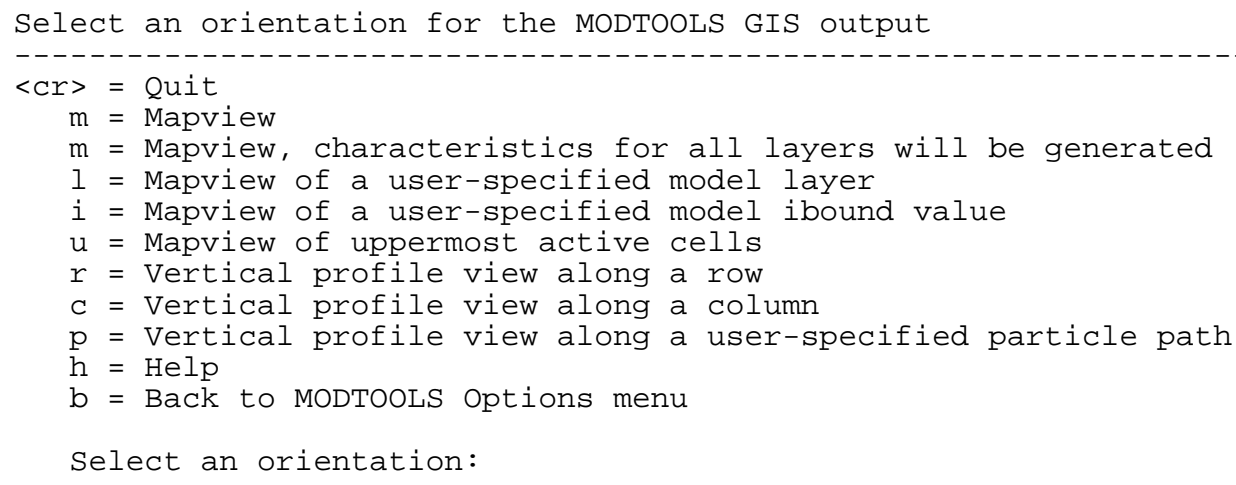

Each option is summarized below:

---> m (Mapview)

The specified GIS output is constructed in mapview (the x-y plane of the model grid).

---> m (Mapview, characteristics for all layers will be generated)

MODTOOLS displays this option only when the user specifies cell-value GIS output from the cell-by-cell terms of MODFLOW. This option is useful for translating the cell-by-cell terms of MODFLOW into a GIS format. MODTOOLS constructs up to three GIS files depending on which cellby-cell term output by a MODFLOW package was selected from the MODFLOW package menu.

\section{---> I (Mapview of a user-specified model layer)}

MODTOOLS displays this option only when the user specifies contour, velocity-vector, or cellvalue GIS outputs. MODTOOLS constructs the GIS output for cells in a user-specified layer.

\section{----> i (Mapview of a user-specified model ibound value)}

MODTOOLS displays this option only when the user specifies contour, velocity-vector, or cellvalue GIS outputs. MODTOOLS constructs the GIS output for cells that are identified by a value assigned in the IBOUND array. Commonly, an aquifer will be simulated by more than one layer in a ground-water model using MODFLOW, such as in the sample problems developed by Pollock (1994). The user can set the values that were assigned to each cell in the IBOUND array to reflect this vertical discretization scheme. 


\section{f----> u (Mapview of uppermost active cells)}

This option applies only when the user specifies that MODTOOLS construct contour, velocityvector, or cell-value GIS outputs. MODTOOLS constructs the GIS output for the uppermost active cells. This option is useful for constructing GIS output from ground-water models which simulate a water table in cells other than in layer 1 of the model grid. MODTOOLS omits cells from the specified GIS output under several conditions. MODTOOLS automatically omits inactive cells (cell IBOUND=0).

MODTOOLS omits cells that have a value of the cell-by-cell term equal to the user-specified head for dry cells (HDRY item in MAIN file) or no-flow cells (HNOFLO item in MAIN file).

---> r (vertical profile view along a row)

MODTOOLS constructs the specified GIS output in a vertical profile along a specified row. ---> c (vertical profile view along a column)

MODTOOLS constructs the specified GIS output in a vertical profile along a specified column. ---> p (vertical profile view along a user-specified particle path)

This option applies only when the user specifies that MODTOOLS construct a pathline, timeseries, model-grid, or cell-value GIS output. MODTOOLS constructs the specified GIS output in a vertical profile view along a specified particle path.

\section{X-Y Coordinate Conversion Menu}

For mapview orientations, GIS output created by MODTOOLS must be referenced to real-world coordinates to allow proper display of the output. The $x-y$ coordinate conversion multipliers are used to convert the units of length used in MODFLOW/MODPATH to the units of length in the desired coordinate system for the GIS.

For vertical orientations, MODTOOLS requires that particle and cell coordinates have units of length in feet to properly apply the vertical exaggeration and horizontal map scale. The user would specify option 2 in the menu to convert meters to feet if the units of length used in MODFLOW or MODPATH were in meters. 


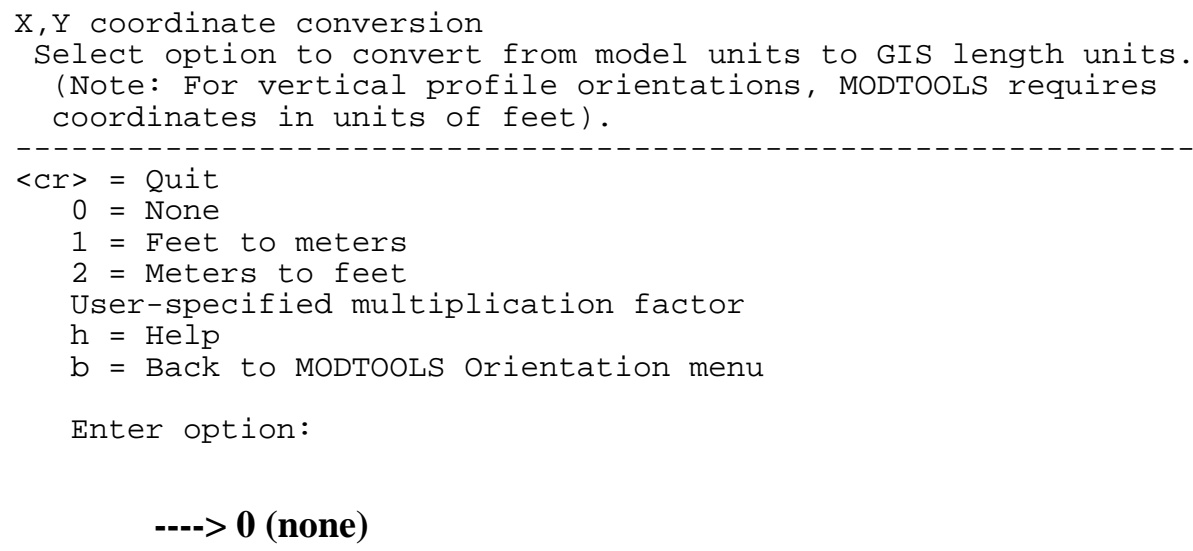

This option causes MODTOOLS to keep particle or cell coordinates in the MODPATH coordinate system specified by the user.

\section{----> 1 (feet to meters)}

This option causes MODTOOLS to translate the particle or cell coordinates from units of feet to units of meters. MODTOOLS multiples the $\mathrm{x}$ and $\mathrm{y}$ coordinates by a factor of 0.3048 .

\section{----> 2 (meters to feet)}

This option causes MODTOOLS to translate the particle or cell coordinates from units of meters to units of feet. MODTOOLS multiplies the $\mathrm{x}$ and $\mathrm{y}$ coordinates by a factor of 3.281.

\section{----> User-specified multiplication factor}

This option causes MODTOOLS to multiply the particle or cell coordinates by a factor specified by the user.

\section{Z Coordinate Conversion Menu}

The $\mathrm{z}$ coordinate conversion multiplier is used to convert the units of length in the vertical direction used in MODFLOW/MODPATH to the units of length in the desired coordinate system for the GIS. For example, if the simulated head output by MODFLOW were in units of feet and the user wanted to produce contours in units of meters, the user would specify option 1. For vertical orientations, MODTOOLS requires the particle and cell coordinates have units of length in feet to properly apply the vertical exaggeration and horizontal map scale. The user would specify option 2 in the menu to convert meters to feet if the units of length used in MODFLOW/MODPATH were in meters. 


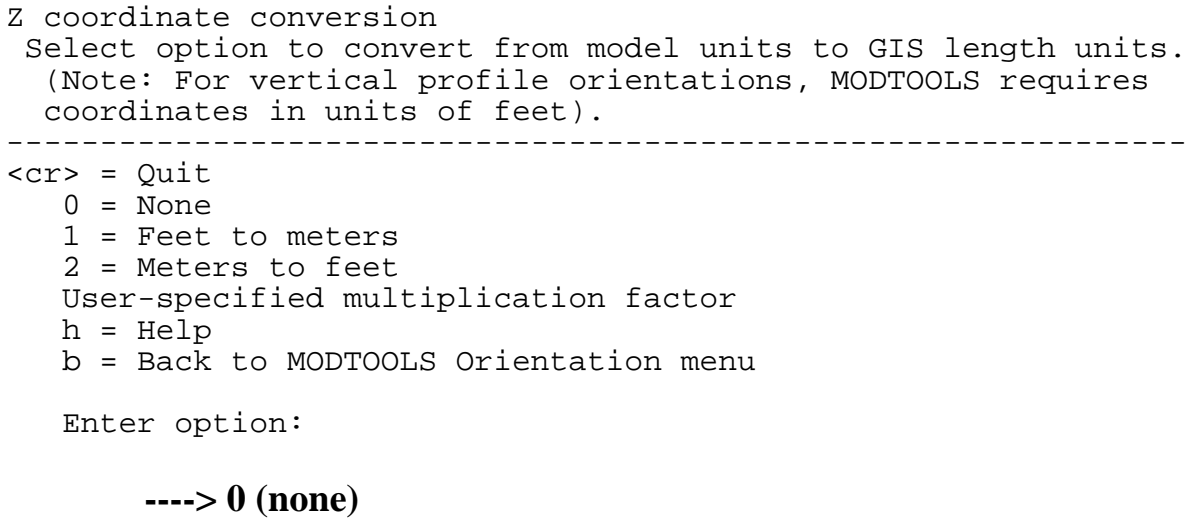

This option causes MODTOOLS to keep particle or cell coordinates in the MODPATH coordinate system specified by the user.

---> 1 (feet to meters)

This option causes MODTOOLS to translate the particle or cell coordinates from units of feet to units of meters. MODTOOLS multiplies the $\mathrm{z}$ coordinates by a factor of 0.3048 .

\section{----> 2 (meters to feet)}

This option causes MODTOOLS to translate the particle or cell coordinates from units of meters to units of feet. MODTOOLS multiplies the $\mathrm{z}$ coordinates by a factor of 3.281.

----> User-specified multiplication factor

This option causes MODTOOLS to multiply the $\mathrm{z}$ coordinates of particle or cell by a factor specified by the user.

\section{Rotation Angle Menu}

MODTOOLS displays this menu only when the user specifies a mapview orientation for some GIS outputs. The rotation angle menu is activated by MODTOOLS to provide a means to rotate, in a counterclockwise direction, the $\mathrm{x}$ and y coordinates of particles and cells to align them with the orientation of the model grid in the real world. The step of rotating these coordinates is another step in translating particle or cell coordinates from the MODPATH coordinate system to the GIS coordinate system. The grid rotation angle is the angle in degrees that the MODFLOW grid has been rotated from north. The angle is specified in the counterclockwise degrees of rotation around the origin of the MODFLOW grid. 


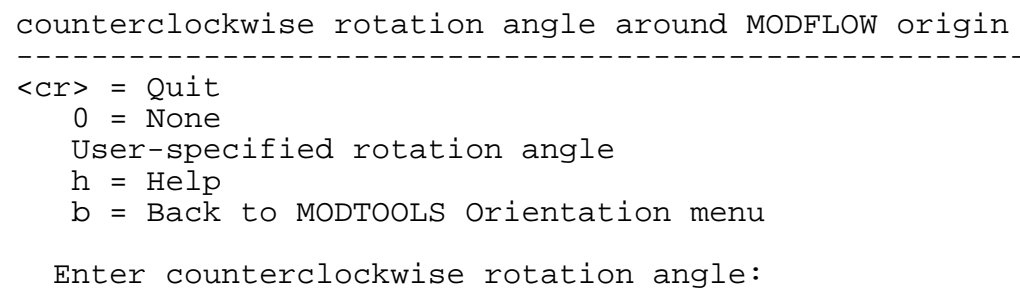

\section{X-Origin Menu}

MODTOOLS displays this menu only when the user specifies a mapview orientation. The $\mathrm{x}$ origin menu is activated by MODTOOLS to provide a means to translate the $\mathrm{x}$ and $\mathrm{y}$ components of the particle or cell coordinates from the MODPATH coordinate system to the GIS coordinate system. The user enters the $\mathrm{x}$ coordinate of the MODFLOW origin using the real-world coordinate. The origin of the MODFLOW grid is the intersection of outer boundaries of the cell in row 1 and column 1.

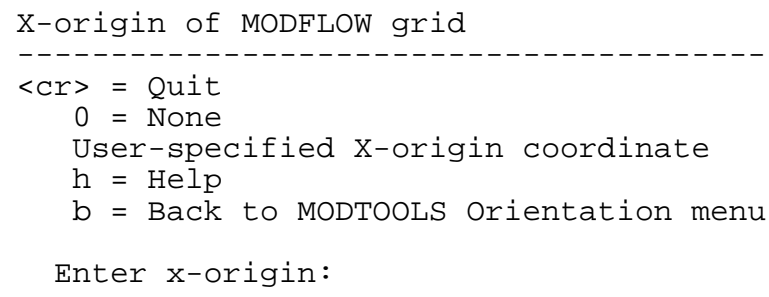

\section{Y-Origin Menu}

MODTOOLS displays this menu only when the user specifies a mapview orientation. The y origin menu is activated by MODTOOLS to provide a means to translate the $\mathrm{x}$ and $\mathrm{y}$ components of the particle or cell coordinates from the MODPATH coordinate system to the GIS coordinate system. The user enters the $y$ coordinate of the MODFLOW origin using the real-world coordinate. The origin of MODFLOW model grid is the intersection of outer boundaries of the cell in row 1 and column 1.

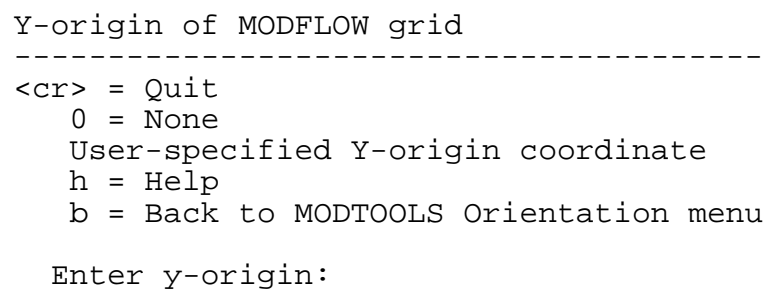

\section{Vertical Exaggeration Menu}

MODTOOLS displays this menu only when the user specifies a vertical profile orientation. The vertical exaggeration menu is activated by MODTOOLS to provide a means to exaggerate the vertical 
component of the particle or cell coordinates. The user enters any positive number. MODTOOLS uses this value as a multiplier to exaggerate the $\mathrm{z}$ coordinates of the GIS output in a vertical profile view.

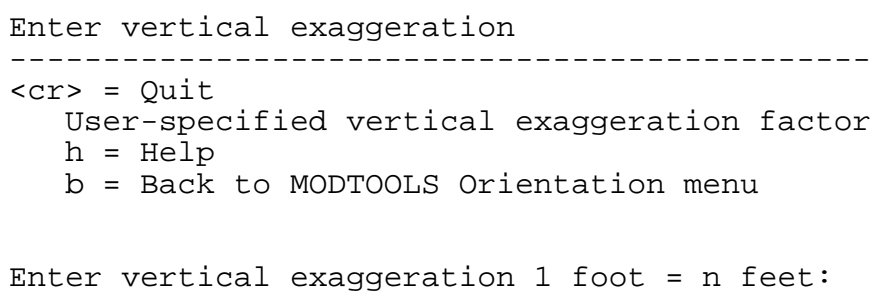

\section{Horizontal Scale Menu}

MODTOOLS displays this menu only when the user specifies a vertical profile orientation. The horizontal map-scale menu is activated by MODTOOLS to provide a means to scale the horizontal component of the particle or cell coordinates of the GIS output in a vertical profile view. The user enters any positive number. For example, to create a view with a horizontal scale of 1:24,000, the user would enter 24000 .

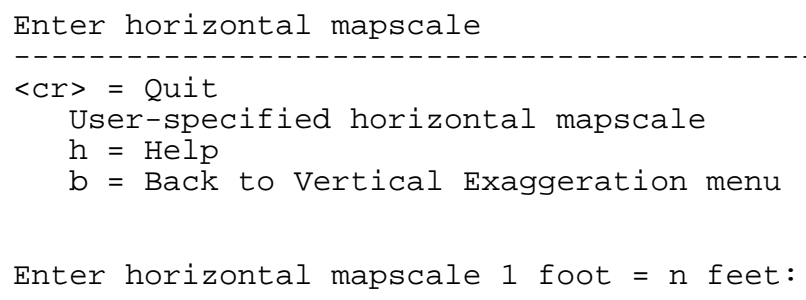

\section{Row, Column, Layer, Ibound, or Particle Path Menu}

This menu is activated by MODTOOLS to provide a means to choose a row, column, or layer from the model grid, a cell IBOUND value, or a particle pathline. MODTOOLS uses this choice to construct GIS output along a specified row, column, or layer of the model grid, for model cells having specified IBOUND values, or along a specified particle pathline. The title of this menu is determined by the type of orientation of the GIS output specified by the user.

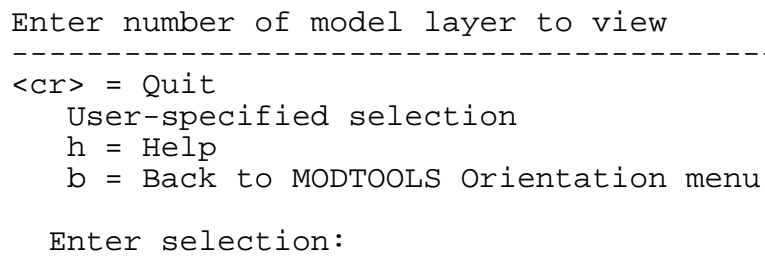




\section{Format of Array Menu}

This menu is activated by MODTOOLS to provide a means to specify the format of the gridded model data for constructing contour and cell-value GIS outputs. MODTOOLS uses this choice to determine how to read gridded model data of MODFLOW and MODPATH, and miscellaneous gridded model data, such as hydraulic conductivity. These data can be provided in a standard ASCII text file or in a binary (unformatted) file. MODTOOLS identifies the file containing these data using the keyword CONTOUR-DATA for contour GIS output, and HEAD or HEAD(BINARY), DRAWDOWN or DRAWDOWN(BINARY), BUDGET, and ARRAY or ARRAY(BINARY) for cell-value GIS output. MODTOOLS applies the user's choice and information in a file identified by the keyword, CONTOURCONTROL for contour GIS output or HEAD-CONTROL,DRAWDOWN-CONTROL, or ARRAYCONTROL for cell-value GIS output, to determine the location and format of the data.

MODTOOLS uses the utility reader U2DREL of MODFLOW to read data with a "twodimensional array" format, such as the head and drawdown values recorded by MODFLOW. The user should follow the instructions outlined in the MODFLOW manual for the utility reader U2DREL (McDonald and Harbaugh, 1988, p. 14-4 to 14-5) to create the array-control files such as HEADCONTROL.

MODTOOLS uses the utility reader U3DREL, which was adapted from the MMSP program (Scott, 1990, p. 197) to read data with a "three-dimensional array" format, such as the cell-by-cell flow terms from the Block Centered Flow Package recorded by MODFLOW. The user follows the instructions in the MODFLOW manual for the utility reader U2DREL (McDonald and Harbaugh, 1988, p. 14-4 to 14-5) to create the files, CONTOUR-CONTROL for contour GIS output, and ARRAYCONTROL, for cell-value GIS output. However, the user needs to include only a single array-control record that is used to read the values for all layers.

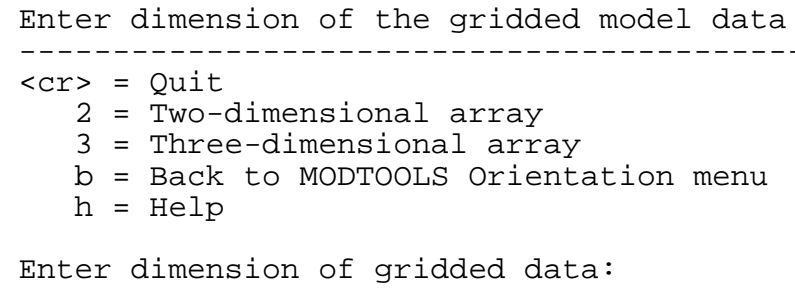

This option causes MODTOOLS to read the gridded model data using the utility reader U2DREL of MODFLOW (McDonald and Harbaugh, 1988, p. 14-4 to 14-5). $--->>3$

This option causes MODTOOLS to read the gridded model data using a utility reader U3DREL adapted from the MMSP program (Scott, 1990, p. 197). 


\section{Contour Interval Menu}

This menu is activated by MODTOOLS to provide a means to specify the contour interval that will be used by MODTOOLS to create the contour GIS output consisting of lines connecting points of equal value from the gridded model data.

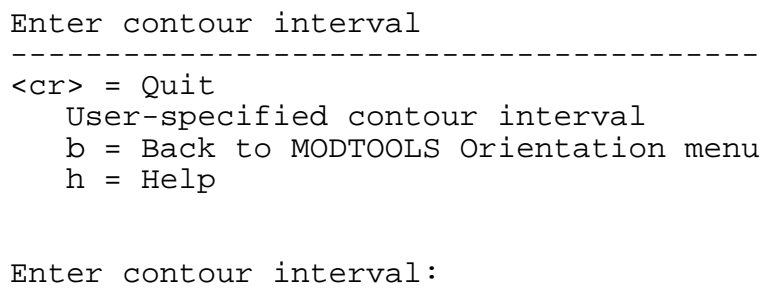

\section{Scaling Factor Menu}

MODTOOLS displays this menu only when the user specifies the option for velocity-vector GIS output. This menu is activated by MODTOOLS to provide a means to specify the scaling factor that will be used by MODTOOLS to create GIS output of lines showing the velocity vectors. MODTOOLS uses two procedures to create a line representing the magnitude of the velocity vector in each active cell of the model grid. A positive number causes MODTOOLS to use an arithmetic scaling procedure directly adapted from the programs developed by Scott (1990, p. 64). When arithmetic scaling is selected, the length of each velocity vector is multiplied by the user-specified scaling factor. A negative number causes MODTOOLS to use a logarithmic scaling procedure. When logarithmic scaling is selected, MODTOOLS computes the minimum power-of-10 multiplier needed to increase the minimum nonzero vector length to a value greater than one. The length of each velocity vector is computed by multiplying by the computed power-of-10, then taking the base-10 logarithm of the product, and finally multiplying by the absolute value of a user-specified scaling factor.

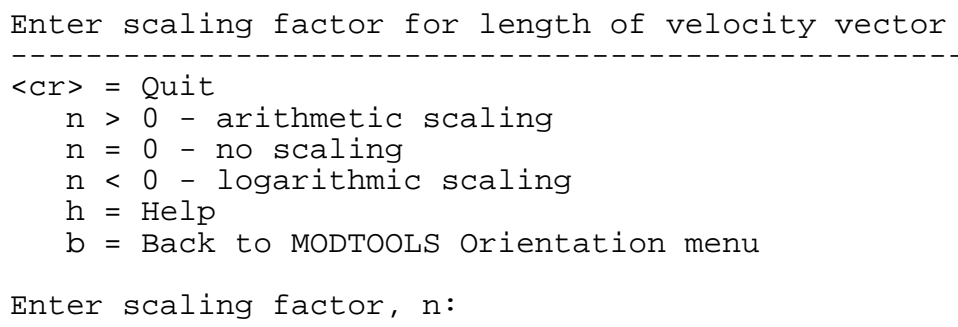

\section{MODFLOW Stress Period Menu}

MODTOOLS displays this menu only when the user specifies the option for contour and cell-value GIS output. This menu provides a means for the user to specify the stress period to MODTOOLS. MODTOOLS uses this choice to select the proper stress period of the cell-by-cell terms output from a transient ground-water simulation. MODFLOW records cell-by-cell terms at a stress period specified by 
the user in a transient ground-water simulation. MODTOOLS will omit all terms that do not have the proper stress period.

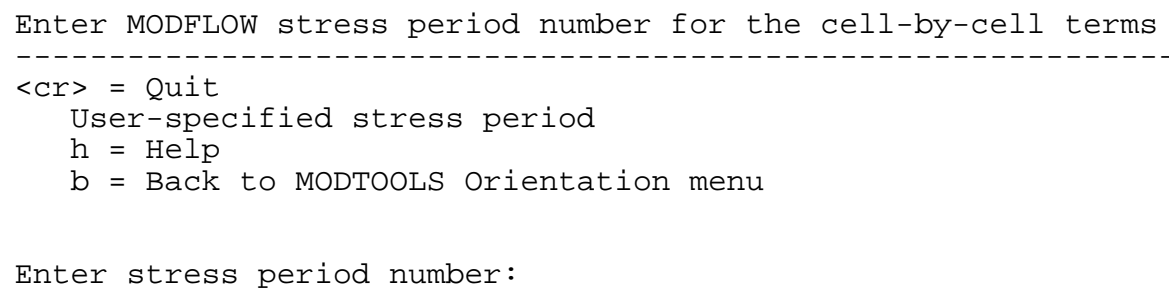

\section{MODFLOW Time Step Menu}

MODTOOLS displays this menu only when the user specifies the option for contour and cell-value GIS output. This menu provides a means for the user to specify the time step to MODTOOLS.

MODTOOLS uses this choice to select the proper time step of the cell-by-cell terms output from a transient ground-water simulation. MODTOOLS will omit all terms that do not have the proper time step for the stress period specified by the user.

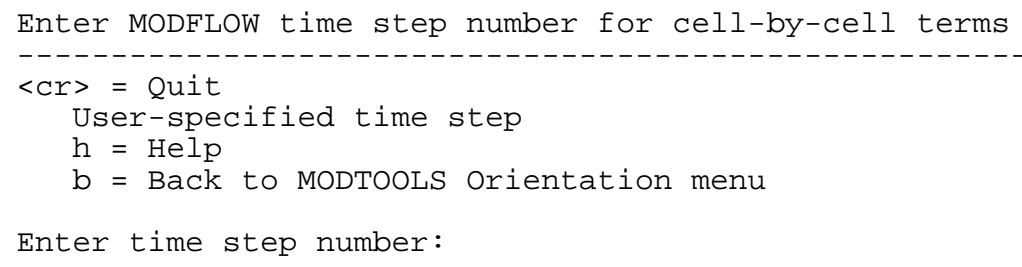

\section{Equal Sectors Menu}

MODTOOLS displays this menu only when the user specifies the option for zones of transport GIS output. This menu is activated by MODTOOLS to provide a means to specify the number of equal sectors used to compute the vertices of polygons that will represent the zones of transport. MODTOOLS uses this choice to compute polygons that represent the projection of the zones of transport to wells onto a user-specified plane of the model grid. The algorithm searches each sector to locate the particle that represents the maximum distance traveled from the center of the cell containing the well for the specified time of travel (see Appendix $\mathrm{C}$ for more information).

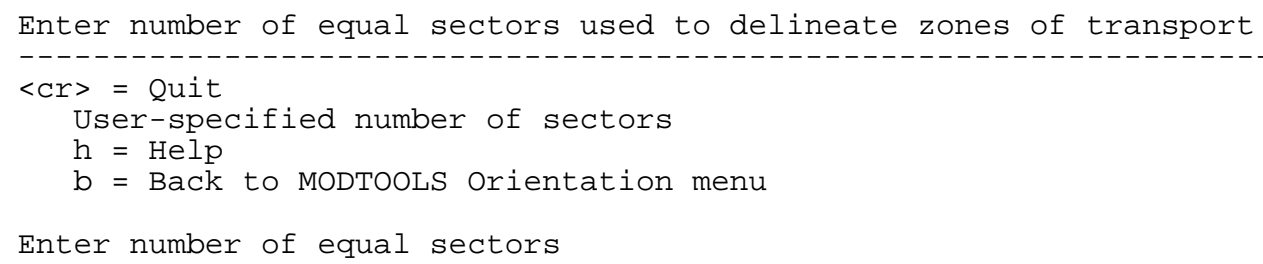




\section{Descriptions of GIS Output Files}

MODTOOLS creates several different types of GIS output from particle data recorded by MODPATH during a particle-tracking analysis, from gridded data of MODFLOW, or from miscellaneous gridded model data. During the process of creating GIS output, MODTOOLS associates particle and cell characteristics recorded by MODPATH to the appropriate particle or cell in the GIS output. MODTOOLS also associates characteristics to contour lines and velocity vectors that are derived from gridded model data, such as head values or flow terms output by MODFLOW. The values of these characteristics are recorded by MODTOOLS in data terms of the GIS output, called attributes in GIS nomenclature. Each attribute must be defined in the GIS output by type (integer or real number), by the number of digits needed to store and display the value of the attribute (input and output width), and by the number of decimal places. The input and output width of some attributes that are associated with cell characteristics such as the row, column, or layer, are determined by MODTOOLS using the number of rows, columns, and layers defining the model grid.

\section{Output from MODPATH}

As part of the GIS output it constructs, MODTOOLS creates a set of attributes from each record of particle data output by MODPATH in the ENDPOINT, PATHLINE, and TIMESERS files. ENDPOINT, PATHLINE, and TIMESERS output from MODPATH all contain particle positions and characteristics in space and time. Several criteria determine whether MODPATH writes a record of data for each particle position (Pollock, 1994). Particle positions are recorded in both local and global coordinates. Local coordinates are relative within the boundaries of each cell, whereas global coordinates are relative to the entire model grid.

Particle characteristics contain information concerning the location, velocity, and travel time of individual particles during a particle-tracking analysis. Each particle travels from a start position to a final position. Intermediate positions and characteristics along this pathline are recorded when a particle intercepts a cell boundary and at user-specified times (Pollock, 1994). A single particle may travel along a pathline that is described by a set of positions: a start position (point 1 in fig. 11), intermediate positions (points 2 and 3 in fig. 11), and a final position (point 4 in fig. 11). The segment of the pathline connecting particle positions is termed an "arc" in GIS nomenclature. Each particle position and characteristics associated with this position within the model grid are output by MODPATH as a record of data in one or more output files. The positions shown in figure 11 would be represented by four records of particle data output by MODPATH in the PATHLINE file. These positions would be represented by one record in the ENDPOINT file and up to four records in the TIMESERS file (determined if the particle-tracking time equaled the user-specified times).

The starting position is the initial position of a particle at the beginning of a simulation. Characteristics that are derived from this position are termed "start attributes." The names of these attributes in GIS files are prefixed with the character string STR. Particle characteristics describing row, column, and layer positions and local and global $\mathrm{x}$ and $\mathrm{y}$ coordinates within the model cell and model 
Locations where attribute values are evaluated:

Start attributes:
STRSTP
STRTIM
STRCOL
STRROW
STRLAY
STRIBD
STRXGC
STRXLC
STRYGC
STRYLC
STRZGC
STRZLC

$\begin{array}{rrr}\text { Arc } \mathbf{A} & \text { Arc B } & \text { Arc C } \\ \text { at } 1 & \text { at } 1 & \text { at } 1 \\ \text { at } 1 & \text { at } 1 & \text { at } 1 \\ \text { at } 1 & \text { at } 1 & \text { at } 1 \\ \text { at } 1 & \text { at } 1 & \text { at } 1 \\ \text { at } 1 & \text { at } 1 & \text { at } 1 \\ \text { at } 1 & \text { at } 1 & \text { at } 1 \\ \text { at } 1 & \text { at } 1 & \text { at } 1 \\ \text { at } 1 & \text { at } 1 & \text { at } 1 \\ \text { at } 1 & \text { at } 1 & \text { at } 1 \\ \text { at } 1 & \text { at } 1 & \text { at } 1 \\ \text { at } 1 & \text { at } 1 & \text { at } 1 \\ \text { at } 1 & \text { at } 1 & \text { at } 1\end{array}$

Last attributes:

LSTTIM

LSTCOL

LSTROW

LSTLAY

LSTIBD

LSTXGC

LSTXLC

LSTYGC

LSTYLC

LSTZGC

LSTZLC

$\begin{array}{lll}\text { at } 1 & \text { at } 2 & \text { at } 3 \\ \text { at } 1 & \text { at } 2 & \text { at } 3 \\ \text { at } 1 & \text { at } 2 & \text { at } 3 \\ \text { at } 1 & \text { at } 2 & \text { at } 3 \\ \text { at } 1 & \text { at } 2 & \text { at } 3 \\ \text { at } 1 & \text { at } 2 & \text { at } 3 \\ \text { at } 1 & \text { at } 2 & \text { at } 3 \\ \text { at } 1 & \text { at } 2 & \text { at } 3 \\ \text { at } 1 & \text { at 2 } & \text { at } 3 \\ \text { at } 1 & \text { at 2 } & \text { at } 3 \\ \text { at } 1 & \text { at 2 } & \text { at } 3\end{array}$

Present attributes:

PRESTP

PRETIM

PRECOL

PREROW

PRELAY

PREIBD

PREXGC

PREXLC

PREYGC

PREYLC

PREZGC

PREZLC

PRETRV

PREXVL

PREYVI

PREZVI

PRESPD

Cumulative attributes:

CUMXVL

CUMYVL

CUMZVL

CUMSPD

Final attributes:

FINSTP

FINTIM

FINCOL

FINROW

FINLAY

FINIBD

FINZGC

FINXGC

FINXLC

FINYGC

FINYLC

FINZLC

FINXVL

FINYVL

FINZVL

FINSPD

$\begin{array}{lll}\text { at } 2 & \text { at } 3 & \text { at } 4 \\ \text { at } 2 & \text { at } 3 & \text { at } 4 \\ \text { at } 2 & \text { at } 3 & \text { at } 4 \\ \text { at } 2 & \text { at } 3 & \text { at } 4 \\ \text { at } 2 & \text { at } 3 & \text { at } 4 \\ \text { at } 2 & \text { at } 3 & \text { at } 4 \\ \text { at } 2 & \text { at } 3 & \text { at } 4 \\ \text { at } 2 & \text { at } 3 & \text { at } 4 \\ \text { at } 2 & \text { at } 3 & \text { at } 4 \\ \text { at } 2 & \text { at } 3 & \text { at } 4 \\ \text { at } 2 & \text { at } 3 & \text { at } 4 \\ \text { at } 2 & \text { at } 3 & \text { at } 4 \\ 1 \text { to } 2 & 2 \text { to } 3 & 3 \text { to } 4 \\ 1 \text { to } 2 & 2 \text { to } 3 & 3 \text { to } 4 \\ 1 \text { to } 2 & 2 \text { to } 3 & 3 \text { to } 4 \\ 1 \text { to } 2 & 2 \text { to } 3 & 3 \text { to } 4 \\ 1 \text { to } 2 & 2 \text { to } 3 & 3 \text { to } 4\end{array}$

1 to $2 \quad 1$ to $3 \quad 1$ to 4

1 to $2 \quad 1$ to $3 \quad 1$ to 4

1 to $2 \quad 1$ to $3 \quad 1$ to 4

at 4

$\begin{array}{ccc}\text { at } 4 & \text { at } 4 & \text { at } 4 \\ 1 \text { to } 4 & 1 \text { to } 4 & 1 \text { to } 4 \\ \text { at } 4 & \text { at } 4 & \text { at } 4 \\ \text { at } 4 & \text { at } 4 & \text { at } 4 \\ \text { at } 4 & \text { at } 4 & \text { at } 4 \\ \text { at } 4 & \text { at } 4 & \text { at } 4 \\ \text { at } 4 & \text { at } 4 & \text { at } 4 \\ \text { at } 4 & \text { at } 4 & \text { at } 4 \\ \text { at } 4 & \text { at } 4 & \text { at } 4 \\ \text { at } 4 & \text { at } 4 & \text { at } 4 \\ \text { at } 4 & \text { at } 4 & \text { at } 4 \\ \text { at } 4 & \text { at } 4 & \text { at } 4 \\ 1 \text { to } 4 & 1 \text { to } 4 & 1 \text { to } 4 \\ 1 \text { to } 4 & 1 \text { to } 4 & 1 \text { to } 4 \\ 1 \text { to } 4 & 1 \text { to } 4 & 1 \text { to } 4 \\ 1 \text { to } 4 & 1 \text { to } 4 & 1 \text { to } 4\end{array}$

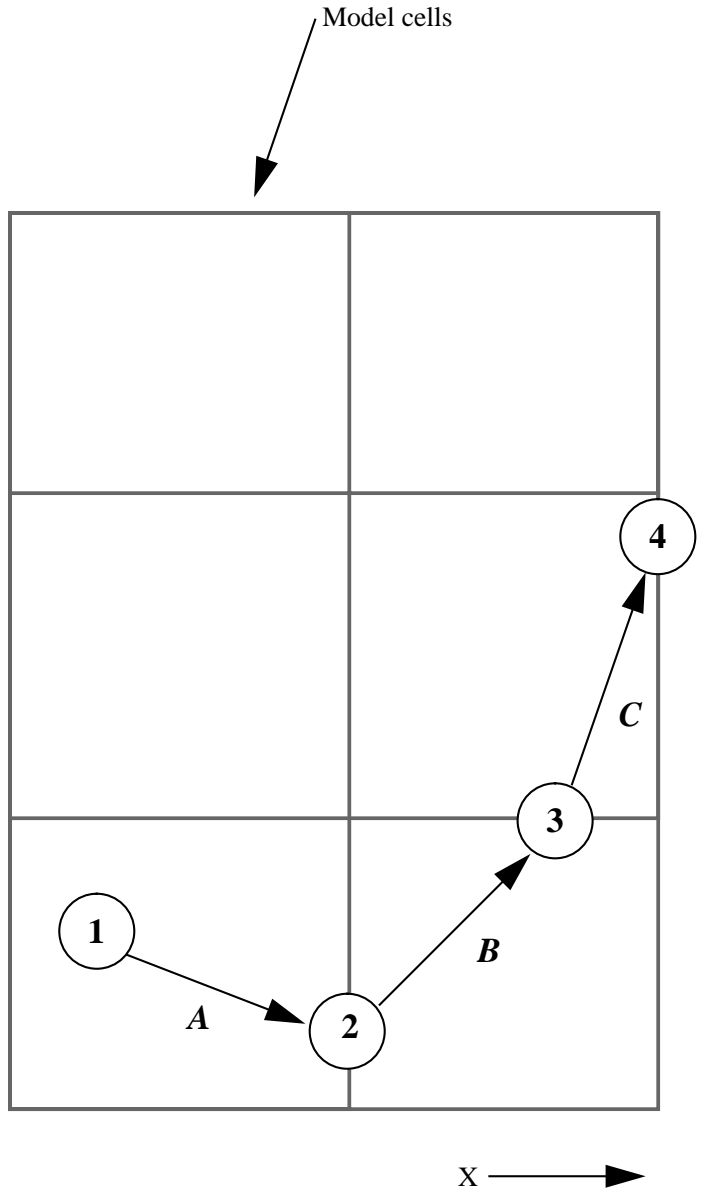

Mapview

Figure 11. Example showing the backward movement of a particle and attributes created for the particle. (See tables 5 and 6 for descriptions of attributes). 
grid, respectively, are recorded along with the vertical position of each particle within a cell (local z-elevation) and within the model grid (global z-elevation). MODTOOLS records this information for each particle and associates these attributes to the appropriate particle.

Intermediate positions that are occupied by particles during a simulation are described by last, present, and cumulative attributes. These attributes are evaluated for each arc of a pathline and may contain redundant information. Last attributes describe particle positions and characteristics at a previous position that is occupied by a particle during a simulation. Names of these attributes in GIS files are prefixed with the character string LST. Present attributes describe current particle positions and characteristics. Present attributes are evaluated along each arc using the previous position and the current position, which describe the arc. Names of these attributes in GIS files are prefixed with the character string PRE. Cumulative attributes describe particle positions and characteristics during a simulation using the start position and the current position. Cumulative attributes are evaluated along each arc. Names of these attributes in GIS files are prefixed with the character string CUM. This information is recorded for each particle. Final attributes are evaluated at the end of the pathline. Names of these attributes in GIS files are prefixed with the character string FIN. This information is recorded for each particle.

For this example, a single particle is tracked backward through cells to a recharge-source cell (fig. 11). Point 1 is assigned the start position information and this information is recorded. As this selected particle moves through other cells, last, present, and cumulative attributes for intermediate positions at points 2 and 3 are evaluated and recorded. At this point in the simulation, some information is identical for these attributes from arcs A and B. If more intermediate positions exist, these attributes would differ. At point 4, last, present, and cumulative attributes for arc $\mathrm{C}$ are again evaluated and recorded. At point 4, final attributes for this particle are evaluated and recorded for arcs A, B, and C. The method of assigning attributes to particles and arcs is identical for forward-tracked particles.

\section{Pathline and Time-Series Data}

MODTOOLS constructs pathline and time-series GIS output from particle data recorded in the PATHLINE and TIMESERS files. MODTOOLS computes 62 characteristics associated with each particle position (table 5). The pathline GIS output has line topology and consists of a series of connected lines for each particle pathline. Attributes derived from particle characteristics in the PATHLINE output by MODPATH are assigned to each line. A time-series GIS output has point topology and consists of a set of points at specified times of travel along each pathline. In this case, the attributes are assigned to each point. 
Table 5. Attributes associated with pathline and time-series GIS output from MODTOOLS

[n, width determined by MODTOOLS from model grid]

\begin{tabular}{|c|c|c|c|c|c|}
\hline $\begin{array}{c}\text { Attribute } \\
\text { name }\end{array}$ & $\begin{array}{l}\text { Item } \\
\text { type }\end{array}$ & $\begin{array}{l}\text { Input } \\
\text { width }\end{array}$ & $\begin{array}{l}\text { Output } \\
\text { width }\end{array}$ & $\begin{array}{c}\text { Number } \\
\text { of } \\
\text { decimals }\end{array}$ & Description \\
\hline PARTID & Integer & 10 & 10 & 0 & $\begin{array}{l}\text { Particle-id from PATHLINE or TIMESERS files output } \\
\text { by MODPATH }\end{array}$ \\
\hline STRSTP & Integer & 10 & 10 & 0 & Starting time step \\
\hline STRTIM & Floating & 16 & 8 & 3 & Starting time of particle at time zero \\
\hline STRROW & Integer & $\mathrm{n}$ & $\mathrm{n}$ & 0 & Starting row at time STRTIM \\
\hline STRCOL & Integer & $\mathrm{n}$ & $\mathrm{n}$ & 0 & Starting column at time STRTIM \\
\hline STRLAY & Integer & $\mathrm{n}$ & $\mathrm{n}$ & 0 & Starting model layer at time STRTIM \\
\hline STRIBD & Integer & 10 & 10 & 0 & Starting model ibound value at time STRTIM \\
\hline STRXGC & Floating & 8 & 16 & 3 & Starting global particle $\mathrm{x}$-coordinate at time STRTIM \\
\hline STRXLC & Floating & 8 & 16 & 3 & Starting local particle $\mathrm{x}$-coordinate at time STRTIM \\
\hline STRYGC & Floating & 8 & 16 & 3 & Starting global particle y-coordinate at time STRTIM \\
\hline STRYLC & Floating & 8 & 16 & 3 & Starting local particle y-coordinate at time STRTIM \\
\hline STRZGC & Floating & 8 & 16 & 3 & Starting global particle z-coordinate at time STRTIM \\
\hline STRZLC & Floating & 8 & 16 & 3 & Starting local particle z-coordinate at time STRTIM \\
\hline FINSTP & Integer & 10 & 10 & 0 & Final time step \\
\hline FINTIM & Floating & 8 & 16 & 3 & Final cumulative time of particle \\
\hline FINROW & Integer & $\mathrm{n}$ & $\mathrm{n}$ & 0 & Final row at time FINTIM \\
\hline FINCOL & Integer & $\mathrm{n}$ & $\mathrm{n}$ & 0 & Final column at time FINTIM \\
\hline FINLAY & Integer & $\mathrm{n}$ & $\mathrm{n}$ & 0 & Final model layer at time FINTIM \\
\hline FINIBD & Integer & 10 & 10 & 0 & Final model ibound value at time FINTIM \\
\hline FINXGC & Floating & 8 & 16 & 3 & Final global particle $\mathrm{x}$-coordinate at time FINTIM \\
\hline FINXLC & Floating & 8 & 16 & 3 & Final local particle $\mathrm{x}$-coordinate at time FINTIM \\
\hline FINYGC & Floating & 8 & 16 & 3 & Final global particle y-coordinate at time FINTIM \\
\hline FINYLC & Floating & 8 & 16 & 3 & Final local particle y-coordinate at time FINTIM \\
\hline FINZGC & Floating & 8 & 16 & 3 & Final global particle z-coordinate at time FINTIM \\
\hline FINZLC & Floating & 8 & 16 & 3 & Final local particle z-coordinate at time FINTIM \\
\hline FINXVL & Floating & 8 & 16 & 8 & Particle $\mathrm{x}$-direction velocity along entire particle path \\
\hline FINYVL & Floating & 8 & 16 & 8 & Particle y-direction velocity along entire particle path \\
\hline FINZVL & Floating & 8 & 16 & 8 & Particle z-direction velocity along entire particle path \\
\hline FINSPD & Floating & 8 & 16 & 8 & Particle speed along entire particle path \\
\hline LSTTIM & Floating & 8 & 16 & 3 & Last time of particle \\
\hline LSTROW & Integer & $\mathrm{n}$ & $\mathrm{n}$ & 0 & Last row at time LSTTIM \\
\hline LSTCOL & Integer & $\mathrm{n}$ & $\mathrm{n}$ & 0 & Last column at time LSTTIM \\
\hline LSTLAY & Integer & $\mathrm{n}$ & $\mathrm{n}$ & 0 & Last model layer at time LSTTIM \\
\hline
\end{tabular}


Table 5. Attributes associated with pathline and time-series GIS output from MODTOOLS—Continued [n, width determined by MODTOOLS from model grid]

\begin{tabular}{|c|c|c|c|c|c|}
\hline $\begin{array}{l}\text { Attribute } \\
\text { name }\end{array}$ & $\begin{array}{l}\text { Item } \\
\text { type }\end{array}$ & $\begin{array}{l}\text { Input } \\
\text { width }\end{array}$ & $\begin{array}{l}\text { Output } \\
\text { width }\end{array}$ & $\begin{array}{c}\text { Number } \\
\text { of } \\
\text { decimals }\end{array}$ & Description \\
\hline LSTIBD & Integer & 10 & 10 & 0 & Last model ibound value at time LSTTIM \\
\hline LSTXGC & Floating & 8 & 16 & 3 & Last global particle $\mathrm{x}$-coordinate at time LSTTIM \\
\hline LSTXLC & Floating & 8 & 16 & 3 & Last local particle $\mathrm{x}$-coordinate at time LSTTIM \\
\hline LSTYGC & Floating & 8 & 16 & 3 & Last global particle y-coordinate at time LSTTIM \\
\hline LSTYLC & Floating & 8 & 16 & 3 & Last local particle y-coordinate at time LSTTIM \\
\hline LSTZGC & Floating & 8 & 16 & 3 & Last global particle z-coordinate at time LSTTIM \\
\hline LSTZLC & Floating & 8 & 16 & 3 & Last local particle z-coordinate at time LSTTIM \\
\hline PRESTP & Integer & 10 & 10 & 0 & Present time step \\
\hline PRETIM & Floating & 8 & 16 & 3 & Present time of particle \\
\hline PREROW & Integer & $\mathrm{n}$ & $\mathrm{n}$ & 0 & Present row at time PRETIM \\
\hline PRECOL & Integer & $\mathrm{n}$ & $\mathrm{n}$ & 0 & Present column at time PRETIM \\
\hline PRELAY & Integer & $\mathrm{n}$ & $\mathrm{n}$ & 0 & Present model layer at time PRETIM \\
\hline PREIBD & Integer & 10 & 10 & 0 & Present model ibound value at time PRETIM \\
\hline PREXGC & Floating & 8 & 16 & 3 & Present global particle $\mathrm{x}$-coordinate at time PRETIM \\
\hline PREXLC & Floating & 8 & 16 & 3 & Present local particle $\mathrm{x}$-coordinate at time PRETIM \\
\hline PREYGC & Floating & 8 & 16 & 3 & Present global particle y-coordinate at time PRETIM \\
\hline PREYLC & Floating & 8 & 16 & 3 & Present local particle y-coordinate at time PRETIM \\
\hline PREZGC & Floating & 8 & 16 & 3 & Present global particle z-coordinate at time PRETIM \\
\hline PREZLC & Floating & 8 & 16 & 3 & Present local particle z-coordinate at time PRETIM \\
\hline PRETRV & Floating & 8 & 16 & 3 & Travel time along this arc \\
\hline PREXVL & Floating & 8 & 16 & 8 & Present particle $\mathrm{x}$-direction velocity along pathline \\
\hline PREYVL & Floating & 8 & 16 & 8 & Present particle y-direction velocity along pathline \\
\hline PREZVL & Floating & 8 & 16 & 8 & Present particle z-direction velocity along pathline \\
\hline PRESPD & Floating & 8 & 16 & 8 & Present particle speed along pathline \\
\hline CUMXVL & Floating & 8 & 16 & 8 & $\begin{array}{l}\text { Cumulative particle } \mathrm{x} \text {-direction velocity along particle } \\
\text { path from start to present }\end{array}$ \\
\hline CUMYVL & Floating & 8 & 16 & 8 & $\begin{array}{l}\text { Cumulative particle y-direction velocity along particle } \\
\text { path from start to present }\end{array}$ \\
\hline CUMZVL & Floating & 8 & 16 & 8 & $\begin{array}{l}\text { Cumulative particle z-direction velocity along particle } \\
\text { path from start to present }\end{array}$ \\
\hline CUMSPD & Floating & 8 & 16 & 8 & $\begin{array}{l}\text { Cumulative particle speed along particle path from start } \\
\text { to present }\end{array}$ \\
\hline MODSTP & Integer & 10 & 10 & 0 & $\begin{array}{l}\text { Cumulative MODFLOW time step number (Pollock, } \\
\text { 1994, p. B-4) }\end{array}$ \\
\hline
\end{tabular}




\section{Endpoint Data}

MODTOOLS constructs endpoint GIS output from particle data recorded in the ENDPOINT file. MODTOOLS computes 32 attributes associated with each particle position (table 6). Intermediate attributes like those from the pathline and time-series GIS outputs are not present because intermediate particle positions are not recorded in the ENDPOINT file by MODPATH.

\section{Zones of Transport Data}

MODTOOLS constructs zones of transport GIS output from particle data recorded in the TIMESERS and ENDPOINT files of a backward-tracking analysis. MODTOOLS constructs two types of GIS output from the combined particle data. The first consists of polygons that represent the projection of the zones of transport onto the user-specified plane of the model grid. Only one attribute, TIMSTP, is associated with each polygon (table 7). This attribute identifies the model time step associated with each polygon that represents a zone of transport.

The second GIS output constructed by MODTOOLS for the zones of transport GIS output has "point topology," which means this GIS output consists of points that represent the vertices of the zones of transport polygons. The attributes associated with these vertices are derived from particle characteristics of the particle used to derive the vertices, as described in Appendix C.

\section{Model Grid}

MODTOOLS constructs GIS output of model-cell geometry using the cell data recorded in the MAIN file. The MAIN file contains information about the cell spacing in the model grid as well as data about whether a cell is active or inactive. MODTOOLS can construct two types of GIS output, which show different views of the model grid, mapview and vertical profile. The number of attributes associated with each cell (polygon) is determined by the view. All possible attributes are listed in table 8. Vertical profile views may be along a model row or column, or a user-specified particle path. Eight attributes, shown in table 8 , are computed by MODTOOLS for vertical profile GIS output. For mapview GIS output of the model grid, the last four attributes shown in table 8, IBOUND, TOPELEV, BOTELEV, and THICK, are not included in the attributes. MODTOOLS constructs "normalized" cross sections (like those constructed by MODPATH-PLOT (Pollock, 1994, p. 4-12) to accompany contour and velocityvector GIS output created using vertical profile orientations. MODTOOLS computes an average thickness for each model layer and generates a rectangular cross section with layers of constant thickness. To accompany the remaining six types of GIS output created using vertical profile orientations, MODTOOLS uses the top and bottom elevations of the cells read from the MAIN file to construct a cross section. Each cell is constructed as a rectangle, which allows the shape of variable thickness and dipping layers to be viewed. 
Table 6. Attributes associated with endpoint GIS output from MODTOOLS

[n, width determined by MODTOOLS from model grid]

\begin{tabular}{|c|c|c|c|c|c|}
\hline $\begin{array}{l}\text { Attribute } \\
\text { name }\end{array}$ & $\begin{array}{l}\text { Item } \\
\text { type }\end{array}$ & $\begin{array}{l}\text { Input } \\
\text { width }\end{array}$ & $\begin{array}{l}\text { Output } \\
\text { width }\end{array}$ & $\begin{array}{c}\text { Number } \\
\text { of } \\
\text { decimals }\end{array}$ & Description \\
\hline PARTID & Binary & 4 & 5 & 0 & Particle-id from ENDPOINT files output by MODPATH \\
\hline STRTIM & Floating & 8 & 16 & 3 & Starting time of particle at time zero \\
\hline STRROW & Integer & $\mathrm{n}$ & $\mathrm{n}$ & 0 & Starting row at time STRTIM \\
\hline STRCOL & Integer & $\mathrm{n}$ & $\mathrm{n}$ & 0 & Starting column at time STRTIM \\
\hline STRLAY & Integer & $\mathrm{n}$ & $\mathrm{n}$ & 0 & Starting model layer at time STRTIM \\
\hline STRIBD & Integer & 10 & 10 & 0 & Starting model ibound value at time STRTIM \\
\hline STRXGC & Floating & 8 & 16 & 3 & Starting global particle $\mathrm{x}$-coordinate at time STRTIM \\
\hline STRXLC & Floating & 8 & 16 & 3 & Starting local particle $\mathrm{x}$-coordinate at time STRTIM \\
\hline STRYGC & Floating & 8 & 16 & 3 & Starting global particle y-coordinate at time STRTIM \\
\hline STRYLC & Floating & 8 & 16 & 3 & Starting local particle y-coordinate at time STRTIM \\
\hline STRZGC & Floating & 8 & 16 & 3 & Starting global particle z-coordinate at time STRTIM \\
\hline STRZLC & Floating & 8 & 16 & 3 & Starting local particle z-coordinate at time STRTIM \\
\hline FINTIM & Floating & 8 & 16 & 3 & Final cumulative time of particle \\
\hline FINROW & Integer & $\mathrm{n}$ & $\mathrm{n}$ & 0 & Final row at time FINTIM \\
\hline FINCOL & Integer & $\mathrm{n}$ & $\mathrm{n}$ & 0 & Final column at time FINTIM \\
\hline FINLAY & Integer & $\mathrm{n}$ & $\mathrm{n}$ & 0 & Final model layer at time FINTIM \\
\hline FINIBD & Integer & 10 & 10 & 0 & Final model ibound value at time FINTIM \\
\hline FINXGC & Floating & 8 & 16 & 3 & Final global particle $\mathrm{x}$-coordinate at time FINTIM \\
\hline FINXLC & Floating & 8 & 16 & 3 & Final local particle $\mathrm{x}$-coordinate at time FINTIM \\
\hline FINYGC & Floating & 8 & 16 & 3 & Final global particle y-coordinate at time FINTIM \\
\hline FINYLC & Floating & 8 & 16 & 3 & Final local particle y-coordinate at time FINTIM \\
\hline FINZGC & Floating & 8 & 16 & 3 & Final global particle z-coordinate at time FINTIM \\
\hline FINZLC & Floating & 8 & 16 & 3 & Final local particle $\mathrm{z}$-coordinate at time FINTIM \\
\hline FINXVL & Floating & 8 & 16 & 8 & Particle x-direction velocity along entire particle path \\
\hline FINYVL & Floating & 8 & 16 & 8 & Particle y-direction velocity along entire particle path \\
\hline FINZVL & Floating & 8 & 16 & 8 & Particle z-direction velocity along entire particle path \\
\hline FINSPD & Floating & 8 & 16 & 8 & Particle speed along entire particle path \\
\hline FINDIS & Floating & 8 & 16 & 3 & Distance along entire particle path \\
\hline MODSTP & Integer & 10 & 10 & 0 & $\begin{array}{l}\text { Cumulative MODFLOW time step number (Pollock, } \\
\text { 1994, p. B-4) }\end{array}$ \\
\hline IPCODE & Integer & 10 & 10 & 0 & Particle termination code (Pollock, 1994, p. B-4) \\
\hline IDCODE & Integer & 10 & 10 & 0 & Particle discharge code (Pollock, 1994, p. B-4) \\
\hline RESTIM & Floating & 8 & 16 & 3 & Release time (Pollock, 1994, p. B-4) \\
\hline
\end{tabular}


Table 7. Attributes associated with zones of transport GIS output from MODTOOLS

[n - width determined by MODTOOLS from model grid]

\begin{tabular}{|c|c|c|c|c|c|}
\hline $\begin{array}{l}\text { Attribute } \\
\text { name }\end{array}$ & $\begin{array}{l}\text { Item } \\
\text { type }\end{array}$ & $\begin{array}{l}\text { Input } \\
\text { width }\end{array}$ & $\begin{array}{l}\text { Output } \\
\text { width }\end{array}$ & $\begin{array}{c}\text { Number } \\
\text { of } \\
\text { decimals }\end{array}$ & Description \\
\hline TIMSTP & Integer & 10 & 10 & 0 & $\begin{array}{l}\text { Model time step from TIMESERS file output by } \\
\text { MODPATH }\end{array}$ \\
\hline PARTID & Binary & 4 & 5 & 0 & Particle-id from TIMESERS files output by MODPATH \\
\hline STRTIM & Floating & 8 & 16 & 3 & Starting time of particle at time zero \\
\hline STRROW & Integer & $\mathrm{n}$ & $\mathrm{n}$ & 0 & Starting row at time STRTIM \\
\hline STRCOL & Integer & $\mathrm{n}$ & $\mathrm{n}$ & 0 & Starting column at time STRTIM \\
\hline STRLAY & Integer & $\mathrm{n}$ & $\mathrm{n}$ & 0 & Starting model layer at time STRTIM \\
\hline STRIBD & Integer & 10 & 10 & 0 & Starting model ibound value at time STRTIM \\
\hline STRXGC & Floating & 8 & 16 & 3 & Starting global particle $\mathrm{x}$-coordinate at time STRTIM \\
\hline STRXLC & Floating & 8 & 16 & 3 & Starting local particle x-coordinate at time STRTIM \\
\hline STRYGC & Floating & 8 & 16 & 3 & Starting global particle y-coordinate at time STRTIM \\
\hline STRYLC & Floating & 8 & 16 & 3 & Starting local particle y-coordinate at time STRTIM \\
\hline STRZGC & Floating & 8 & 16 & 3 & Starting global particle z-coordinate at time STRTIM \\
\hline STRZLC & Floating & 8 & 16 & 3 & Starting local particle z-coordinate at time STRTIM \\
\hline FINTIM & Floating & 8 & 16 & 3 & Final cumulative time of particle \\
\hline FINROW & Integer & $\mathrm{n}$ & $\mathrm{n}$ & 0 & Final row at time FINTIM \\
\hline FINCOL & Integer & $\mathrm{n}$ & $\mathrm{n}$ & 0 & Final column at time FINTIM \\
\hline FINLAY & Integer & $\mathrm{n}$ & $\mathrm{n}$ & 0 & Final model layer at time FINTIM \\
\hline FINIBD & Integer & 10 & 10 & 0 & Final model ibound value at time FINTIM \\
\hline FINXGC & Floating & 8 & 16 & 3 & Final global particle $\mathrm{x}$-coordinate at time FINTIM \\
\hline FINXLC & Floating & 8 & 16 & 3 & Final local particle $\mathrm{x}$-coordinate at time FINTIM \\
\hline FINYGC & Floating & 8 & 16 & 3 & Final global particle y-coordinate at time FINTIM \\
\hline FINYLC & Floating & 8 & 16 & 3 & Final local particle y-coordinate at time FINTIM \\
\hline FINZGC & Floating & 8 & 16 & 3 & Final global particle z-coordinate at time FINTIM \\
\hline FINZLC & Floating & 8 & 16 & 3 & Final local particle $\mathrm{z}$-coordinate at time FINTIM \\
\hline FINXVL & Floating & 8 & 16 & 6 & Particle $\mathrm{x}$-direction velocity along entire particle path \\
\hline FINYVL & Floating & 8 & 16 & 6 & Particle y-direction velocity along entire particle path \\
\hline FINZVL & Floating & 8 & 16 & 6 & Particle z-direction velocity along entire particle path \\
\hline FINSPD & Floating & 8 & 16 & 6 & Particle speed along entire particle path \\
\hline FINDIS & Floating & 8 & 16 & 3 & Distance along entire particle path \\
\hline MODSTP & Integer & 10 & 10 & 0 & MODFLOW time step number \\
\hline IPCODE & Integer & 10 & 10 & 0 & Particle termination code (Pollock, 1994, p. B-4) \\
\hline IDCODE & Integer & 10 & 10 & 0 & Particle discharge code (Pollock, 1994, p. B-4) \\
\hline RESTIM & Floating & 8 & 16 & 3 & Release time (Pollock, 1994, p. B-4) \\
\hline
\end{tabular}


Table 8. Attributes associated with model-grid GIS output from MODTOOLS [n, width determined by MODTOOLS from model grid]

\begin{tabular}{|l|l|c|c|c|l|}
\hline \multicolumn{1}{|c|}{$\begin{array}{l}\text { Attribute } \\
\text { name }\end{array}$} & $\begin{array}{c}\text { Item } \\
\text { type }\end{array}$ & $\begin{array}{c}\text { Input } \\
\text { width }\end{array}$ & $\begin{array}{c}\text { Output } \\
\text { width }\end{array}$ & $\begin{array}{c}\text { Number } \\
\text { of } \\
\text { decimals }\end{array}$ & \multicolumn{1}{|c|}{ Description } \\
\hline xxxID & Binary & 4 & 5 & 0 & Id identifying the polygons output by MODTOOLS \\
\hline ROW & Integer & $\mathrm{n}$ & $\mathrm{n}$ & 0 & Row in the model grid \\
\hline COLUMN & Integer & $\mathrm{n}$ & $\mathrm{n}$ & 0 & Column in the model grid \\
\hline LAYER & Integer & $\mathrm{n}$ & $\mathrm{n}$ & 0 & Layer in the model grid \\
\hline IBOUND & Integer & 10 & 10 & 0 & Value of IBOUND array for this cell \\
\hline TOPELEV & Floating & 8 & 16 & 3 & Top elevation of cell in global z-coordinate units \\
\hline BOTELEV & Floating & 8 & 16 & 3 & Bottom elevation of cell in global z-coordinate units \\
\hline THICK & Floating & 8 & 16 & 3 & Thickness of cell in global z-coordinate units \\
\hline
\end{tabular}

\section{Output from MODFLOW}

MODTOOLS creates three types of GIS output from MODFLOW data: contour, velocity-vector, and cell-value files. MODTOOLS omits cells from GIS output on the basis of several conditions. Cells that are inactive (cell IBOUND $=0$ ) are automatically omitted. For cell values, cells that have a value equal to the user-specified value for dry cells (HDRY item in MAIN file) or for no-flow cells (HNOFLO item in MAIN file) are omitted. Also, the user can choose to output the cell values for cells in a specified layer, for cells with a specific IBOUND value, or for the uppermost active cells.

For contour and velocity-vector GIS output, MODTOOLS uses the "normalized" approach (Pollock, 1994, p. 4-12) for vertical profiles instead of a global system for mapview perspectives. MODTOOLS computes an average thickness for each model layer and constructs a rectangular cross section with layers of constant thickness. This approach is used for a contour GIS output only for vertical profile views, because the computer program CONTOUR developed by Harbaugh (1990) was designed only for a mapview perspective and to work with gridded data of MODFLOW. CONTOUR has been adapted to work for vertical profile views, but cells with constant thickness must be used considering the numerical problems caused by vertical discretization schemes. This same approach produced better plots for a velocity-vector GIS output in vertical profile views, because the varying thicknesses of the grid cells caused by vertical discretization schemes produced less desirable results.

\section{Contour Data}

MODTOOLS constructs contour GIS output from cell-by-cell terms recorded in the CONTOURDATA file identified in the NAME file. MODTOOLS incorporates a contouring package that is adapted directly from the program developed and described by Harbaugh (1990). MODTOOLS reads the cellby-cell terms of MODFLOW and computes a set of lines connecting points of equal value. MODTOOLS reads formatting information recorded in the CONTOUR-CONTROL file identified in the NAME file to properly read the cell-by-cell terms. 
MODTOOLS allows the user several options for orientation. MODTOOLS constructs only a contour GIS output if the user specifies a mapview orientation. MODTOOLS constructs a contour GIS output and a separate model-grid GIS output showing the cell geometry if the user specifies a vertical profile orientation along a specified row or column of the model grid or along a specified particle pathline read from the PATHLINE file. The two GIS outputs created for vertical profile orientations use the local coordinate system and the user can combine the digital images into one display or plot using the capabilities of the GIS. MODTOOLS records the value of the contour line in an attribute called CONTOUR in the contour GIS output.

\section{Velocity-Vector Data}

MODTOOLS constructs velocity-vector GIS output using a flow-vector routine that is adapted from MMSP (modular model statistical processor) developed for MODFLOW by Scott (1990, p. 62). MODTOOLS constructs velocity vectors (representing average interstitial velocity) using this routine and additional information from the cell geometry and porosity arrays used by MODPATH and from the simulated head and cell-by-cell flow terms output by the Basic and the Block Centered Flow Packages of MODFLOW. MODTOOLS reads the cell geometry and porosity data from the MAIN file identified in the NAME file. MODTOOLS reads the cell-by-cell terms output by the Block Centered Flow Package of MODFLOW and recorded in the BUDGET file identified in the NAME file. MODTOOLS also reads the head values output by the Basic Package of MODFLOW and recorded in the HEAD or HEAD(BINARY) file identified in the NAME file.

MODTOOLS computes the orthogonal components (x, y, and $\mathrm{z}$ ) of flow in each active cell in a manner similar to that used by the flow-vector routine of MMSP (Scott, 1990, p. 62-64). However, MODTOOLS computes the velocity vector by dividing the volumetric flow components by the product of the cross-sectional area of saturated flow and the effective porosity of the cell. The length of the velocity vector is determined by multiplying the velocity component by a user-specified scaling value. MODTOOLS uses the user-specified viewing orientation to determine which two orthogonal components of the velocity to use when computing the direction of the line representing the velocity vector $(\mathrm{x}-\mathrm{y}, \mathrm{x}-\mathrm{z}$, or $\mathrm{y}-\mathrm{z})$.

MODTOOLS allows the length of velocity vectors to be scaled either arithmetically or logarithmically. When arithmetic scaling is selected, the length of each velocity vector is multiplied by a user-specified constant. When logarithmic scaling is selected, the length of each velocity vector is multiplied by a computed constant. The computed constant is the product of the absolute value of the user-specified constant and the minimum power-of-10 multiplier needed to increase the minimum nonzero vector length to a value greater than one (Scott, 1990, p. 64).

MODTOOLS allows the user several options in the viewing orientation. MODTOOLS constructs only a velocity-vector GIS output if the user specifies a mapview orientation. MODTOOLS constructs a velocity-vector GIS output and a separate model-grid GIS output showing the cell geometry for vertical profiles along a specified row or column of the model grid. The two GIS outputs created for vertical profile orientations use the local coordinate system and can be combined into one display or plot using 
the capabilities of the GIS. MODTOOLS computes up to 12 attributes for each vector depending upon the orientation of the view (table 9).

Table 9. Attributes associated with velocity-vector GIS output from MODTOOLS [n - width determined by MODTOOLS from model grid]

\begin{tabular}{|c|c|c|c|c|c|}
\hline $\begin{array}{l}\text { Attribute name } \\
\text { ROWCOL }\end{array}$ & $\begin{array}{c}\text { Item } \\
\text { type } \\
\text { character }\end{array}$ & $\begin{array}{l}\text { Input } \\
\text { width } \\
\mathrm{n}\end{array}$ & $\begin{array}{l}\text { Output } \\
\text { width } \\
\text { n }\end{array}$ & $\begin{array}{c}\begin{array}{c}\text { Number } \\
\text { of } \\
\text { decimals }\end{array} \\
0\end{array}$ & $\begin{array}{l}\text { Descriptions } \\
\text { Combined row and column item }\end{array}$ \\
\hline ROW & Integer & $\mathrm{n}$ & $\mathrm{n}$ & 0 & Row in the model grid \\
\hline COLUMN & Integer & $\mathrm{n}$ & $\mathrm{n}$ & 0 & Column in the model grid \\
\hline LAYER & Integer & $\mathrm{n}$ & $\mathrm{n}$ & 0 & Layer in the model grid \\
\hline IBOUND & Integer & 10 & 10 & 0 & Value of IBOUND array for this cell \\
\hline LAYER_ & Floating & 8 & 16 & 3 & Value of cell-by-cell term \\
\hline XVELOCITY & Floating & 8 & 16 & 3 & $\begin{array}{l}\text { Value of velocity vector in the } \mathrm{x} \text {-direction of the } \\
\text { model grid }\end{array}$ \\
\hline YVELOCITY & Floating & 8 & 16 & 3 & $\begin{array}{l}\text { Value of velocity vector in the y-direction of the } \\
\text { model grid }\end{array}$ \\
\hline ZVELOCITY & Floating & 8 & 16 & 3 & $\begin{array}{l}\text { Value of velocity vector in the } \mathrm{z} \text {-direction of the } \\
\text { model grid }\end{array}$ \\
\hline XYSPEED & Floating & 8 & 16 & 3 & Value of flow speed in the $x-y$ plane of the model grid \\
\hline XZSPEED & Floating & 8 & 16 & 3 & Value of flow speed in the $\mathrm{x}-\mathrm{z}$ plane of the model grid \\
\hline YZSPEED & Floating & 8 & 16 & 3 & Value of flow speed in the $y-z$ plane of the model grid \\
\hline
\end{tabular}

\section{Cell-Value Data}

MODTOOLS reads the cell-by-cell terms of MODFLOW and records a set of attributes associated with each cell to the GIS file(s) or appends the cell values to the set of attributes associated with each cell of a model-grid GIS output (see table 8 for cell attributes). The user may select the stress period and time step of the cell values. MODTOOLS constructs a model-grid GIS output showing the cell geometry in vertical profiles along a specified row or column of the model grid and along a specified particle pathline read from the PATHLINE file. The cell values of MODFLOW are appended to the cell attributes.

When the user has specified a mapview orientation, MODTOOLS reads the cell-by-cell terms output by the user-specified package of MODFLOW and records a set of attributes associated with each cell to a GIS file(s). The names and definitions of these attributes are shown in table 10. The names and the number of attributes are determined by the package of MODFLOW selected by the user and the type of mapview orientation. The user can choose to record cell-by-cell terms for all model Slayers to a GIS file. The value of each term is recorded in an item for each layer called LAYER_xx, where $\mathrm{xx}$ is the layer number. 
Table 10. Attributes associated with cell-value GIS output from MODTOOLS (adapted from Pollock, 1994, p. A-7) [n, width determined by MODTOOLS from model grid]

\begin{tabular}{|c|c|c|c|c|c|}
\hline $\begin{array}{l}\text { Attribute } \\
\text { name }\end{array}$ & $\begin{array}{l}\text { Item } \\
\text { type }\end{array}$ & $\begin{array}{l}\text { Input } \\
\text { width }\end{array}$ & $\begin{array}{l}\text { Output } \\
\text { width }\end{array}$ & $\begin{array}{c}\text { Number } \\
\text { of } \\
\text { decimals }\end{array}$ & Descriptions \\
\hline xxxID & Binary & 4 & 5 & 0 & Id identifying the polygons output by MODTOOLS \\
\hline SEQNUM & Integer & $\mathrm{n}$ & $\mathrm{n}$ & 0 & Sequential number assigned to cells \\
\hline ROW & Integer & $\mathrm{n}$ & $\mathrm{n}$ & 0 & Row in the model grid \\
\hline COLUMN & Integer & $\mathrm{n}$ & $\mathrm{n}$ & 0 & Column in the model grid \\
\hline LAYER_xx & Integer & $\mathrm{n}$ & $\mathrm{n}$ & 0 & Layer in the model grid \\
\hline IBOUND & Integer & 10 & 10 & 0 & Value of IBOUND array for this cell \\
\hline LAYER & Floating & 8 & 16 & 3 & Value of cell-by-cell term \\
\hline HEDTRM & Floating & 8 & 16 & 3 & Value of head from Basic Package \\
\hline DDNTRM & Floating & 8 & 16 & 3 & Value of drawdown from Basic Package \\
\hline FFFTRM & Floating & 8 & 16 & 3 & $\begin{array}{l}\text { Value of flow through front face cell-by-cell term of Block } \\
\text { Centered Flow Package }\end{array}$ \\
\hline FLFTRM & Floating & 8 & 16 & 3 & $\begin{array}{l}\text { Value of flow through lower face cell-by-cell term of } \\
\text { Block Centered Flow Package }\end{array}$ \\
\hline FRFTRM & Floating & 8 & 16 & 3 & $\begin{array}{l}\text { Value of flow through right face cell-by-cell term of Block } \\
\text { Centered Flow Package }\end{array}$ \\
\hline STOTRM & Floating & 8 & 16 & 3 & $\begin{array}{l}\text { Value of flow from storage term of the Block Centered } \\
\text { Flow Package }\end{array}$ \\
\hline RCHTRM & Floating & 8 & 16 & 3 & Value of cell-by-cell term of Recharge Package \\
\hline WELTRM & Floating & 8 & 16 & 3 & Value of cell-by-cell term of Well Package \\
\hline RIVTRM & Floating & 8 & 16 & 3 & Value of cell-by-cell term of River Package \\
\hline STRTRM & Floating & 8 & 16 & 3 & Value of cell-by-cell term of Streamflow Routing Package \\
\hline STRFLO & Floating & 8 & 16 & 3 & $\begin{array}{l}\text { Value of cell-by-cell streamflow of Streamflow Routing } \\
\text { Package }\end{array}$ \\
\hline DRNTRM & Floating & 8 & 16 & 3 & Value of cell-by-cell term of Drain Package \\
\hline GHBTRM & Floating & 8 & 16 & 3 & $\begin{array}{l}\text { Value of cell-by-cell term of General Head Boundary } \\
\text { Package }\end{array}$ \\
\hline EVTTRM & Floating & 8 & 16 & 3 & Value of cell-by-cell term of Evapotranspiration Package \\
\hline IBSTRM & Floating & 8 & 16 & 3 & Value of cell-by-cell term of Interbed Storage Package \\
\hline ARRTRM & Floating & 8 & 16 & 8 & Value of miscellaneous gridded model data \\
\hline
\end{tabular}


This file structure matches the file structure used by MODFLOWARC (Orzol and McGrath, 1992). Also, an item called SEQNUM (a unique model-cell identifier in the row-column plane) has been added to the set of attributes so that the GIS output from MODTOOLS is compatible with the GIS output from the MODELGRID programs (Kernodle and Philip, 1988). The user can choose to record cell values for a specific layer to a GIS file. The value of each term is recorded in an item for the specific layer called LAYER_xx. The user can choose to record cell values for cells which have a specific IBOUND value to a GIS file (see discussion by Pollock, 1994, p. 3-7). The sum of the terms is recorded in an item called IBOUND. The user can choose to record cell values for the uppermost active cells to a GIS file. The value of each term is recorded in an item for each uppermost active cell called xxxTRM, where xxx is generally a string of three characters similar to the character string identifying the MODFLOW package in the MODPATH NAME file developed by Pollock (1994, p. A6 to A7). For example, the user may choose to record the cell-by-cell terms output by the Drain Package of MODFLOW in a GIS file for the uppermost active cells. The values of these terms would be recorded in an item called DRNTRM. 


\section{REFERENCES}

Harbaugh, A.W., 1990, A simple contouring program for gridded data: U.S.Geological Survey OpenFile Report 90-144, 37 p.

Harbaugh, A.W., and McDonald, M.G., 1996, User's documentation for MODFLOW-96, an update to the U.S. Geological Survey modular finite-difference ground-water flow model: U.S. Geological Survey Open-File Report 96-485, 56 p.

Hinkle, S.R., and Snyder, D.T., in press, Comparison of chlorofluorocarbon-age dating with particletracking results of a regional ground-water flow model of the Portland Basin, Oregon and Washington: U.S. Geological Survey Water-Supply Paper 2483.

Kernodle, J.M., and Philip, R.D., 1988, Using a geographic information system to develop a groundwater flow model: American Water Resources Association Monograph, series no. 14, p. 191-202.

McDonald, M.G., and Harbaugh, A.W., 1988, A modular three-dimensional finite-difference groundwater flow model: U.S. Geological Survey Techniques of Water-Resources Investigations, book 6, chap. A1, $586 \mathrm{p}$.

Morgan, D.S., and McFarland, W.D., 1994, Simulation analysis of the ground-water flow system in the Portland Basin, Oregon and Washington: U.S.Geological Survey Open-File Report 94-505, 85 p.

Orzol, L.L., and McGrath, T.S., 1992, Modifications of the U.S. Geological Survey modular, finitedifference, ground-water flow model to read and write geographic information system files: U.S. Geological Survey Open-File Report 92-50, 202 p.

Pollock, D.W.,1994, User's guide for MODPATH/MODPATH-PLOT, version 3-A particle tracking post-processing package for MODFLOW, the U.S. Geological Survey finite-difference groundwater flow model: U.S. Geological Survey Open-File Report 94-464, [variously paged].

Prudic, D.E., 1989, Documentation of a computer program to simulate stream-aquifer relations using a modular, finite-difference, ground-water flow model: U.S. Geological Survey Open-File Report $88-729,113 \mathrm{p}$.

Scott, J.C., 1990, A statistical processor for analyzing simulations made using the modular finitedifference ground-water flow model: U.S. Geological Survey Water-Resources Investigations Report 89-4159, 218 p.

Snyder, D.T., Wilkinson, J.M. and Orzol, L.L., 1996, Use of a ground-water flow model with particle tracking to evaluate ground-water vulnerability: U. S. Geological Survey Open-File Report 96-328, $71 \mathrm{p}$.

U.S. Environmental Protection Agency, 1987, Guidelines for delineation of wellhead protection areas: Washington, D.C., Office of Ground-Water Protection, [variously paged]. 
APPENDIXES 


\section{APPENDIX A. OBTAINING AND INSTALLING MODTOOLS}

The computer programs described in this report are designed to translate data from the USGS modular finite-difference ground-water flow model (commonly known as MODFLOW) and particletracking programs (commonly known as MODPATH) into GIS files. The programs, named MODTOOLS, are available for downloading over the Internet from a USGS software repository. The repository is accessible on the World Wide Web (WWW) from the USGS Water Resources Information Web page at URL http://water.usgs.gov/. The URL for the public repository is: http://water.usgs.gov/ software/. The public anonymous FTP site is on the Water Resources Information server (water.usgs.gov or 130.11.50.175) in the /pub/software/ground_water/modtools directory. When this code is revised or updated in the future, new versions or releases will be made available for downloading from these same sites.

MODTOOLS should work on any computer that has ARC/INFO software and has the capability to use AML programs. It has been tested on a Data General AViiON Unix workstation. MODTOOLS conforms to the FORTRAN-77 programming standard and, therefore, can be compiled on virtually any computer with a FORTRAN-77 compiler.

Installation involves three major steps: (1) copying and restoring the MODTOOLS directories onto your computer system, (2) editing the MODTOOLS AML programs, and (3) compiling the MODTOOLS FORTRAN programs. There are many public-domain and standard UNIX software programs that have the ability to restore the compressed MODTOOLS directory system.

For the AML programs of MODTOOLS to work properly, the user must edit two pathnames in the AML program called MODTOOLS.AML. The first pathname is on a line identified by the keywords "\&s aml_path" and is followed by the pathname to the directory containing the AML programs. The user must edit the pathname to the directory where the MODTOOLS AML programs are restored. The second pathname is on the next line in MODTOOLS.AML. The user must edit the pathname to the directory where the MODTOOLS FORTRAN programs are restored.

For the FORTRAN programs of MODTOOLS to work properly, the following two steps must be done: (1) compile the FORTRAN programs of MODTOOLS and (2) link these programs of MODTOOLS and, if needed, link computer system libraries to produce an executable program. A file called MAKEFILE is included in the directory containing the FORTRAN programs. The user is encouraged to use this file to compile and link the MODTOOLS FORTRAN programs (see the UNIX "make" command for more information). 


\section{APPENDIX B. FILES AND MENU RESPONSES FOR EXAMPLES}

\section{Example 1: Particle Pathlines}

\section{NAME File}

The MODTOOLS NAME file listed below was used to produce GIS output of each of the four pathline analyses shown in figure 3. The user will need to rename the particle endpoint and pathline data files after each analysis. Four PATHLINE files are required for example 1. The user could omit all files, except the files identified by the keywords MAIN and PATHLINE. In this case, MODTOOLS uses the MODPATH NAME file of the pathline analysis from the transient flow problem developed by Pollock (1994, p. E-33) for problem 2, run 1.

$\begin{array}{lll}\text { main } & \mathbf{1 0} & \text { demo-t.mdf } \\ \text { wel } & 11 & \text { demo-t.wel } \\ \text { riv } & 12 & \text { demo-t.riv } \\ \text { rch } & 13 & \text { demo-t.rch } \\ \text { budget } & 50 & \text { demo-t.bud } \\ \text { head(binary) } & 60 & \text { demo-t.hed } \\ \text { cbf } & 70 & \text { demo-t.cbf } \\ \text { endpoint } & 75 & \text { endpoint.t1 } \\ \text { pathline } & \mathbf{7 6} & \text { pathline.t1 }\end{array}$

\section{Menu Responses}

The following is a list of menu responses necessary to reproduce the pathline GIS output during an interactive session between the user and MODTOOLS for example 1. After creating the first pathline GIS output from the particle-tracking analysis at a time of 500 years, the user can use the batch file that MODTOOLS created to automatically produce the pathline GIS output for the remaining three simulation times of 501, 503, 510 years.

Because the particle coordinates and attributes computed by MODTOOLS were not translated into another coordinate system, the user answers using the "none" option to multiplier and origin menus. However, these menus would generally be used to translate particle coordinates from MODPATH coordinates to GIS coordinates.

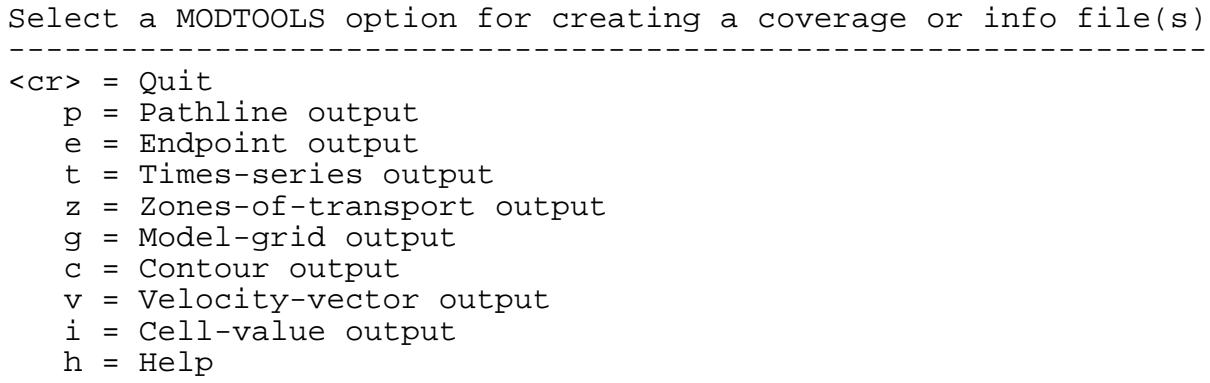




\section{APPENDIX B. FILES AND MENU RESPONSES FOR EXAMPLES-CONTINUED}

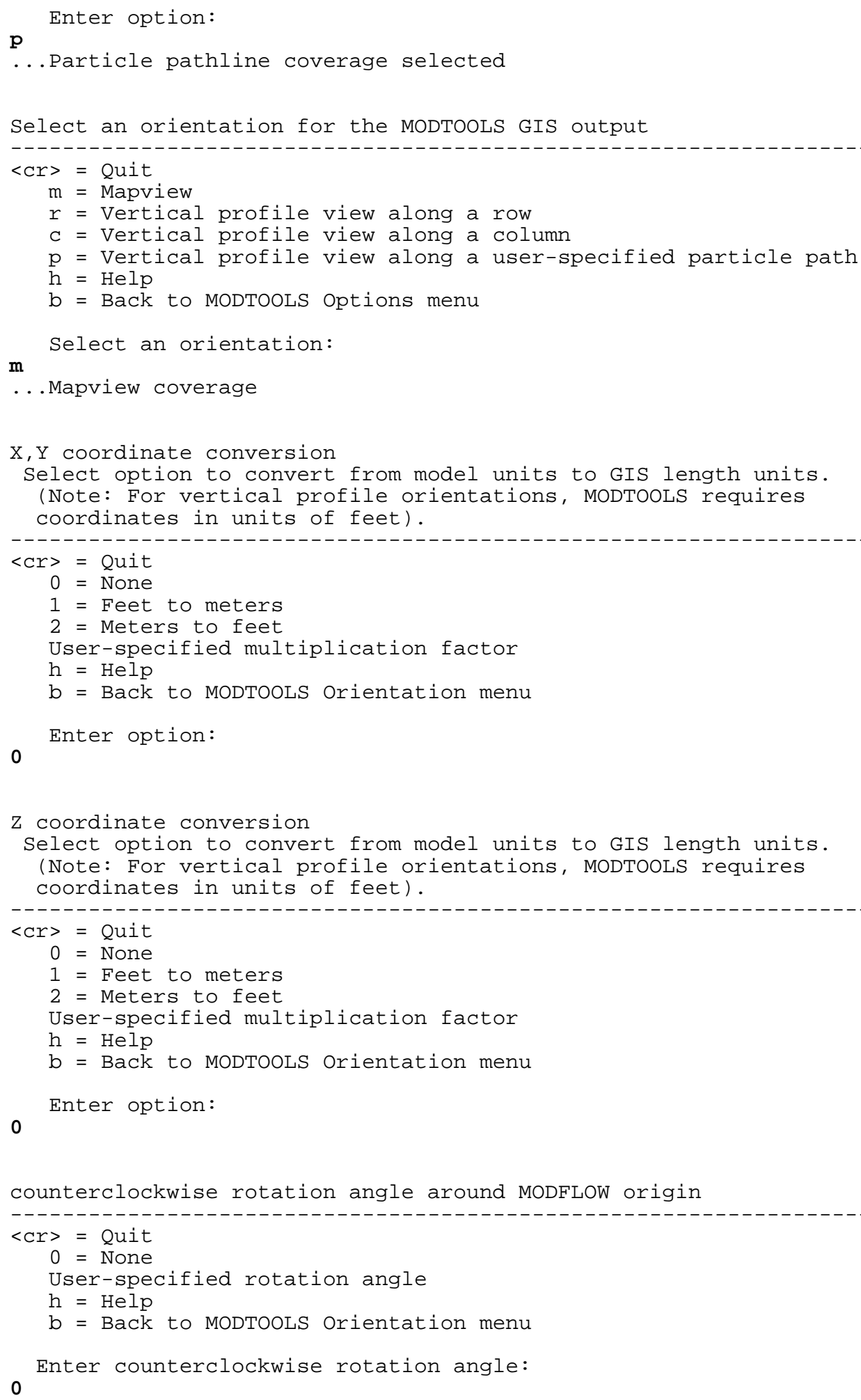




\section{APPENDIX B. FILES AND MENU RESPONSES FOR EXAMPLES-CONTINUED}

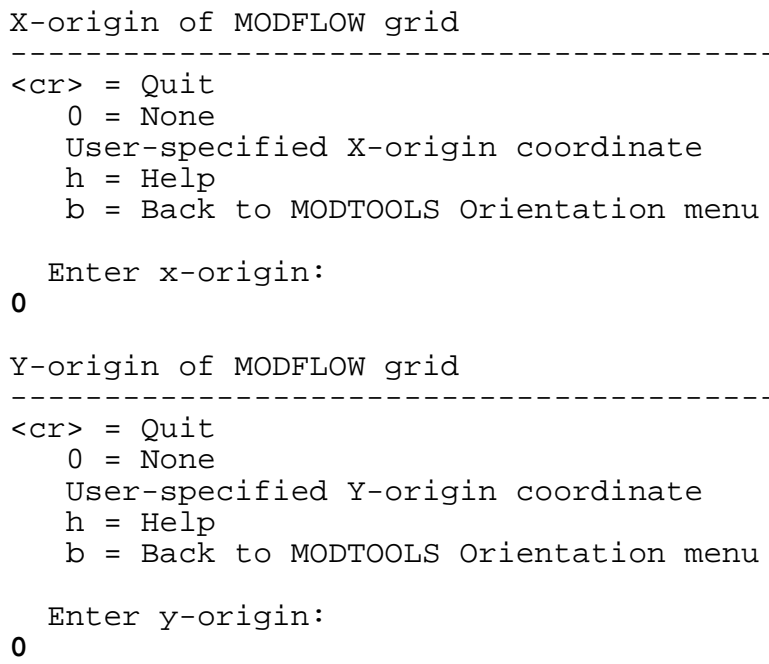

\section{Batch File}

The following listing is from the batch file, MODTOOLS.OUT, which contains a summary of the menu responses necessary to reproduce the pathline GIS output created during the above interactive session between the user and MODTOOLS for example 1.

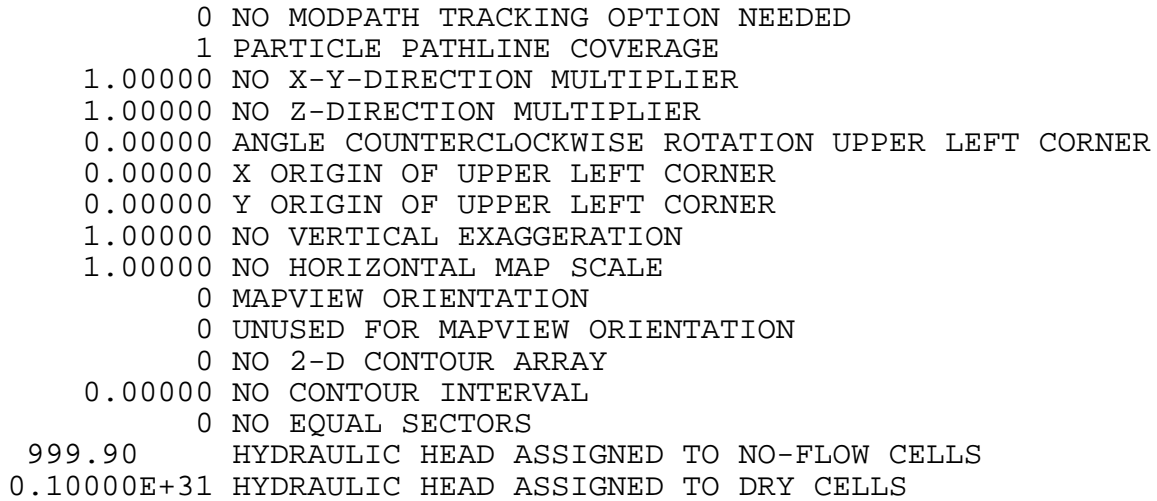

\section{Example 2: Particle Endpoints}

\section{NAME File}

The MODTOOLS NAME file listed below was used to produce the endpoint GIS output for the endpoint analysis shown in figure 4. MODTOOLS needs only two data files from the list to construct the endpoint GIS output. The user could omit all files, except the files identified by the keywords MAIN and ENDPOINT. In this case, MODTOOLS uses the MODPATH NAME file of the endpoint analysis from the transient flow problem for problem 2, run 3 developed by Pollock (1994, p. E-33). 


\section{APPENDIX B. FILES AND MENU RESPONSES FOR EXAMPLES-CONTINUED}

$\begin{array}{lll}\text { main } & \mathbf{1 0} & \text { demo-t.mdf } \\ \text { wel } & 11 & \text { demo-t.wel } \\ \text { riv } & 12 & \text { demo-t.riv } \\ \text { rch } & 13 & \text { demo-t.rch } \\ \text { budget } & 50 & \text { demo-t.bud } \\ \text { head(binary) } & 60 & \text { demo-t.hed } \\ \text { cbf } & 70 & \text { demo-t.cbf } \\ \text { endpoint } & \mathbf{7 5} & \text { endpoint.t3 }\end{array}$

\section{Menu Responses}

The following is a list of menu responses necessary to reproduce the endpoint GIS output during an interactive session between the user and MODTOOLS for example 2. After creating an endpoint GIS output from a particle-tracking analysis, the user can use the batch file that MODTOOLS created to automatically produce another endpoint GIS output for a different arrangement of starting particle locations to test an alternative scenario.

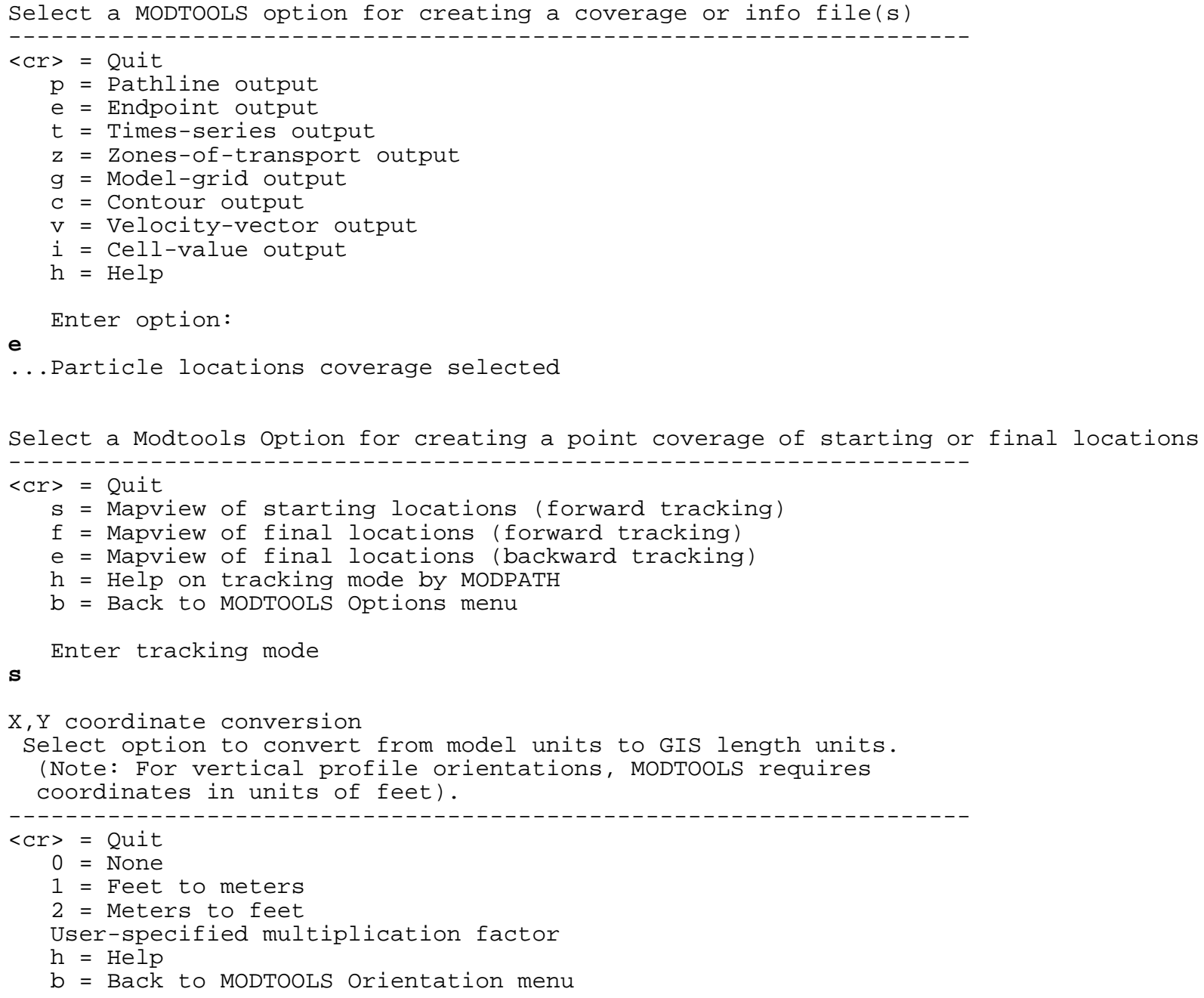




\section{APPENDIX B. FILES AND MENU RESPONSES FOR EXAMPLES—CONTINUED}

0

Enter option:

coordinate conversion

Select option to convert from model units to GIS length units.

(Note: For vertical profile orientations, MODTOOLS requires

coordinates in units of feet).

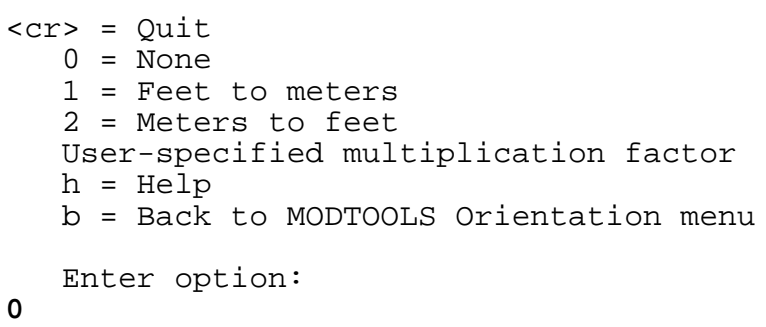

\section{Batch File}

The following listing is from the batch file, MODTOOLS.OUT, which contains a summary of the menu responses necessary to reproduce the endpoint GIS output created during the above interactive session between the user and MODTOOLS for example 2. 


\section{APPENDIX B. FILES AND MENU RESPONSES FOR EXAMPLES-CONTINUED}

\section{Example 3: Particle Time-Series}

\section{NAME File}

The MODTOOLS NAME file listed below was used to produce particle GIS output for the timeseries analysis shown in figure 5. MODTOOLS needs only two data files from the list to construct the time-series GIS output. The user could omit all files, except the files identified by the keywords MAIN and TIME-SERIES. In this case, MODTOOLS uses the MODPATH NAME file from the steady-state flow problem developed by Pollock (1994, p. E-6) for problem 1, run 4.

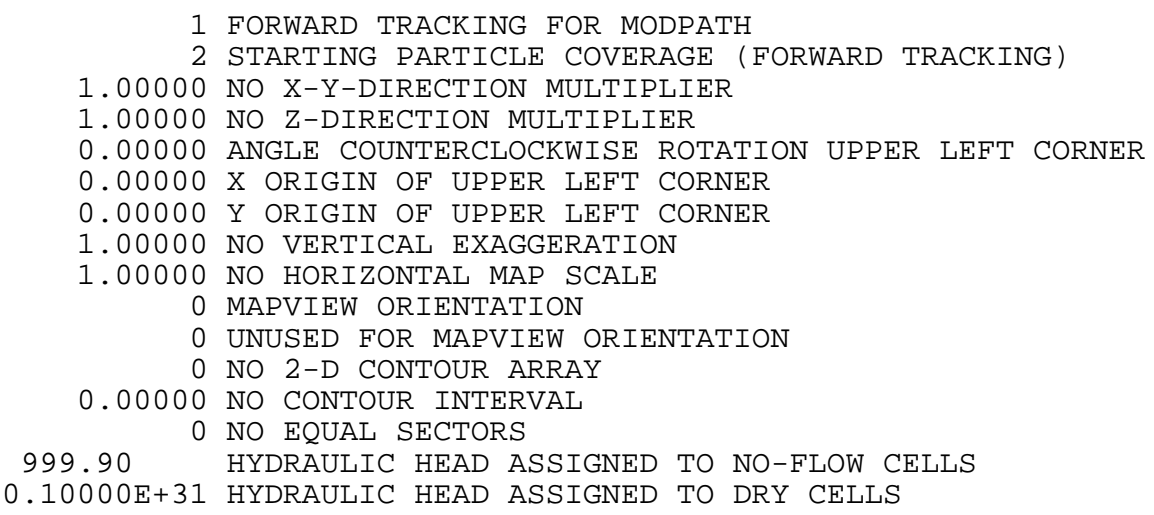

$\begin{array}{lll}\text { main } & \mathbf{1 0} & \text { demo-s.mdf } \\ \text { wel } & 11 & \text { demo-s.wel } \\ \text { riv } & 12 & \text { demo-s.riv } \\ \text { rch } & 13 & \text { demo-s.rch } \\ \text { budget } & 50 & \text { demo-s.bud } \\ \text { head(binary) } & 60 & \text { demo-s.hed } \\ \text { endpoint } & 75 & \text { endpoint.s4 } \\ \text { time-series } & \mathbf{7 7} & \text { timesers.s4 }\end{array}$

\section{Menu Responses}

The following is a list of menu responses necessary to reproduce the time-series GIS output during an interactive session between the user and MODTOOLS for example 3. After creating the time-series GIS output from the particle-tracking analysis, the user can use the batch file that MODTOOLS created to automatically produce another time-series GIS output for a different set of multiple release times of travel to test an alternative scenario. 


\section{APPENDIX B. FILES AND MENU RESPONSES FOR EXAMPLES—CONTINUED}

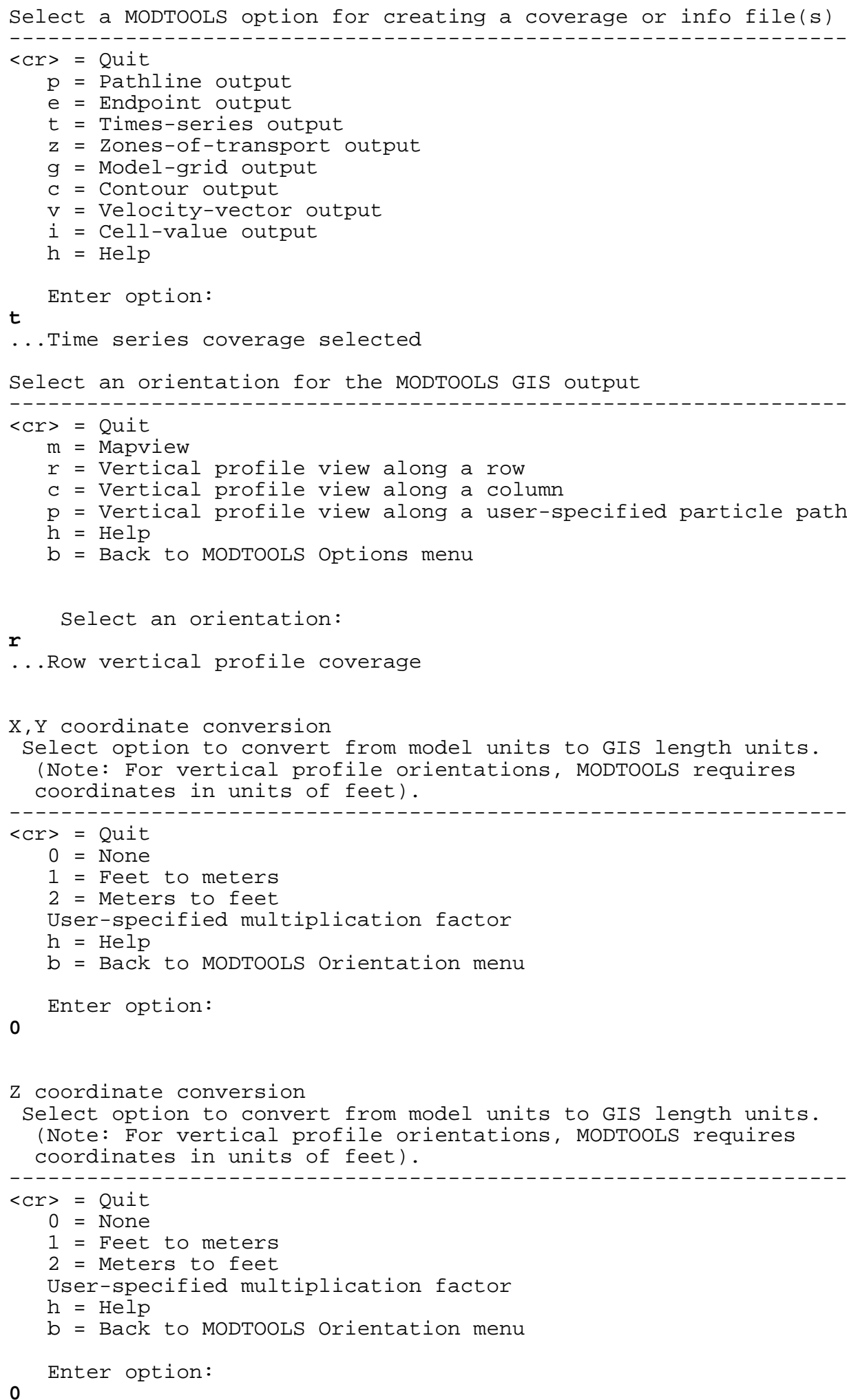




\section{APPENDIX B. FILES AND MENU RESPONSES FOR EXAMPLES-CONTINUED}

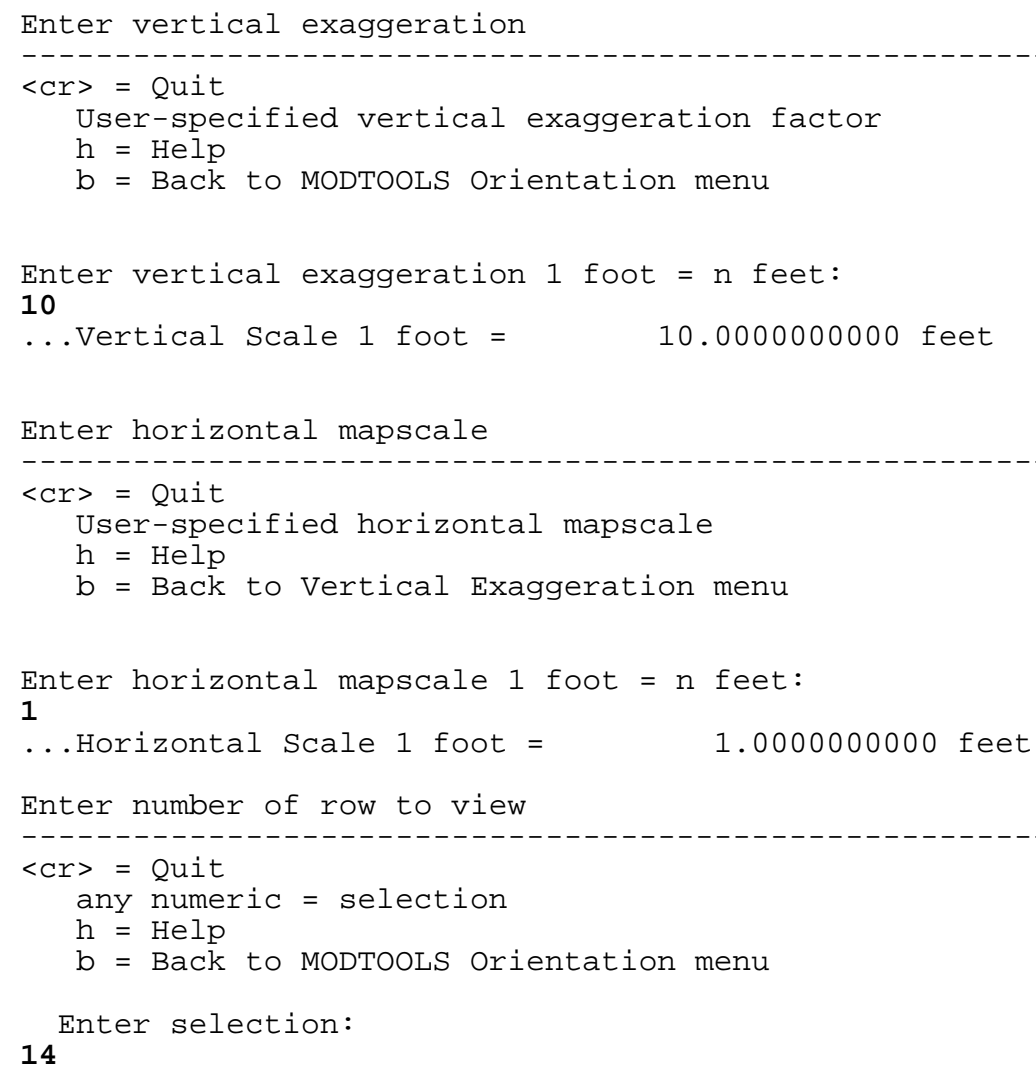

\section{Batch File}

The following listing is from the batch file, MODTOOLS.OUT, which contains a summary of the menu responses necessary to reproduce the time-series GIS output created during the above interactive session between the user and MODTOOLS for example 3.

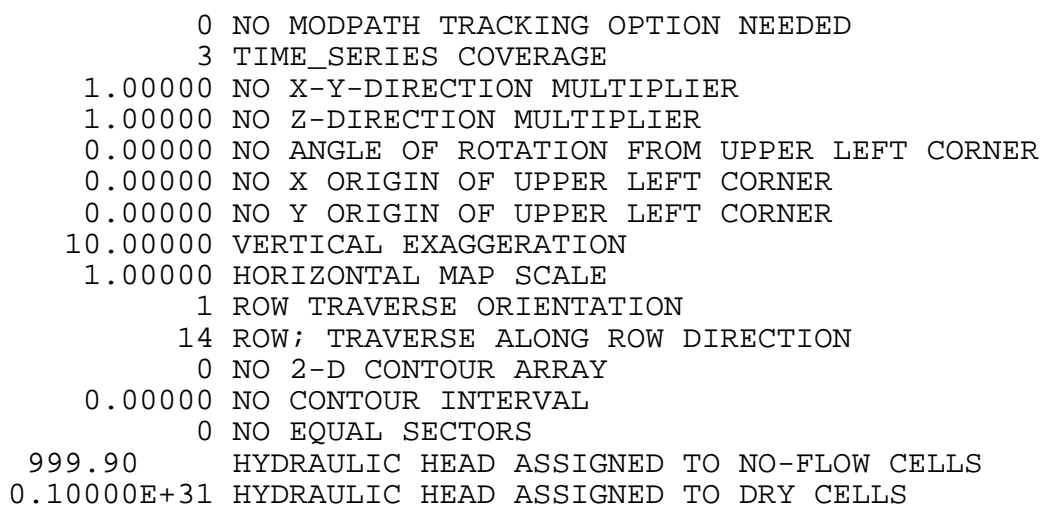




\section{APPENDIX B. FILES AND MENU RESPONSES FOR EXAMPLES—CONTINUED}

\section{Example 4: Zones of Transport}

\section{NAME File}

The MODTOOLS NAME file listed below was used to produce particle GIS output for the zonesof-transport analysis shown in figure 6. MODTOOLS needs only three data files from the list to construct the time-series GIS output. The user could omit all files, except the files identified by the keywords MAIN, TIME-SERIES, and ENDPOINT. In this case, MODTOOLS uses the MODPATH NAME file from the steady-state flow problem developed by Pollock (1994, p. E-6) for problem 1, run 2.

$\begin{array}{lll}\text { main } & \mathbf{1 0} & \text { demo-s.mdf } \\ \text { wel } & 11 & \text { demo-s.wel } \\ \text { riv } & 12 & \text { demo-s.riv } \\ \text { rch } & 13 & \text { demo-s.rch } \\ \text { budget } & 50 & \text { demo-s.bud } \\ \text { head(binary) } & 60 & \text { demo-s.hed } \\ \text { endpoint } & 75 & \text { endpoint.s2 } \\ \text { time-series } & \mathbf{7 7} & \text { timesers.s2 }\end{array}$

\section{Menu Responses}

The following is a list of menu responses necessary to reproduce the zones-of-transport GIS output during an interactive session between the user and MODTOOLS for example 4. After creating the zonesof-transport GIS output from the particle-tracking analysis, the user can use the batch file that MODTOOLS created to automatically produce another time-series GIS output for a different arrangement of starting particle locations to test an alternative scenario.

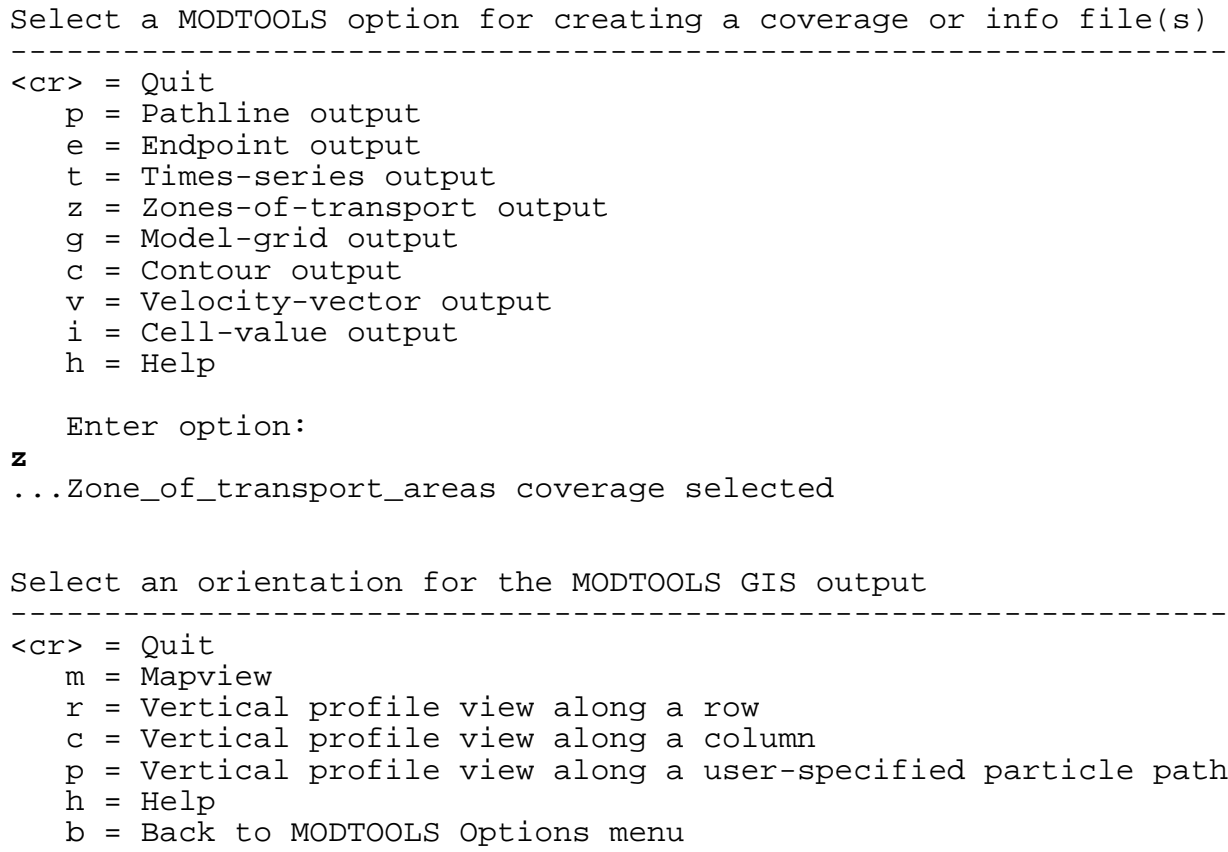




\section{APPENDIX B. FILES AND MENU RESPONSES FOR EXAMPLES-CONTINUED}

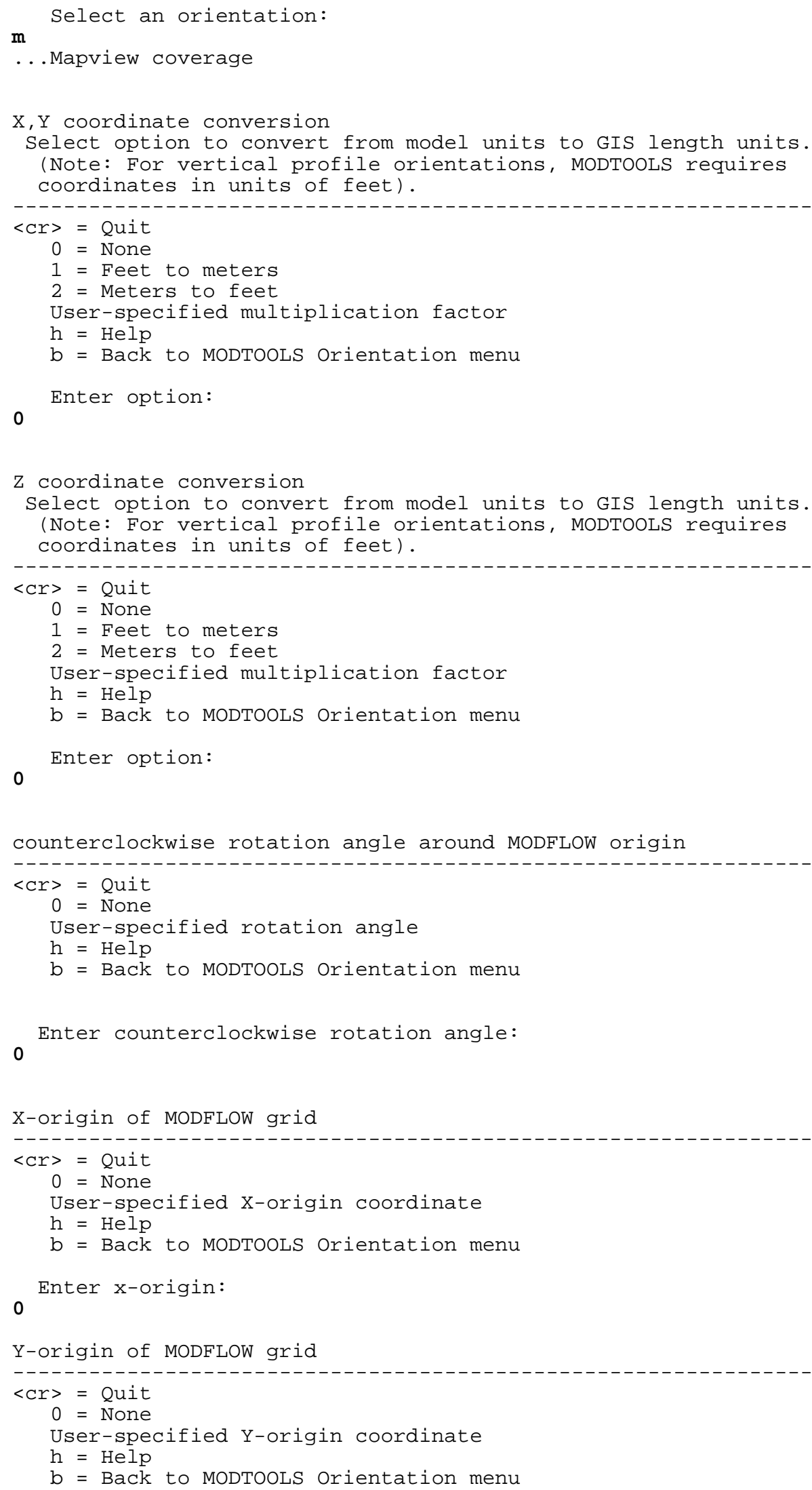




\section{APPENDIX B. FILES AND MENU RESPONSES FOR EXAMPLES—CONTINUED}

$$
0
$$

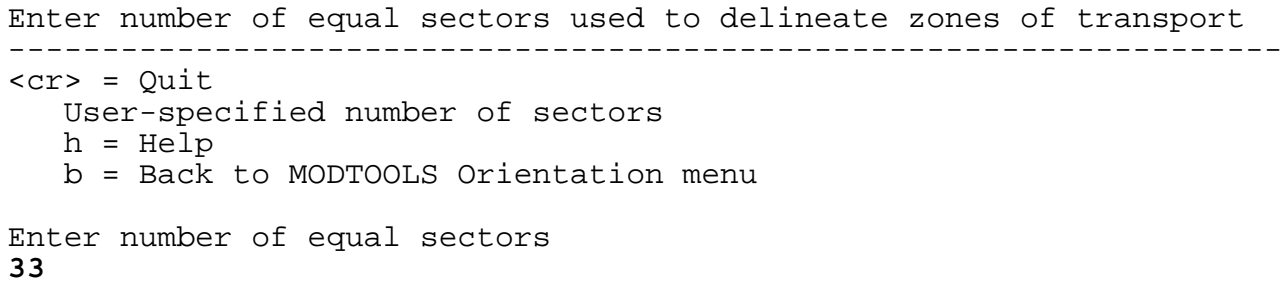

\section{Batch File}

The following listing is from the batch file, MODTOOLS.OUT, which contains a summary of the menu responses necessary to reproduce the zone-of-transport GIS output created during the above interactive session between the user and MODTOOLS for example 4.

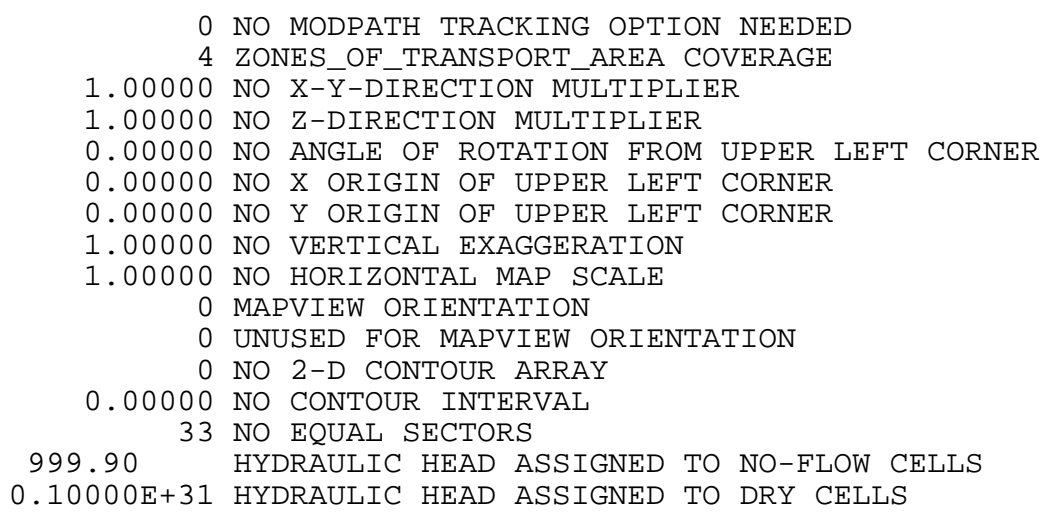

\section{Example 5: Model Grid}

\section{NAME File}

The MODTOOLS NAME file listed below was used to produce a model-grid GIS output shown in figure 7. MODTOOLS needs up to three data files from the list to construct the model-grid GIS output. The user could omit all files, except the files identified by the keywords MAIN, HEAD(BINARY), and PATHLINE. For a GIS output in map view, the user need only construct the MODTOOLS MAIN file. The file identified by the keywords HEAD(BINARY) would only be needed if the user specified a GIS output in the vertical profile view such as along a row of the model grid. MODTOOLS uses the values of the simulated head for the tops of the cells if layer 1 is a water-table layer. A previous particle-tracking pathline analysis is needed to construct a model-grid GIS output for a vertical profile orientation along a particle pathline. Only in this instance would the file identified by the keyword PATHLINE be included in the NAME file resulting in the additional construction of a pathline GIS output in vertical profile view along the specified particle. 


\section{APPENDIX B. FILES AND MENU RESPONSES FOR EXAMPLES-CONTINUED}

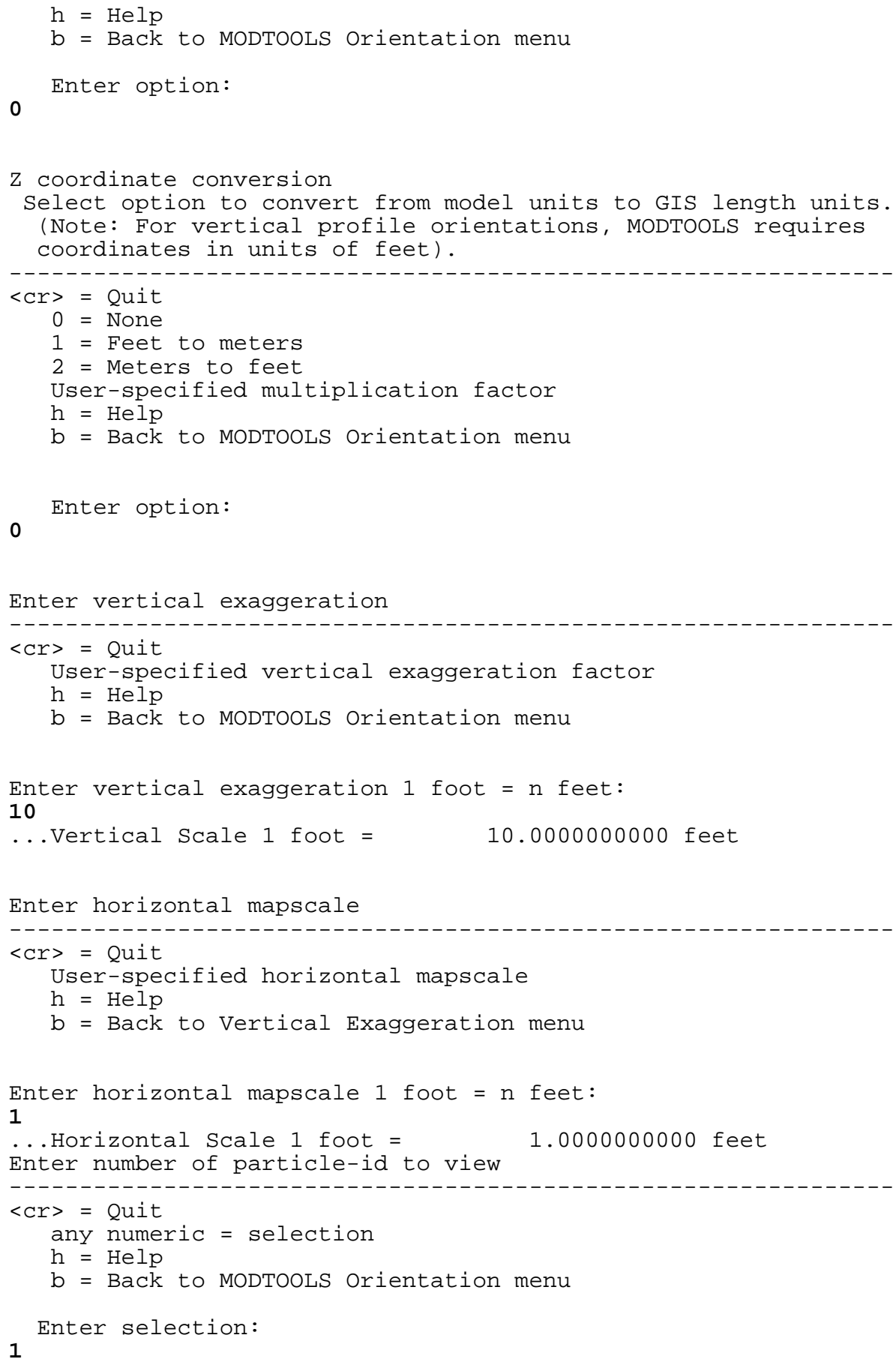

\section{Batch File}

The following listing is from the batch file, MODTOOLS.OUT, which contains a summary of the menu responses necessary to reproduce the two GIS outputs (the particle pathline GIS output and the accompanying model-grid GIS output) during an interactive session between the user and MODTOOLS for example 5 . 


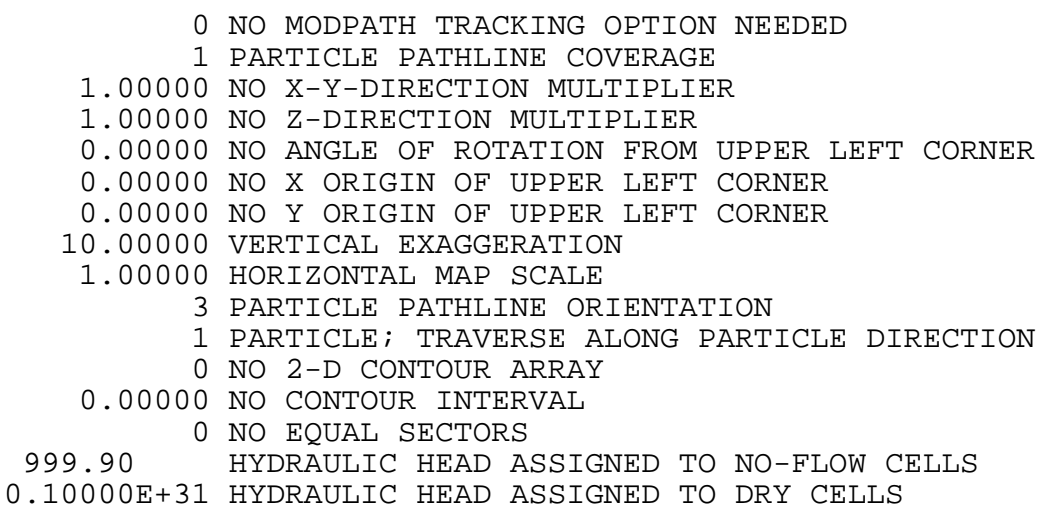

\section{Example 6: Contours of Input and Output Arrays}

\section{NAME File}

The MODTOOLS NAME file listed below was used to produce a contour GIS output shown in figure 8. MODTOOLS needs three data files from the list to construct the contour GIS output. The user could omit all files, except the files identified by the keywords MAIN, CONTOUR-DATA, and CONTOUR-CONTROL. For a GIS output in map view, MODTOOLS only constructs one GIS output which consists of a set of lines connecting points of equal value. For a GIS output in vertical profile view, MODTOOLS also constructs a model-grid GIS output.

$\begin{array}{lll}\text { main } & \mathbf{1 0} & \text { demo-s.mdf } \\ \text { wel } & 11 & \text { demo-s.wel } \\ \text { riv } & 12 & \text { demo-s.riv } \\ \text { rch } & 13 & \text { demo-s.rch } \\ \text { budget } & 50 & \text { demo-s.bud } \\ \text { head(binary) } & 60 & \text { demo-s.hed } \\ \text { contour-data } & 61 & \text { demo-s.hed } \\ \text { contour-control } & \mathbf{6 2} & \text { demo-s.ct1 } \\ \text { endpoint } & 75 & \text { endpoint.s2 } \\ \text { time-series } & 77 & \text { timesers.s2 }\end{array}$

\section{Menu Responses}

The following is a list of menu responses necessary to reproduce the contour GIS output during an interactive session between the user and MODTOOLS for example 6. After creating the contour GIS output, the user can use the batch file that MODTOOLS created to automatically produce another contour GIS output for a different set of input or output arrays to test alternative scenarios.

Select a MODTOOLS option for creating a coverage or info file(s) 


\section{APPENDIX B. FILES AND MENU RESPONSES FOR EXAMPLES-CONTINUED}

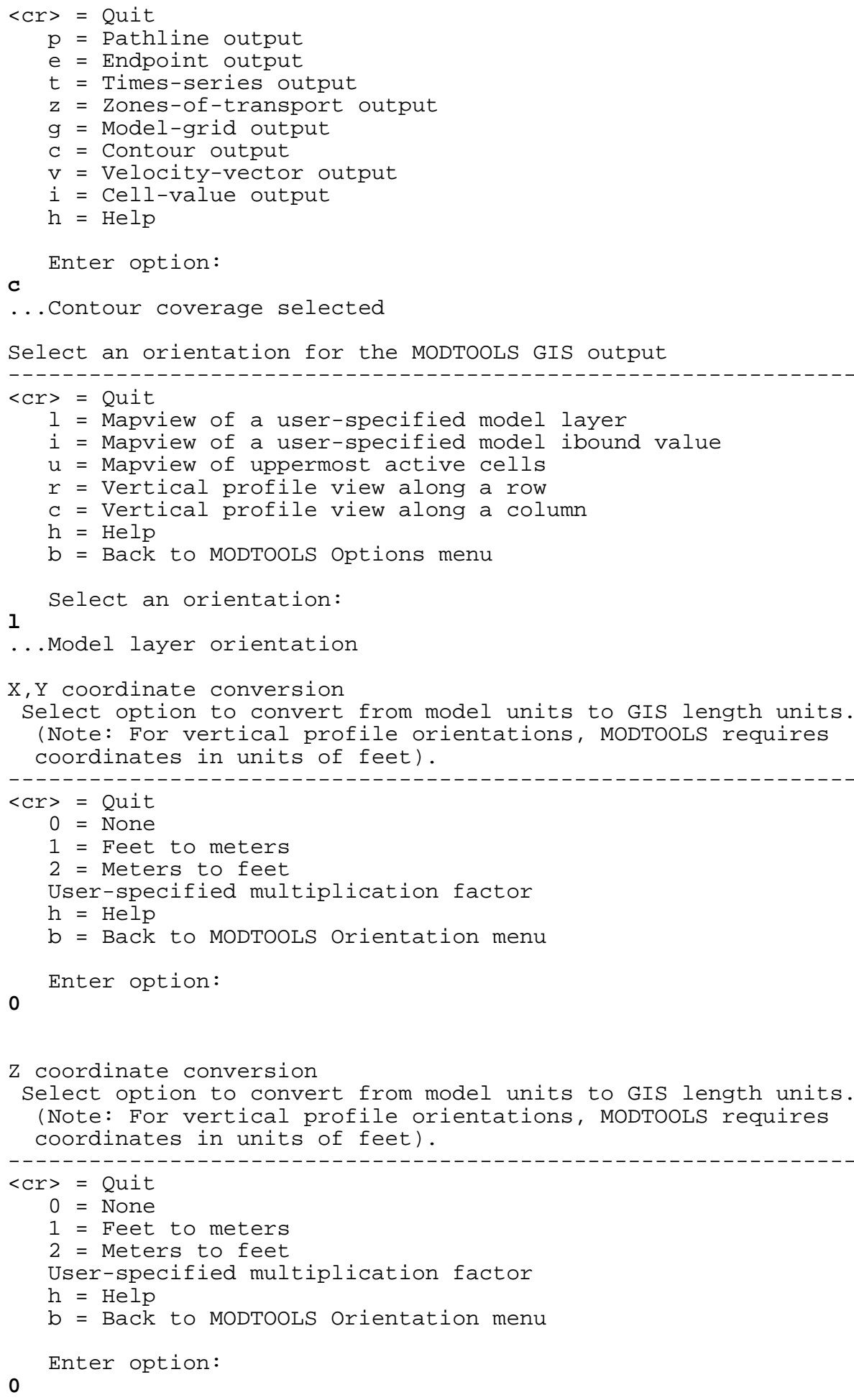




\section{APPENDIX B. FILES AND MENU RESPONSES FOR EXAMPLES-CONTINUED}

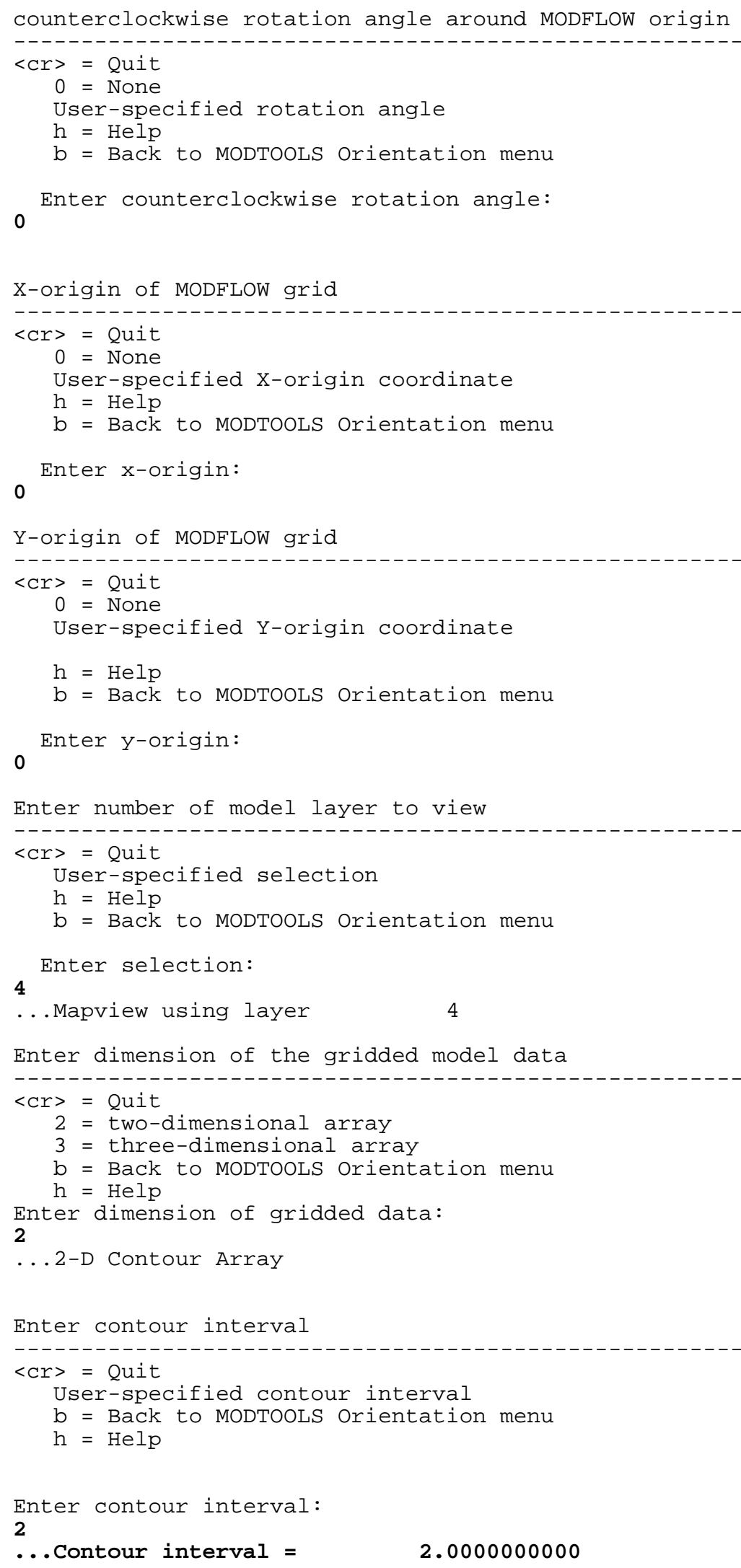




\section{APPENDIX B. FILES AND MENU RESPONSES FOR EXAMPLES—CONTINUED}

\section{Batch File}

The following listing is from the batch file, MODTOOLS.OUT, which contains a summary of the menu responses necessary to reproduce the cell-value GIS output created during the above interactive session between the user and MODTOOLS for example 6 .

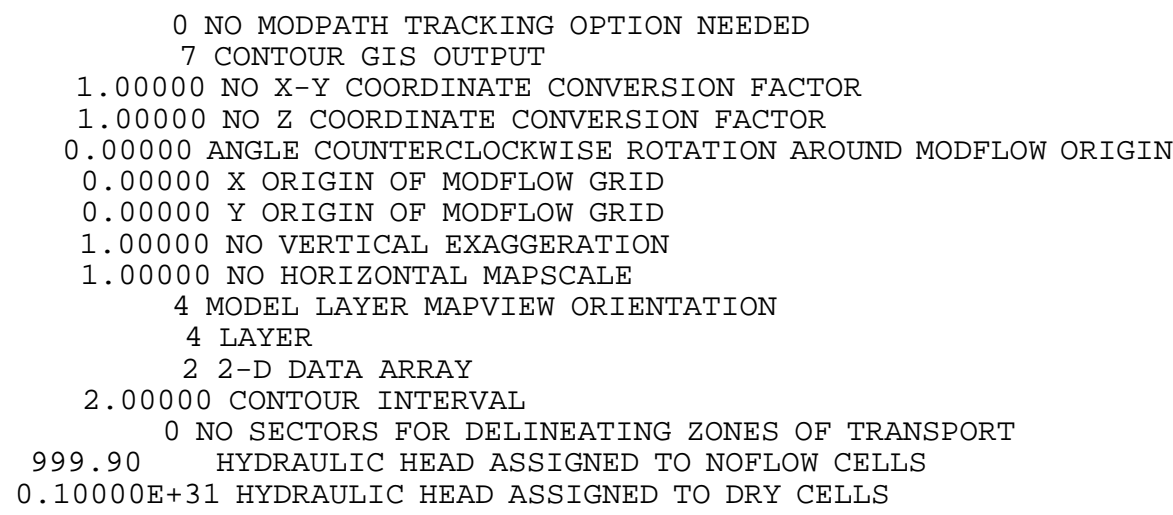

\section{Example 7: Velocity Vectors}

\section{NAME File}

The MODTOOLS NAME file listed below was used to produce a velocity-vector GIS output shown in figure 9. MODTOOLS needs up to four data files from the list to construct the velocity-vector GIS output. The user could omit all files, except the files identified by the keywords MAIN, BUDGET, and HEAD or HEAD(BINARY). The HEAD-CONTROL file would only be needed if the user specified that a formatted head file would be the source of head data using the keyword HEAD in the NAME file. MODTOOLS uses information on the format of the file in the HEAD-CONTROL file to read the simulated heads in the HEAD file. MODTOOLS needs the values of the simulated head to compute a saturated thickness for each cell. For a GIS output in vertical profile view, MODTOOLS also constructs a model-grid GIS output.

$\begin{array}{lll}\text { main } & \mathbf{1 0} & \text { demo-s.mdf } \\ \text { wel } & 11 & \text { demo-s.wel } \\ \text { riv } & 12 & \text { demo-s.riv } \\ \text { rch } & 13 & \text { demo-s.rch } \\ \text { budget } & \mathbf{5 0} & \text { demo-s.bud } \\ \text { head(binary) } & \mathbf{7 0} & \text { demo-s.hed } \\ \text { endpoint } & 75 & \text { endpoint.s1 }\end{array}$

\section{Menu Responses}

The following is a list of menu responses necessary to reproduce the velocity-vector GIS output during an interactive session between the user and MODTOOLS for example 7. After creating the 


\section{APPENDIX B. FILES AND MENU RESPONSES FOR EXAMPLES—CONTINUED}

velocity-vector GIS output, the user can use the batch file that MODTOOLS created to automatically produce another velocity-vector GIS output for a different ground-water simulation.

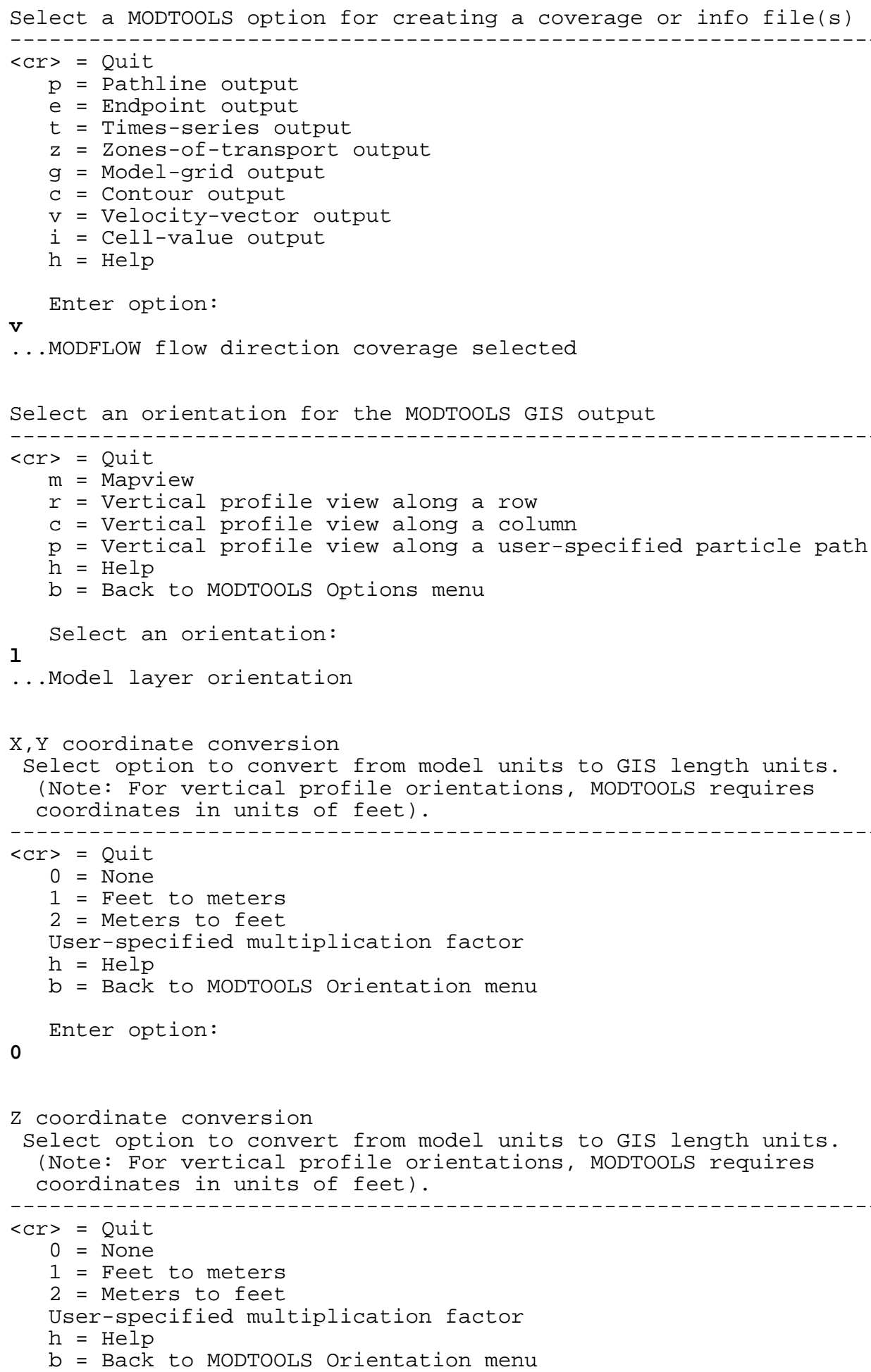




\section{APPENDIX B. FILES AND MENU RESPONSES FOR EXAMPLES-CONTINUED}

0

Enter option:

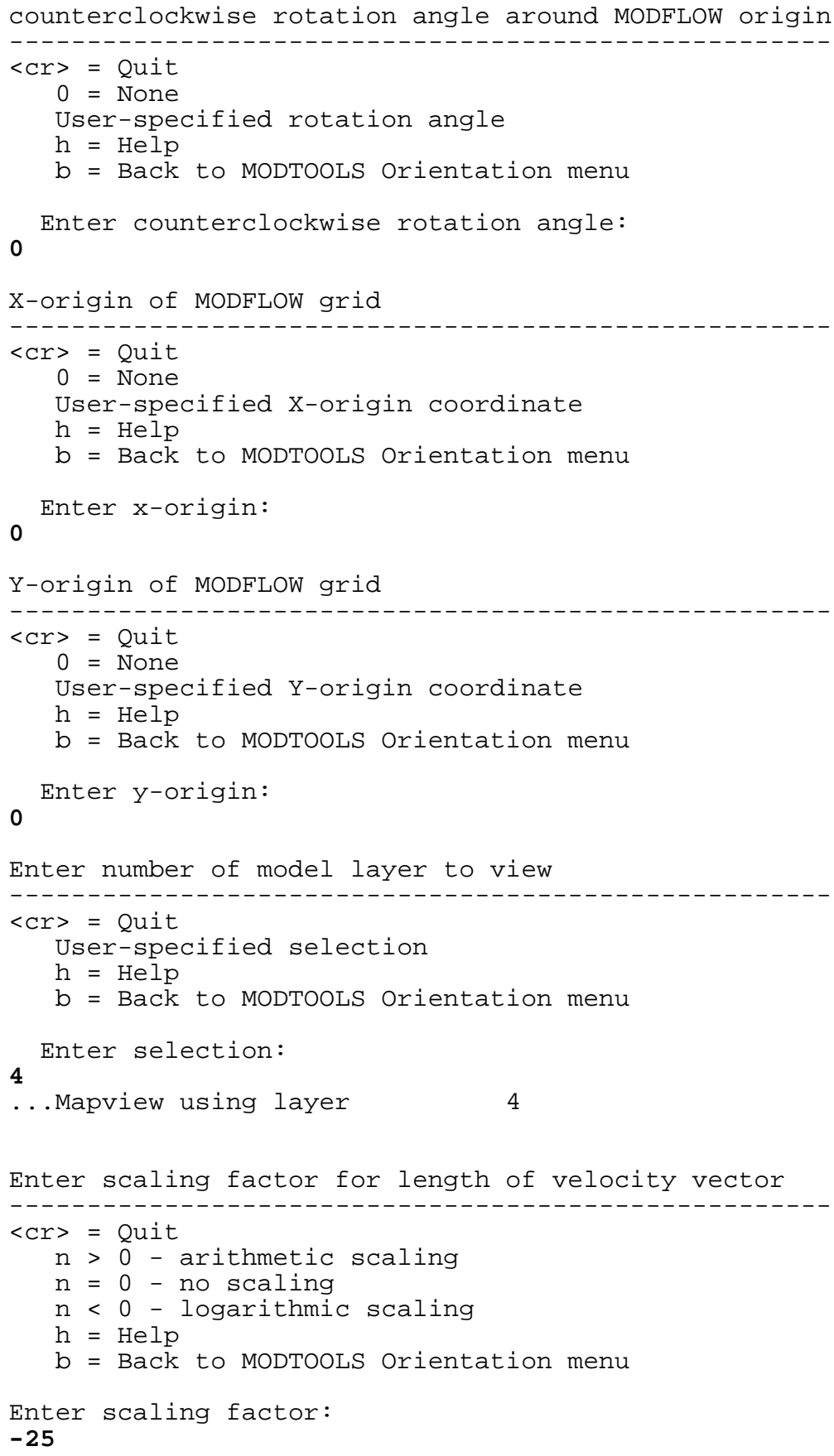




\section{APPENDIX B. FILES AND MENU RESPONSES FOR EXAMPLES-CONTINUED}

\section{Batch File}

The following listing is from the batch file, MODTOOLS.OUT, which contains a summary of the menu responses necessary to reproduce the velocity-vector GIS output created during the above interactive session between the user and MODTOOLS for example 7.

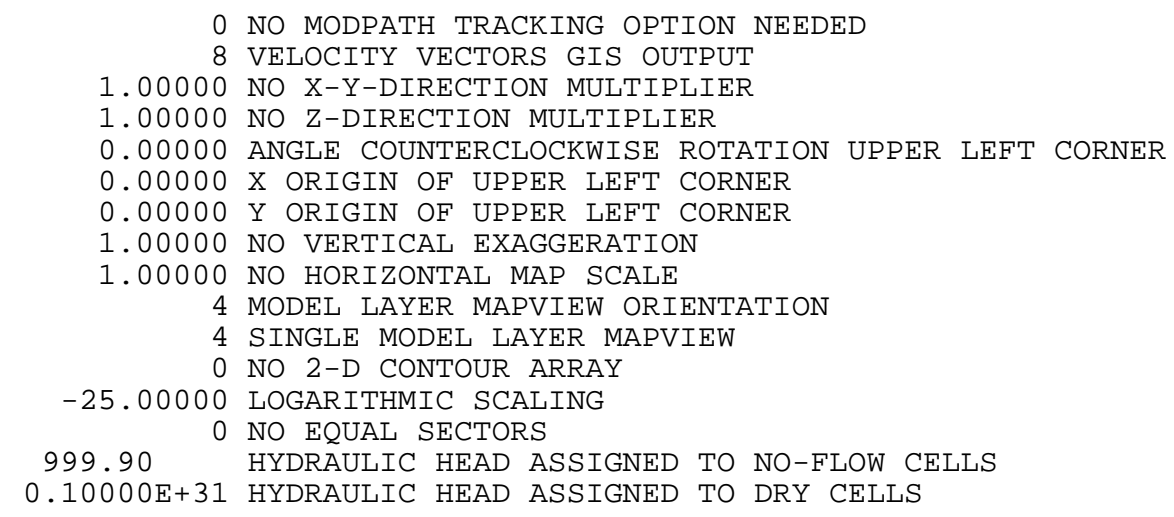

\section{Example 8: Cell Values}

\section{NAME File}

The NAME file listed below was used to produce the cell-value GIS output shown in figure 10. MODTOOLS needs up to four data files from the list to construct the cell-value GIS output. The user could omit all files, except the files identified by the keywords MAIN, BUDGET, HEAD or AHEAD(BINARY), and PATHLINE. For a GIS output in map view, the user need only construct the MODPATH MAIN file and a MODTOOLS NAME file. The file identified by the keywords HEAD or HEAD(BINARY) would only be needed if the user specified a GIS output in the vertical profile view such as along a row of the model grid. MODTOOLS uses the values of the simulated head for the tops of the cells if layer 1 is a water-table layer. The one file identified by the keywords BUDGET or HEAD or HEAD(BINARY) would only be needed if the user specified this file as the source of the cell-by-cell terms. A particle-tracking analysis need only be done in order for MODTOOLS to construct a cell-value GIS output along a particle pathline. Only in this instance would the file identified by the keyword PATHLINE be included in the NAME file resulting in the additional construction of a pathline GIS output in vertical profile view along the specified particle.

$\begin{array}{lll}\text { main } & \mathbf{1 0} & \text { demo-t.mdf } \\ \text { wel } & 11 & \text { demo-t.wel } \\ \text { riv } & 12 & \text { demo-t.riv } \\ \text { rch } & 13 & \text { demo-t.rch } \\ \text { budget } & 50 & \text { demo-t.bud } \\ \text { head(binary) } & \mathbf{6 0} & \text { demo-t.hed } \\ \text { cbf } & 70 & \text { demo-t.cbf } \\ \text { endpoint } & 75 & \text { endpoint.t1 } \\ \text { pathline } & 76 & \text { pathline.t1 }\end{array}$




\section{APPENDIX B. FILES AND MENU RESPONSES FOR EXAMPLES-CONTINUED}

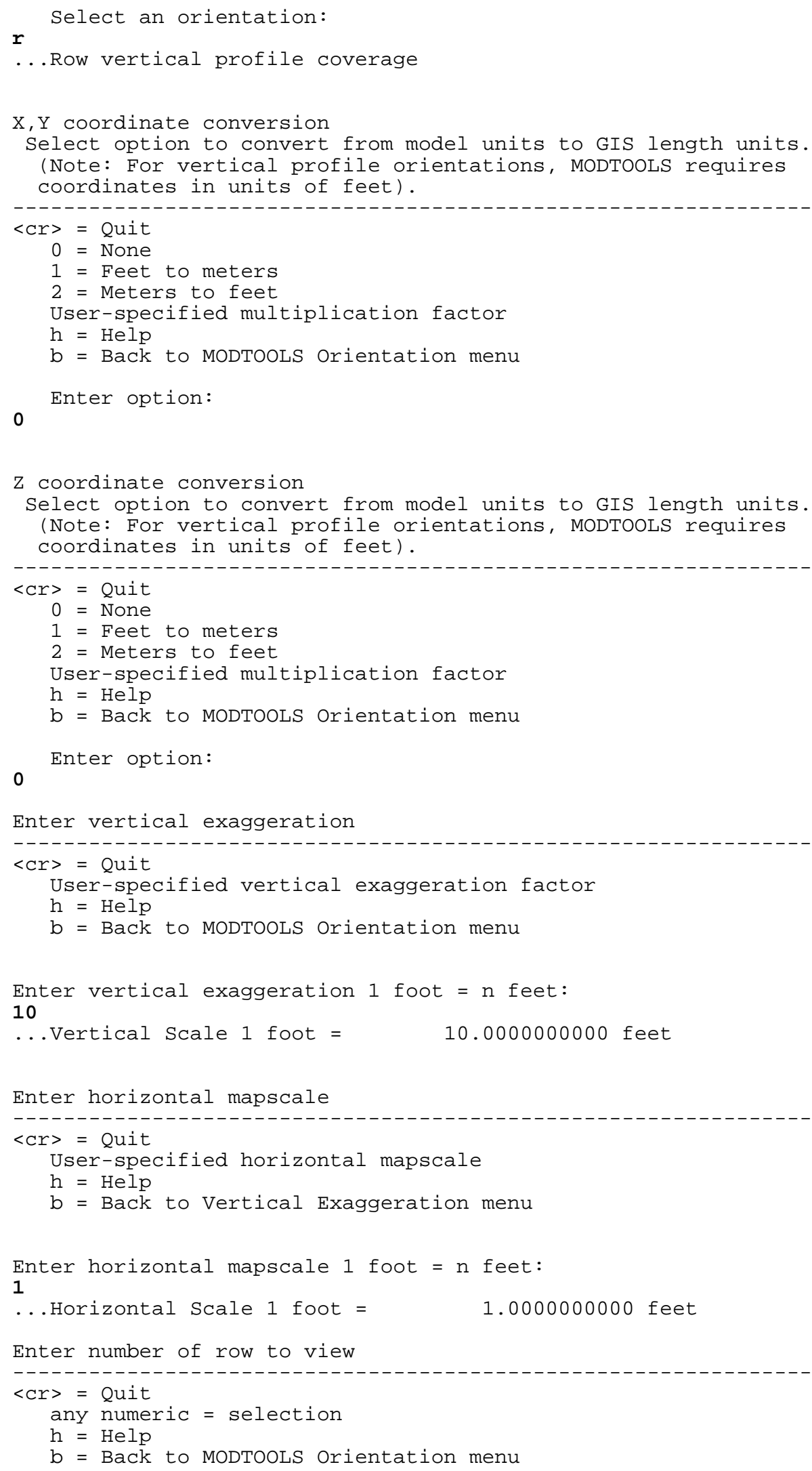




\section{APPENDIX B. FILES AND MENU RESPONSES FOR EXAMPLES-CONTINUED}

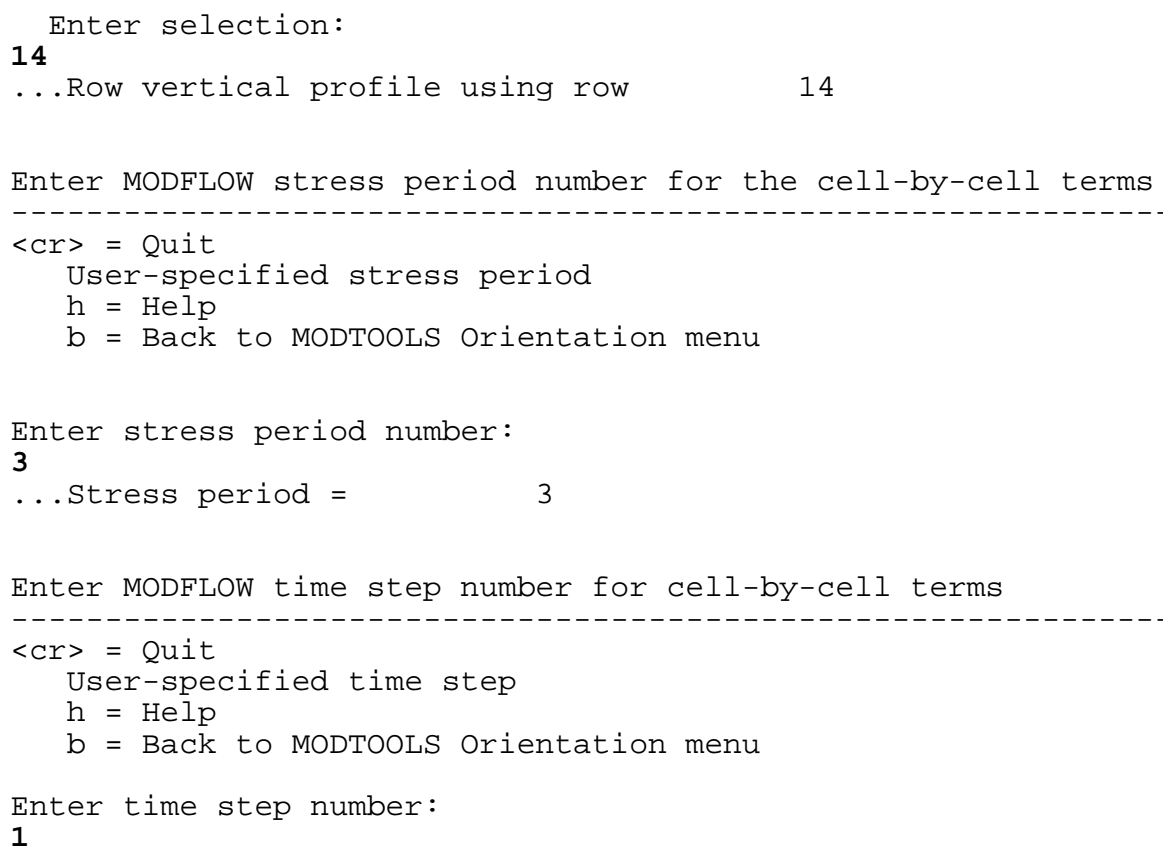

\section{Batch File}

The following listing is from the batch file, MODTOOLS.OUT, which contains a summary of the menu responses necessary to reproduce the cell-value GIS output created during the above interactive session between the user and MODTOOLS for example 8 .

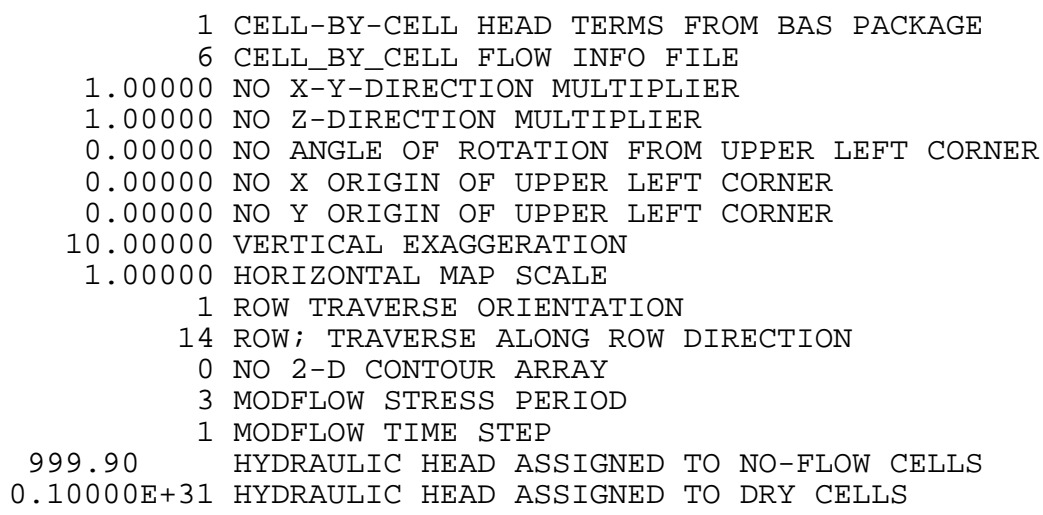




\section{APPENDIX C. DOCUMENTATION OF THE METHOD USED TO CONSTRUCT ZONES OF TRANSPORT}

MODTOOLS uses an algorithm that delineates an approximation of the zones of transport for a pumped well from particle data generated using the time-series option of MODPATH (Pollock, 1994) as particles are backward tracked from the cell(s) containing the pumped well. In the following discussions of the delineation algorithm, the starting particle positions are assigned independently of MODPATH and are input by file to MODPATH rather than using the internal routine in MODPATH. To achieve a better initial configuration of particles for example 4 (zones of transport), the starting particle positions were arranged on the surface of a vertical cylinder, the axis of which passes through the center of the modelgrid cell containing the well. The length and diameter of the cylinder are equal to the thickness and width of the cell. Particles are placed around the perimeter of the cylinder in horizontal planes that are equally spaced along the cylinder's vertical length. To achieve a better distribution, each successive horizontal

plane of particles is rotated clockwise about the vertical axis of the cylinder by $\frac{360}{n(m-1)}$ degrees, where $\mathrm{n}$ is the number of particles in the plane, and $\mathrm{m}$ is the number of planes. The number of particles and the number of planes are specified by the user. This method of specifying starting particle positions is referred to as the vertical-cylindrical positioning method.

The starting positions of particles used to determine the zone of transport define the surface of a volume, a cylinder in this case. This cylinder deforms as the particles representing its surface move backward through the ground-water flow system. Particles from adjacent planes may travel with velocities that vary widely, distorting the surface of the cylinder into a complex three-dimensional form, which is difficult to project on to a reference plane for the delineation of the zone of transport. The reference plane is generally a horizontal plane representing the top of the saturated part of the groundwater system. Because of this complexity, a simple method of delineating polygons, which describe the approximate zones of transport was devised for use in MODTOOLS.

The delineating algorithm used in MODTOOLS approximates the zone of transport for a time step by projecting the particles onto the reference plane and then determining the maximum extent of travel since the last time step within each equal pie-shaped area (or sector) of a circle centered on the originating cell. The approximate positions of the maximum extent for each sector are then joined to form a polygon representing the zone of transport for that time step.

Figure $\mathrm{C} 1$ shows an example of this method for a single time step using particles originating from a single horizontal plane of particles created using the vertical-cylindrical positioning method. The starting particles, located in the cell containing the well, move to new positions, recorded by MODPATH in the TIMESERS file, at the end of time step one (fig. C1a). MODTOOLS also incorporates ending particle positions, recorded by MODPATH in the ENDPOINT files. This ensures particle positions intercepting a model boundary, such as the water table, are included in the delineation of the zones of transport. The area is then divided into a user-specified number of equal pie-shaped sectors centered on the originating cell (fig. C1b). The algorithm starts by searching each sector for all particle positions associated with the first time step (from among all of the particles started using the vertical-cylindrical 


\section{APPENDIX C. DOCUMENTATION OF THE METHOD USED TO CONSTRUCT ZONES OF TRANSPORT-CONTINUED}

positioning method). The algorithm identifies the particle in each sector that has traveled farthest from the center of the originating cell (fig. C1c). This distance, $r_{1}$, is then used to locate a new point out from the center along the bisector, $\mathrm{B}$, of the sector (fig. $\mathrm{C} 1 \mathrm{~d}$ ). This new point (labeled $\mathrm{v}_{1}$ in fig. $\mathrm{C} 1 \mathrm{~d}$ ) becomes one of the vertices that, when connected to adjacent vertices calculated for the other sectors, defines a polygon representing the approximate zone of transport for the time step (fig. C1e). The polygon can be shaded using the plotting capabilities of the GIS (fig. C1f). The process is identical for subsequent time steps except that for each sector the maximum distance of a particle from the originating cell is selected among the current as well as all previous times steps to determine the vertex for the zone of transport polygon in that sector. This means the delineating algorithm does not select particles that have moved closer to the center of the originating cell. For an example, the particles were not selected that have moved towards the center of the originating cell and are within the polygon delineated for the starting positions (fig. C1a).

The example described above and presented in figure $\mathrm{C} 1$ shows only a single plane of particles started using the vertical-cylindrical positioning method. It must be emphasized, however, that to identify th17e particle that has traveled farthest from the center of the originating cell, the delineating algorithm searches all particles in the sector for a given time step, regardless of what horizontal plane the particles originated from.

MODTOOLS constructs two types of GIS output for zones of transport. The first type of output consists of the vertices of the polygons and the location, time, and velocity attributes associated with these vertices as derived from the characteristics of the particles farthest from the originating cell. The second type consists of the polygons that represent the approximate zones of transport for each time step.

The error in delineating zones of transport using this method is related to the initial arrangement (density) of particles relative to the model-grid cell spacing, the number of particles used in the analysis, the size and complexity of the polygon defining the true zone of transport, and the number of sectors (vertices) used to approximate the zone of transport. The relation of the error to the number of sectors and the size of the polygon defining the true zone of transport is illustrated in figure $\mathrm{C} 2$. Note that if no particles are located within a sector for a particular time step, the position of particles from the previous time step is used to locate the vertex of the zone of transport polygon for that sector. The presence of this situation is indicated by triangular gaps in the zone of transport polygon (see fig. 6). Using either more particles, fewer sectors, or more time steps can help minimize the problem. (Adding more particles should be tried first).

Increasing the number of starting particles reduces the possibility of producing triangular gaps and may also increase the definition of the boundaries of the zones of transport. Decreasing the length of individual time steps may result in zones-of-transport polygons that more closely approximate the true zones of transport. For particles with pathlines that move out of a sector, 


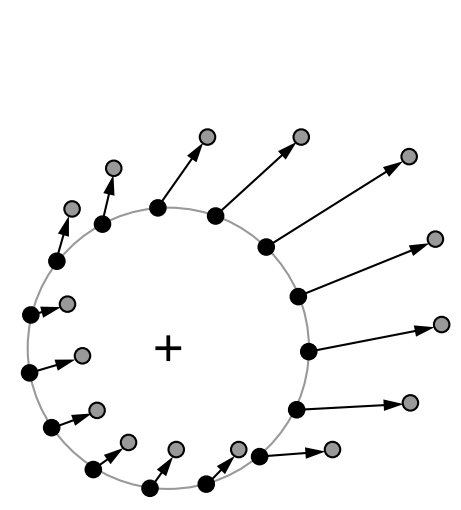

a

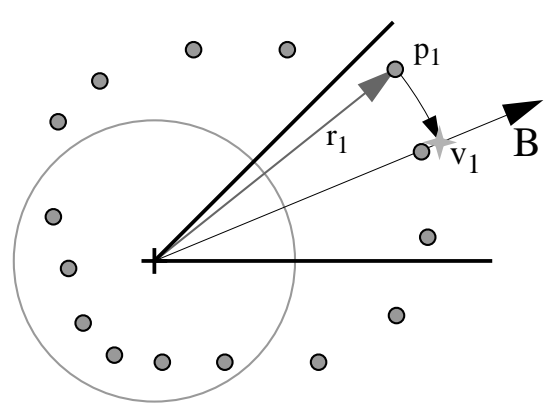

d

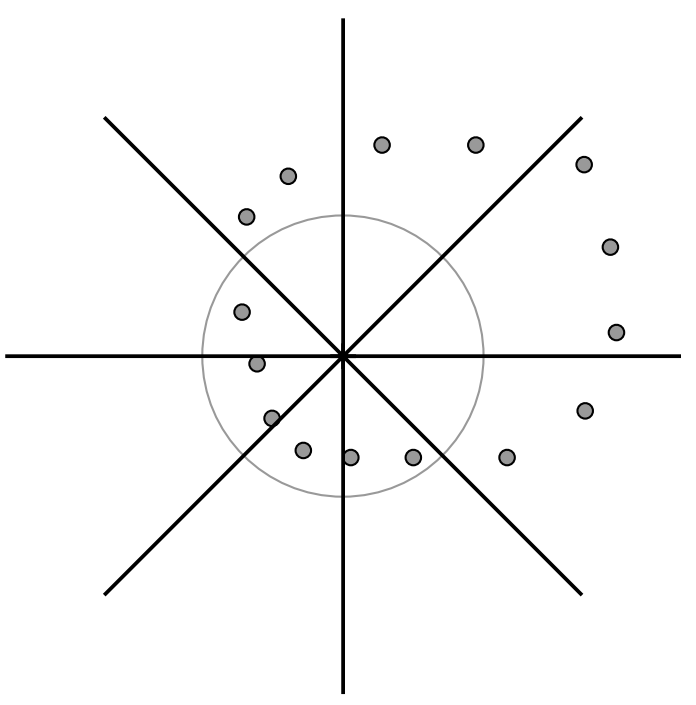

b

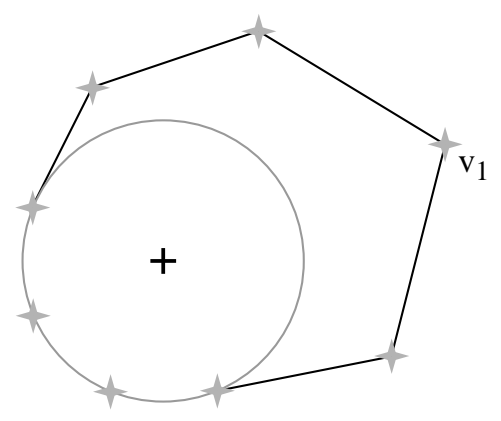

$\mathrm{e}$

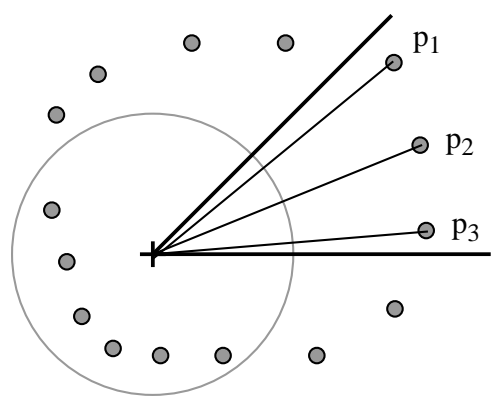

$\mathrm{c}$

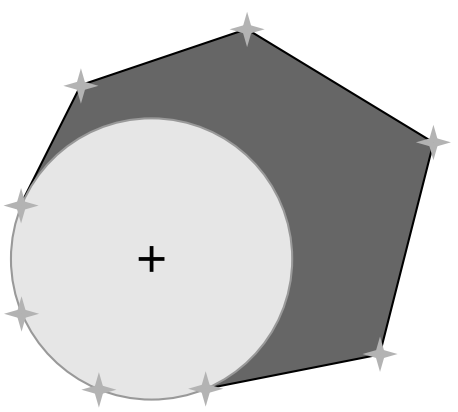

f

\section{EXPLANATION}

+ Center of cell containing pumped well

- Starting particle positions (shown only in fig. a and represented by circle in figs. b-f)

- Particle positions at end of time step 1

+ Position of vertex for zone of transport polygon

Figure C1. Example of steps used to construct polygons representing the approximate zones of transport for a cell containing a pumped well (seen in map view): (a) The starting particle positions (as arranged using the verticalcylindrical positioning method) and the particle positions at the end of a time step; (b) Division of area into a userspecified number of equal sectors; (c) The identification of the particle position $\left(p_{1}\right)$ as farthest from the center of the originating cell among all particle positions within the sector $\left(p_{1}-p_{3}\right)$; $(d)$ The creation of a vertex $\left(v_{1}\right)$ along the bisector (B) of the sector at a distance equal to the farthest particle position $\left(r_{1}\right)$; (e) Steps c- $f$ have been repeated for each sector and the adjacent vertices for each sector joined to form a polygon representing the approximate zone of transport; ( $f$ ) The polygon for the zone of transport shaded using the GIS. This process is repeated for each successive time step. Note that the example uses only a single horizontal plane or starting particles. Typically, multiple planes of particles are started. The same steps are used to construct the zone of transport but the search for the most distant particle by sector includes all particles in a sector regardless of which horizontal plane they were started in. 


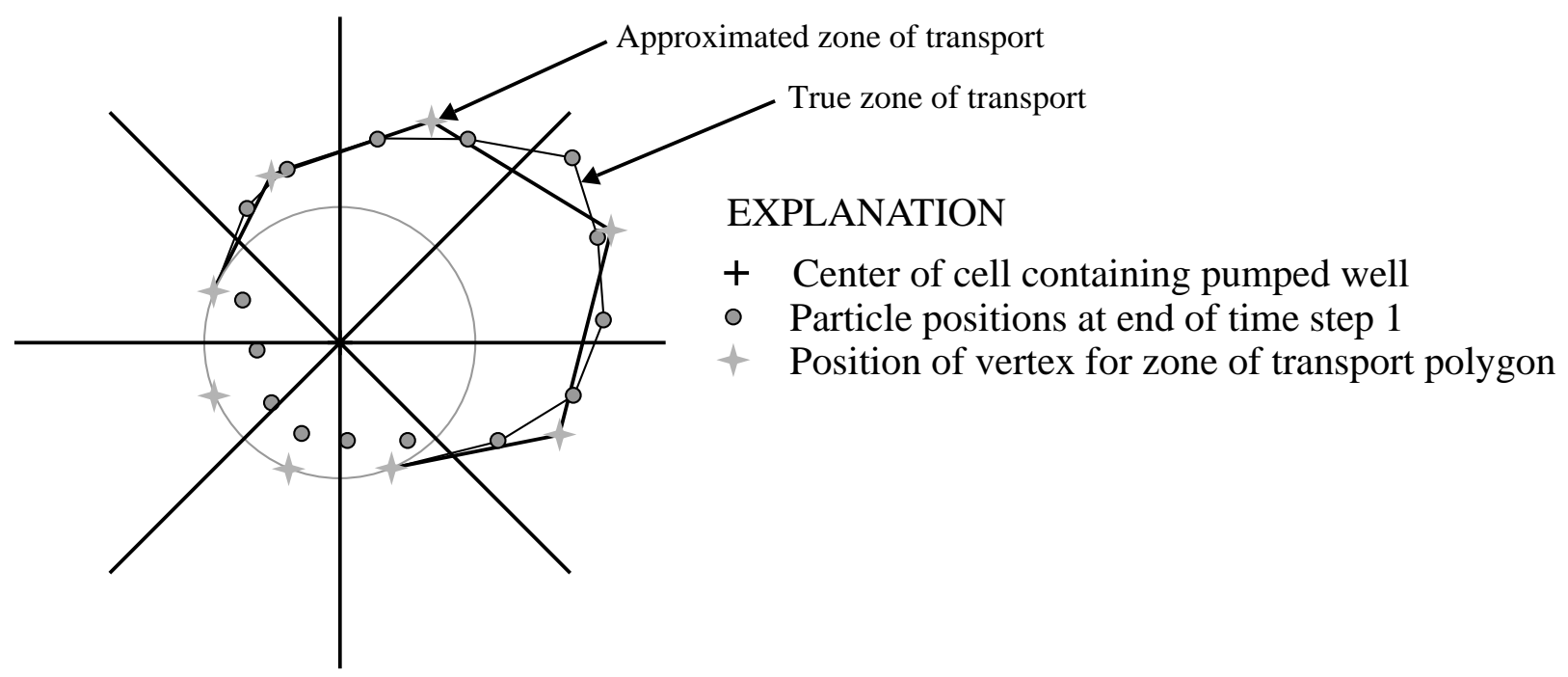

Figure C2. Approximated zone of transport delineated using the bisector method and the true zone of transport delineated by connecting particle positions.

shorter time steps may increase the probability that a particle will be present within the sector during a time step which can then be used to create a vertex for the approximated zone of transport. Longer time steps may be of sufficient duration that a particle moves out of the sector and is not used to create the vertex for that time step. The selection of an optimum number of sectors, number and arrangement of starting particles, and length of time steps will vary for each well and is influenced by the geometry and hydraulic characteristics of the ground-water flow system.

In the situation where much of the water discharging to a cell containing a well enters the cell through the top and bottom faces, placing particles on the top and bottom faces of the cell can produce a more accurate vertical representation of the zone of transport. To visualize a zone of transport in such situations, the user has the option of delineating the zone in a vertical profile view. 
